\title{
Classificação morfológica de neurônios baseada na hierarquia das árvores dendríticas
}

\author{
Evelyn Perez Cervantes
}

TESE APRESENTADA

$\mathrm{AO}$

Instituto De Matemática e EstatísticA

DA

Universidade de SÃo Paulo

PARA

OBTENÇÃO DO TÍTULO

$\mathrm{DE}$

Doutor EM CIÊNCIAS

\author{
Programa: Ciências da Computação \\ Orientador: Prof. Dr. Roberto M. Cesar Junior \\ Coorientador: Prof. Dr. Luciano da Fontoura Costa \\ Coorientador: Prof. Dr. Cesar Henrique Comin
}

Durante o desenvolvimento deste trabalho o autor recebeu auxílio financeiro da CAPES

São Paulo, outubro de 2019 


\section{Classificação morfológica de neurônios baseada na hierarquia das árvores dendríticas}

Versão original

Esta é a versão original da tese elaborada pela candidata Evelyn Perez Cervantes, tal como submetida à Comissão Julgadora.

Orientador: Prof. Dr. Roberto M. Cesar Junior Coorientador: Prof. Dr. Luciano da Fontoura Costa

Coorientador: Prof. Dr. Cesar Henrique Comin 


\section{Resumo}

\section{CERVANTES, EVELYN P. Classificação morfológica de neurônios baseada na}

hierarquia das árvores dendríticas. 2019. 134 f. Tese (Doutorado) - Instituto de Matemática e Estatística, Universidade de São Paulo (IME-USP), São Paulo, 2019.

Entre os desafios que a neuroanatomia tem enfrentado desde seu início, a identificação de características que permitam distinguir diversos tipos de células neuronais do ponto de vista morfológico, tem atraído atenção de pesquisadores pertencentes a diferentes áreas, os quais tentam, até nossos dias caracterizar quantitativamente os neurônios. Por outro lado, considerando a premissa, que a forma está diretamente relacionada com a função das diversas células, a forma do neurônio pode revelar muitas particularidades sobre sua função. A caracterização morfológica de neurônios, portanto, permite fazer análises com a finalidade de atingir um dos principais objetivos da neurociência: entender o funcionamento do cérebro.

Este trabalho tem como objetivo construir e validar novos métodos para analisar morfologicamente conjuntos de neurônios usando, suas reconstruções digitais em diferentes níveis dendríticos. Serão considerados neurônios inteiros bem como apenas as hierarquias das árvores dendríticas, a fim de identificar partes morfologicamente relevantes para a classificação de um neurônio. O método propõe diferentes estratégias de decomposição das árvores dendríticas ao longo de suas hierarquias.

Um conjunto de mais 5.000 neurônios, correspondentes a diferentes classes e provenientes de diversas espécies serão examinados com algoritmos de classificação supervisionados. Neste processo, serão consideradas, 22 medidas morfológicas calculadas sobre os neurônios e focadas principalmente nas árvores dendríticas. Os resultados, mostram que é possível encontrar seções das árvores dendríticas morfologicamente relevantes para a classificação dos neurônios. A relevância recai na possibilidade de usar apenas partes de neurônios para a classificação morfológica das células. As partes mais relevantes à classificação são os ramos mais próximos ao corpo celular, o que biologicamente falando implicaria que a variabilidade causada nos ramos mais distantes do soma, gerada por estímulos externos aos indivíduos estudados por exemplo, poderia ser desconsiderada. Em casos de neurônios similares, o método consegue identificar as hierarquias de ramos mais relevantes para a classificação, as quais não necessariamente correspondem a ramos mais próximos do soma. Neste sentido, os resultados evidenciados abrem novas possibilidades de análise parcial 
de neurônios, sem comprometer o resultado quando comparado à análise global além de expor possíveis implicações biológicas. Obtiveram-se acurácias de classificação similares usando-se neurônios inteiros e apenas partes deles.

Palavras-chave: neurônio, reconstrução morfológica, morfometria, arborização dendrítica, reconstrução neuronal digital, compartilhamento de dados, classificação morfológica, classificação supervisionada, seleção de características. 


\section{Abstract}

\section{CERVANTES, EVELYN P. Morphological classification of neurons based on den-}

dritic tree hierarchy. 2019. 134 f. Tese (Doutorado) - Instituto de Matemática e Estatística, Universidade de São Paulo, São Paulo, 2019.

Among the challenges that neuroanatomy has faced since its inception, the identification of characteristics that allow to distinguish several types of neuronal cells from the morphological point of view, has attracted attention of researchers belonging to different areas, which until today try to characterize quantitatively neurons. On the other hand, considering the premise that the form is directly related to the function of several cells, the shape of the neuron can reveal many properties about its function. The morphological characterization of neurons, therefore, allows analyzes with the purpose of achieving one of the main objectives of neuroscience, a better understand of how the brain works.

This work aims to construct and validate new methods to analyze morphologically sets of neurons using their digital reconstructions at different dendritic levels. This allows considering the entire neurons and only hierarchies of the dendritic trees, in order to identify parts morphologically relevant to the classification of the neuron. The method proposes different strategies for the decomposition of dendritic trees throughout their hierarchies.

A set of more than 5,000 neurons corresponding to different classes and coming from several species will be examined with supervised classification algorithms. In this process, we will consider 22 morphological measures calculated on the neurons and focused mainly on the dendritic trees. The results show that it is possible to find sections of the dendritic trees morphologically relevant for the classification of neurons. The relevance lies in the possibility of using only parts of neurons for the morphological classification of cells. The most relevant parts to the classification are the branches closest to the cell body, which biologically would imply that the variability caused in the branches but distant from the soma, generated by stimuli external to the individuals studied for example, could be disregarded. In cases of similar neurons, the method is able to identify the hierarchies of branches most relevant to classification, which do not necessarily correspond to branches closer to the soma. In this sense, the results revealed open new possibilities of partial analysis of neurons, without compromising the result when compared to the global analysis besides exposing possible biological implications. Similar classification accuracies 
were obtained using whole neurons and using only parts of the neurons.

Keywords: neuron, morphological reconstruction, morphometry, dendritic arborization, digital neuronal reconstruction, data sharing, morphological classification, supervised classification, feature selection. 


\section{Dedicatoria}

Dedico este trabalho a minha avó Marina Rondán Borda (in memoriam) 


\section{Agradecimentos}

Ao longo do desenvolvimento deste trabalho de tese recebi ajuda de muitas pessoas e instituições as quais não poderia deixar de agradecer: Ao Instituto de Matemática e Estatística (IME) e ao Instituto de Física de São Carlos (IFSC) da Universidade de São Paulo, por ter fornecido todas as facilidades para o desenvolvimento deste trabalho.

Quero agradecer também aos meus orientadores os professores doutores Roberto Marcondes César Junior, Luciano da Fontoura Costa e César Henrique Comin pela paciência, as ideias brilhantes, os sábios conselhos, o constante estimulo e dedicação na orientação deste trabalho. Agradeço à FAPESP pelo apoio financeiro FAPESP grant 2015/22308-2, Capes e CNPq e a todos os funcionários do IME.

Ao professor Jesús Mena Chalco pelas ótimas dicas, pela amizade e por sempre estar presente nos meus trabalhos, ainda que de longe.

Agradeço também ao grupo de pesquisa do professor Roberto Marcondes César Junior do qual faço parte, pelas conversas e dicas durante nossos encontros semanais dos quais aprendi muito.

Aos meus colegas de laboratório Miguel, Mariela, Hans, Grover, Nury e Christian pelas discussões de alto nível e pela amizade e por ter me ajudado a trabalhar sempre com paciência e bom ânimo. Por terem vivenciado comigo as diversas etapas de tensão e emoção deste trabalho.

Agradeço à Rosario pela amizade e por ter me motivado a vir para o Brasil, por ter me acolhido e cuidado de mim como uma verdadeira irmã.

Agradeço ao meu noivo Wellington pela compreensão e apoio nos momentos bons mas especialmente nos momentos ruins, obrigada por ter ficado do meu lado sempre e me ensinar a nunca desistir.

Agradeço especialmente a minha família por ter sido meu suporte mesmo na distância, à minha mãe Catalina Cervantes Rondán por ser a mulher lutadora que ela é e por ser minha fonte inesgotável de força, obrigada mãe por estar sempre do meu lado. Às minhas irmãs Sidney e Nataly Perez Cervantes por ser minha motivação e alegria, por ter me apoiado em cada aventura empreendida. Obrigada porque vocês ficaram comigo nos momentos mais difíceis. 


\section{Sumário}

Lista de Figuras $\quad$ xi

Lista de Tabelas $\quad$ XV

1 Introdução 1

1.1 Motivação . . . . . . . . . . . . . . . . . . . . . . 3

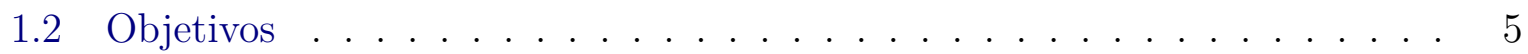

1.3 Contribuições . . . . . . . . . . . . . . . . . . 5

1.4 Organização do trabalho . . . . . . . . . . . . . . . . . . . . 6

2 Conceitos $\quad 9$

2.1 Uma breve história da classificação de neurônios . . . . . . . . . . . . . . 9

2.1.1 Classificação de neurônios . . . . . . . . . . . . . . . . . . . . . 10

2.1.2 Classificação automática de neurônios . . . . . . . . . . . . . 11

2.2 Conceitos básicos . . . . . . . . . . . . . . . . . 16

2.2.1 Princípios de neurociência . . . . . . . . . . . . . . 16

2.2 .2 Princípios da neuroanatomia computacional . . . . . . . . . . 20

3 Metodologia $\quad 29$

3.1 Proposta. . . . . . . . . . . . . . . . . . . . . . . . 29

3.2 Decomposição de neurônios . . . . . . . . . . . . . . . . . . 30

3.2 .1 Representação digital do neurônio . . . . . . . . . . . . . . . . . 30

3.3 Decomposição do neurônio . . . . . . . . . . . . . . . . . . . . . . . . . 32

3.3.1 Decomposição baseada nos ramos principais da árvore dendrítica 34

3.3.2 Decomposição baseada na profundidade de árvore dendrítica . . . . 36

3.3.3 Decomposição baseada na altura da árvore dendrítica . . . . . . . . 38

3.3.4 Decomposição baseada em fatia da árvore dendrítica . . . . . . . . 39

3.4 Classificação morfológica de neurônios ～. . . . . . . . . . . . . . . . . . 40

3.4.1 Medidas morfológicas . . . . . . . . . . . . . . . . . . . 42

3.4.2 Aprendizagem supervisionada . . . . . . . . . . . . . . 43 
4 Experimentos e resultados $\quad 47$

4.1 Conjunto de dados . . . . . . . . . . . . . . . . . . . . . 47

4.2 Experimento 1: Classificação de neurônios completos . . . . . . . . . . . 51

4.3 Experimento 2: Classificação baseada em ramos principais da árvore den-

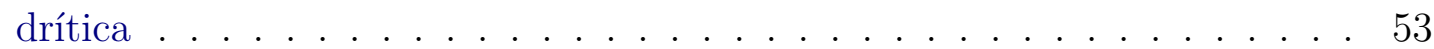

4.4 Experimento 3: Classificação baseada na profundidade da árvore dendrítica 56

4.5 Experimento 4: Classificação baseada na altura da árvore dendrítica . . . . 58

4.6 Experimento 5: Classificação baseada em fatias da árvore dendrítica . . . . 59

4.7 Experimento 6: Classificação baseada em fatias de rato e camundongo. . . 61

4.8 Experimento 7: Classificação baseada em fatias na região neocortical. . . . 68

5 Considerações finais $\quad 75$

5.1 Conclusões . . . . . . . . . . . . . . . . . . . . 75

5.2 Trabalhos futuros . . . . . . . . . . . . . . . . 77

$\begin{array}{lll}\text { A Gráficos do PCA e do LDA do experimento } 3 & 79\end{array}$

B Gráficos do PCA e do LDA de dendritos apicais e basais $\quad 91$

$\begin{array}{lll}\text { C Publicações } & 103\end{array}$

$\begin{array}{ll}\text { Referências Bibliográficas } & 107\end{array}$ 


\section{Lista de Figuras}

1.1 Representação gráfica da motivação deste trabalho . . . . . . . . . . . . 4

2.1 Classes de neurônios segundo sua forma . . . . . . . . . . . . . . . . . 11

2.2 Site oficial do Neuromorpho.Org . . . . . . . . . . . . . . . . 12

2.3 Evolução do NeuroMorpho.org . . . . . . . . . . . . . . . . . . . 12

2.4 Principais componentes de um neurônio . . . . . . . . . . . . . . . 18

2.5 Direção do impulso nervoso . . . . . . . . . . . . . . . . . . . . 19

2.6 Representação natural do neurônio (lado esquerdo) como um grafo (lado direito), os segmentos do neurônio são representados por arestas. . . . . . . 22

2.7 Reconstrução do neurônio: (a) imagem original do microscópio [fonte:celltypes.brainmap.org], (2) reconstrução 3D fornecida pelo Allen Brain Atlas utilizando o método de reconstrução semiautomático da ferramenta Vaa3D-Neuron, (c) representação do neurônio como grafo. . . . . . . . . . . . . . . 23

2.8 Representação gráfica de uma segmento de neurônio representado no formato SWC . . . . . . . . . . . . . . . . . . 24

2.9 Representação gráfica do arquivo SWC . . . . . . . . . . . . . 25

3.1 Uma visão da proposta deste trabalho dividida em três etapas: Na etapa de decomposição de neurônios, o neurônio foi decomposto sistematicamente nas diferentes hierarquias dos ramos. Na segunda etapa, foi efetuada a classificação supervisionada de neurônios depois de um processo de normalização e seleção de características. Por fim, na última etapa, foi feita uma análise comparativa, baseada na acurácia, dos resultados obtidos nos diferentes processos de classificação. . . . . . . . . . . . . . . . 30

3.2 Representação dos componentes do neurônio. . . . . . . . . . . . . . . 31

3.3 Estrutura de árvore usada para armazenar os dados do neurônio . . . . . . . 32

3.4 Um exemplo de decomposição do neurônio baseado na estrutura da árvore dendrítica. . . . . . . . . . . . . . . . . . . 33 
3.5 Ilustração da altura e profundidade de ramos dendríticas em uma árvore. A profundidade de um ramo representa o número de bifurcações indo ao longo do caminho da raiz até os ramos terminais. A altura é o complemento da profundidade. Note-se que, de acordo com a nossa definição, ramos terminais não necessariamente tem altura igual a zero. . . . . . . . . . . . 34

3.6 Neurônios criados usando o método de decomposição por ramos principais. 35

3.7 Neurônios criados usando o procedimento de decomposição baseado na profundidade da árvore dendrítica. . . . . . . . . . . . . . . . . . . . . 37

3.8 Neurônios criados usando o método de decomposição por altura. . . . . . . 39

3.9 Neurônios criados aplicando o método de decomposição por fatia. . . . . . 41

3.10 Medida-F dos classificadores testados. . . . . . . . . . . . . . . . . . . . 44

3.11 Um exemplo do hiperplano de separação ideal entre duas classes, identificado pelo SVM. . . . . . . . . . . . . . . . . . . 45

4.1 Dez exemplos de reconstruções digitais de neurônios pertencentes às diferentes classes utilizadas em nossos testes. . . . . . . . . . . . . . . . . . . 48

4.2 PCA das dez maiores classes envolvidas neste estudo. É possível observar a predominância de algumas classes em determinadas regiões, mas também existem regiões com sobreposição. . . . . . . . . . . . . . . . . . . . 50

4.3 t-SNE das dez maiores classes envolvidas neste estudo. . . . . . . . . . . . 51

4.4 Resultados do Experimento 1. . . . . . . . . . . . . . . . . . . 52

4.5 Resultados do Experimento 2. . . . . . . . . . . . . . . . 55

4.6 PCA das medidas morfológicas do Experimento 2 . . . . . . . . . . . 55

4.7 Resultados do Experimento 3. . . . . . . . . . . . . . . 57

4.8 Resultados do Experimento 4. . . . . . . . . . . . . . . . . . . . . . . . 59

4.9 Resultados do Experimento 5. . . . . . . . . . . . . . . . . . . 60

4.10 A ordem máxima dos ramos de cada classe de neurônios, pode ser observada a heterogeneidade das profundidades. . . . . . . . . . . . . . . 61

4.11 Mapa de calor dos resultados obtidos usando o método de classificação por fatias com quatro classes de neurônios com profundidade de árvore dendrítica igual a $5 . \ldots \ldots$. . . . . . . . . . . . . . 62

4.12 Representação gráfica de neurônios escolhidos aleatoriamente das classes (a) camundongo e (b) rato envolvidas neste experimento. . . . . . . . . 63

4.13 PCA das medidas dos neurônios das espécies rato e camundongo envolvidas no teste do Experimento 6. . . . . . . . . . . . . . . . . . 65

4.14 Resultados do Experimento 6. . . . . . . . . . . . . . . . . . . 67

4.15 Representação gráfica de neurônios escolhidos aleatoriamente das classes (a) piramidal e (b) interneurônio envolvidas neste experimento. . . . . . . . 69 
4.16 Representação gráfica de neurônios escolhidos aleatoriamente das classes (a) piramidal e (b) interneurônio envolvidas neste experimento. . . . . . . 71

4.17 Resultados do Experimento 7. . . . . . . . . . . . . . . . . . . . 72

4.18 Medidas-F médias obtidas após a classificação de neurônios piramidais e interneurônios das espécies de camundongos, considerando apenas os dendritos basais. . . . . . . . . . . . . . . . . . . . 73

A.1 PCA e LDA utilizando dendritos até a profundidade $0 \ldots \ldots$. . . . 80

A.2 PCA e LDA utilizando dendritos até a profundidade 1 . . . . . . . . 81

A.3 PCA e LDA utilizando dendritos até a profundidade 2 . . . . . . . . . . 82

A.4 PCA e LDA utilizando dendritos até a profundidade $3 \quad \ldots$. . . . . . . 83

A.5 PCA e LDA utilizando dendritos até a profundidade 4 . . . . . . . . . 84

A.6 PCA e LDA utilizando dendritos até a profundidade $5 \ldots$. . . . . . 85

A.7 PCA e LDA utilizando dendritos até a profundidade 6 . . . . . . . . 86

A.8 PCA e LDA utilizando dendritos até a profundidade 8 . . . . . . . . . 87

A.9 PCA e LDA utilizando dendritos até a profundidade $10 \ldots \ldots$. . . . . 88

A.10 PCA e LDA utilizando dendritos até a profundidade 16 . . . . . . . . . 89

A.11 PCA e LDA utilizando dendritos até a profundidade 20 . . . . . . . . . . 90

B.1 PCA e LDA utilizando dendritos apicais até a profundidade 0 . . . . . . 92

B.2 PCA e LDA utilizando dendritos apicais até a profundidade 1 . . . . . . 93

B.3 PCA e LDA utilizando dendritos apicais até a profundidade 2 . . . . . . . 94

B.4 PCA e LDA utilizando dendritos apicais até a profundidade 6 . . . . . 95

B.5 PCA e LDA utilizando dendritos apicais até a profundidade 9 . . . . . . 96

B.6 PCA e LDA utilizando dendritos basais até a profundidade 0 . . . . . . . 97

B.7 PCA e LDA utilizando dendritos basais até a profundidade 1 . . . . . . . 98

B.8 PCA e LDA utilizando dendritos basais até a profundidade 2 . . . . . . . . 99

B.9 PCA e LDA utilizando dendritos basais até a profundidade 6 . . . . . . . . 100

B.10 PCA e LDA utilizando dendritos basais até a profundidade 9 . . . . . . . . 101 


\section{Lista de Tabelas}

2.1 Exemplo de arquivo SWC . . . . . . . . . . . . . . . . . 25

3.1 Medidas morfológicas consideradas para caracterização do neurônio. . . . . 43

4.1 Lista de classes de neurônios consideradas neste estudo. . . . . . . . . . . . 48

4.2 Média e desvio padrão das medidas usadas como características para cada uma das dez classes consideradas. . . . . . . . . . . . . . . . . . . . 49

4.3 PCA 3 componentes. . . . . . . . . . . . . . . . . . . 53

4.4 Média e desvio padrão das medidas usadas como características para cada uma das dez classes consideradas no Experimento 2 . . . . . . . . . . . . 54

4.5 PCA 3 componentes. . . . . . . . . . . . . . . . . 56

4.6 Média e desvio padrão das medidas usadas como características as duas classes consideradas no experimento 6. . . . . . . . . . . . . . . . . . 64

4.7 PCA 3 componentes. . . . . . . . . . . . . . . 66

4.8 Tabela comparativa das medidas usadas no Experimento 6, no qual foram contempladas fatias entre 0-8 e 4-12. São mostradas as médias e desvio padrão de todas as medidas para cada uma das classes em estudo. . . . . . 68

4.9 Média e desvio padrão das medidas usadas no experimento 7 . . . . . . 70

4.10 Tabela comparativa das medidas obtidas no Experimento 7 com fatias entre 0-6 e 3-12. A tabela mostra a média, desvio padrão para ambos os intervalos considerados. . . . . . . . . . . . . . . . . . . . . . 73 


\section{Capítulo 1}

\section{Introdução}

Classificar neurônios, em sentido estrito, é o processo de separar um conjunto de neurônios em classes distinguíveis com características semelhantes. No entanto, ainda não existem respostas definitivas gerais para questões tais como quantas classes de neurônios existem no cérebro, ou o que queremos dizer com uma classe de neurônios [Armañanzas e Ascoli, 2015, Bota e Swanson, 2007, Masland, 2004]. Com fins pragmáticos, neste trabalho um conjunto de neurônios com estruturas semelhantes pertencem a uma mesma classe, e está baseado na premissa de que estruturas diferentes indicam funções diferentes [Masland, 2004]. Essas questões vêm sendo estudadas desde a própria origem da neurociência, bem antes de existirem os impressionantes instrumentos eletrônicos atuais. Em 1911 Cajal e Azoulay [Cajal, 1911] fizeram uma interpretação funcional das estruturas do sistema nervoso e demonstraram a independência morfológica e funcional das células nervosas usando a chamada mancha de Golgi, proposta por Camillo Golgi em 1873, para identificar as formas dos neurônios. Com base nos conhecimentos fornecidos por Cajal e Azoulay, muitas pesquisas estão sendo desenvolvidas até nossos dias, com a finalidade de melhorar a compreensão do funcionamento do cérebro. Ter um censo dos diferentes tipos ou classes de células nervosas bem como conhecer suas funcionalidades representaria um grande avanço nesse caminho.

A tarefa de classificar neurônios, que aparenta ser simples, na realidade está longe de ser resolvida plenamente. Mesmo com os atuais avanços tecnológicos, existem diversas limitações abrangendo desde o processo de aquisição das imagens, devido ao tamanho 
das células, passando pelo desconhecimento de uma alguma característica que defina a classe do neurônio na ausência de informações moleculares, até a falta de uma nomenclatura padrão e em consequência disso ainda não existe um número definido de classes de neurônios [Bernard et al., 2009, Sümbül et al., 2014b].

O neurônio, unidade fundamental do sistema nervoso, é composto por três estruturas principais: o corpo celular ou soma, o axônio e os dendritos, cada uma delas com funções importantes no transporte do impulso nervoso [Kandel et al., 2000]. O neurônio pode ser caracterizado por sua morfologia, função ou suas propriedades bioquímicas [McGarry et al., 2010, Seung e Sümbül, 2014, Uji et al., 1995]. Estas características podem ser muito variáveis mesmo num único tipo de neurônio, dependendo, por exemplo, da localização ou da função [Barbosa et al., 2003, Ding e Glanzman, 2011], além de ser de difícil acesso. A automação das análises quantitativas de neurônios é feita em reconstruções histológicas digitais. Ao longo dos anos surgiram diversas propostas para classificar neurônios, baseadas na análise dessas reconstruções, que proveem abundantes informações morfológicas [Armañanzas e Ascoli, 2015, Halavi et al., 2012, Mottini et al., 2014, Ruz e Schultz, 2014, Sharpee, 2014, Sümbül et al., 2014a].

A morfologia neuronal é uma característica chave no estudo dos neurônios por estar diretamente vinculada com sua funcionalidade [Masland, 2004]. Entretanto, o acesso a características funcionais e bioquímicas ainda é trabalhoso. Nos últimos anos, as informações morfológicas dos neurônios vêm sendo compartilhadas por pesquisadores de diferentes partes do mundo, usando reconstruções digitais 3D, em bancos de dados de acesso público como no caso de NeuroMorpho.org [Ascoli et al., 2007]. Embora estas características apresentem ainda algum grau de variabilidade dependendo do laboratório de processamento, por exemplo, e portanto tornando ainda mais complicado o processo de escolha de características [Armañanzas e Ascoli, 2015, Bazán e Lolley, 2013, Bota e Swanson, 2007, Comin e da Fontoura Costa, 2013, DeFelipe, 2001, López-Cruz et al., 2014, Uylings e van Pelt, 2002, Uylings et al., 1989], são de grande ajuda no desenvolvimento de trabalhos de pesquisa como o nosso.

Neste trabalho, é analisada comparativamente a classificação morfológica de um con- 
junto de mais de 5.000 neurônios em diferentes níveis hierárquicos, isto é, utilizando neurônios com suas árvores dendríticas inteiras e apenas subárvores dendríticas pertencentes a diferentes hierarquias. Com a finalidade de mostrar se as características morfológicas que ajudam a distinguir classes de neurônios inteiros ainda podem ser detectadas nesses níveis, e se existem partes das árvores dendríticas relevantes à classificação morfológica dos neurônios. Nesse sentido, são apresentados alguns métodos de decomposição dos neurônios baseados na hierarquia do ramos.

\subsection{Motivação}

Embora a análise da morfologia dos neurônios geralmente leve células inteiras (soma, dendritos e axônios) em consideração, seria interessante investigar se as propriedades morfológicas que distinguem diferentes tipos de neurônios se estendem quando a morfologia neuronal é abordada em níveis hierárquicos (por exemplo, ramos das árvores dendríticas etc.). Essa é a principal motivação deste trabalho, mais especificamente, abordamos o problema da classificação supervisionada das células neuronais, considerando não só várias classes de neurônios, mas também comparamos os resultados da classificação quando as árvores dendríticas são decompostas em partes menores baseadas nas hierarquias dos ramos. Esse processo também pode ser entendido como a caracterização de neurônios em diferentes níveis de detalhe, o que deve permitir fazer uma descrição morfológica mais sucinta, além de fornecer informações relevantes sobre a organização das formas dos neurônios.

Na Figura 1.1 apresentamos uma descrição da perspectiva de nosso trabalho usando um exemplo simples, consideramos dois tipos neuronais, A e B. Esses tipos são definidos por uma região num espaço de características, a qual caracteriza a morfologia típica de cada um dos tipos envolvidos. No entanto, cada neurônio distinto, sendo ele tipo A ou B, pertence a posições diferentes em tal espaço. Alguns neurônios podem até ter características que não são típicas de sua classe e, portanto, estarem localizados fora da região da classe.

Além disso, consideramos que cada neurônio é definido por um conjunto de árvores 
(árvores dendríticas). Se espera que as árvores dendríticas ou partes das árvores dendríticas do mesmo neurônio compartilhem propriedades semelhantes. No entanto, uma determinada árvore pode não ser típica do neurônio.

Figura 1.1: Representação gráfica da motivação deste trabalho. A figura representa um espaço de características bidimensionais usado para caracterizar um conjunto de neurônios pertencentes a duas classes, A e B. Linhas sólidas indicam regiões típicas. Os neurônios são representados por grupos de linhas pontilhadas e as árvores dendríticas são representadas por pontos.
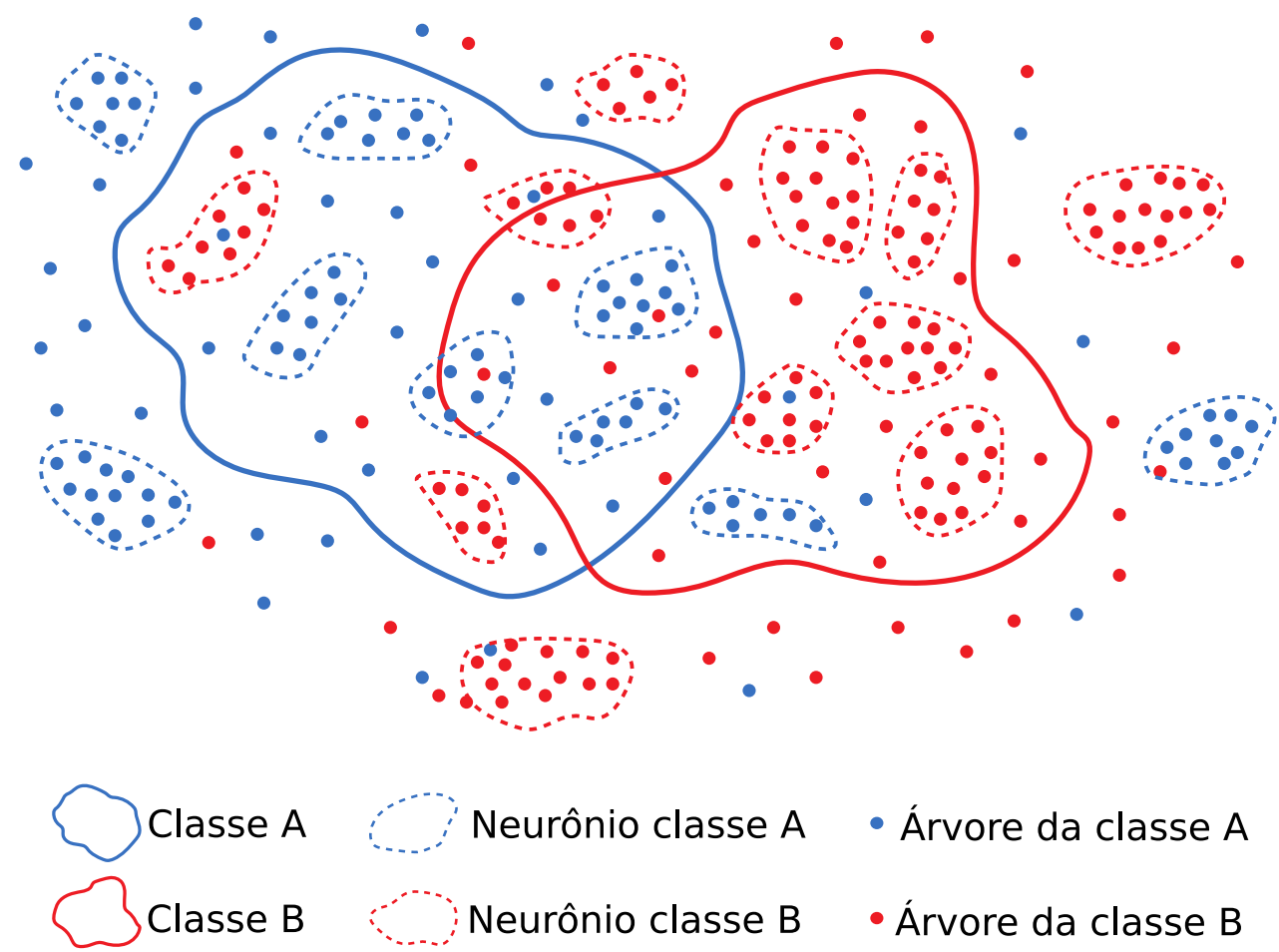

Fonte: adaptação da ilustração publicada em Cervantes et al. [2016]

Como um subproduto desta análise, quando os neurônios são decompostos, o número de indivíduos no banco de dados tende a crescer significativamente, aumentando as possibilidades de abordagens com grandes quantidades de dados.

No presente trabalho se pretende implementar os seguintes métodos de decomposição de neurônios:

- Por ramos principais, com a finalidade de determinar a existência de subárvores mais relevantes do que outras à classificação.

- Por níveis de profundidade, com a finalidade de determinar a relevância dos níveis de profundidade na caracterização dos neurônios. Este resultado permitirá determinar 
quão profundo na árvore dendrítica precisamos analisar para conseguir classificar eficientemente quando os ramos são acumulados, incluindo o soma.

- Por níveis de altura, com a finalidade de determinar a relevância dos níveis de altura na caraterização dos neurônios. Este resultado permitirá determinar se apenas a morfologia dos ramos mais distantes do soma consegue separar eficientemente as classes dos neurônios.

- Por fatias de árvores, com a finalidade de identificar seções, das árvores dendríticas relevantes para a caracterização dos neurônios. Este resultado permitirá avaliar se considerando apenas a morfologia de ramos intermediários, desconsiderando os mais próximos mais distantes do soma, é possível classificar os neurônios.

Serão analisadas todas as partes resultantes dos processos de decomposição na classificação morfológica de neurônios, com a finalidade de identificar partes das árvores dendríticas relevantes à classificação morfológica bem como avaliar algumas de suas possíveis implicâncias biológicas.

\subsection{Objetivos}

Este projeto de doutorado pretende analisar se a classificação morfológica de neurônios utilizando partes de reconstruções digitais é eficiente quando comparada com outros métodos de classificação existentes. Para isso, propomos uma nova metodologia de decomposição de neurônios prévia à sua classificação morfológica. Um estudo extensivo da metodologia proposta aplicada a dados reais foi realizado.

\subsection{Contribuições}

Segundo o nosso conhecimento, não existem na literatura abordagens que tratem o problema da classificação morfológica de neurônios usando apenas partes das árvores dendríticas. Esta tese apresenta um novo método para isso, trazendo as seguintes contribuições originais: 
- Identificar conjuntos significativos de neurônios procedentes de diferentes espécies, classes e regiões do sistema nervoso.

- Calcular e escolher as medidas quantitativas de neurônios que permitem distinguir as diferentes classes de neurônios usando tanto estruturas completas das árvores como subárvores dendríticas.

- Implementar um método de segmentação sistemático de árvores dendríticas de neurônios que leve em consideração a hierarquia das árvores.

- Selecionar um método de classificação automático de neurônios que permita fazer a classificação morfológicas com árvores e subárvores dendríticas.

- Analisar comparativamente os resultados da classificação morfológica com a finalidade de determinar se características que distinguem neurônios podem ser identificadas em diferentes níveis hierárquicos.

- Avaliar a possibilidade de identificar partes morfologicamente relevantes para classificar neurônios e identificar quais seriam estas partes, assim como identificar suas peculiaridades para a classificação e possíveis explicações e implicações biológicas.

\subsection{Organização do trabalho}

O texto desta tese foi organizado usando informações dos artigos produzidos durante esta pesquisa [Cervantes et al., 2016, 2019]. Este trabalho está organizado da seguinte maneira: O capítulo 1 contará com uma introdução básica à classificação morfológica de neurônios, considerando a relevância do tema proposto, as motivações do trabalho assim como os objetivos gerais e específicos e as contribuições da pesquisa.

No Capítulo 2 será apresentada uma breve história da classificação de neurônios considerando algumas referências bibliográficas importantes. Dado que o projeto envolve conceitos tanto de neurociência quanto da ciência da computação neste capítulo também são apresentados alguns conceitos básicos. 
No Capítulo 3 serão abordados os passos desenvolvidos para atingir nossos objetivos. Neste capítulo serão descritos os métodos de representação dos neurônios bem como os métodos de decomposição implementados para depois classificar os neurônios.

No Capítulo 4 serão mostrados os resultados preliminares obtidos dos diferentes testes até agora executados. No Capítulo 5 são apresentadas algumas conclusões e sugerimos possíveis trabalhos futuros. Por fim, nos Apêndices A e B são apresentadas algumas visualizações dos experimentos e no Apêndice C são mostradas as publicações produzidas durante este trabalho. 


\section{Capítulo 2}

\section{Conceitos}

\subsection{Uma breve história da classificação de neurônios}

Todos temos a ideia de quanto é importante o sistema nervoso para a vida. Atualmente, essa ideia tem suporte na grande diversidade de estudos científicos em diferentes áreas, tais como: anatomia, fisiologia, psicologia entre outras. Embora o termo "neurociência" seja relativamente novo, usado pela primeira vez em 1962 pelo Francis O. Schmitt's, a curiosidade humana e o fascínio pelo cérebro têm uma longa história. Há evidência de que nossos antepassados pré-históricos já deram uma importância privilegiada ao cérebro. Os antigos gregos, como Hipócrates, acreditavam que o cérebro era o órgão da sensação e também a sede da inteligência. Galeno abraçou esta ideia e trabalhou com dissecações de animais. Ele concluiu que o corpo funciona de acordo com alguns fluídos vitais que se movem do cérebro ou para o cérebro através dos nervos [Bear et al., 2007, Galenus, Kandel et al., 2000, Singer, 1956].

O sistema nervoso só foi completamente dissecado no final do século XVIII, configurando assim a era da localização cerebral, na qual cada região do cérebro desempenha uma função diferente. Um dos principais obstáculos que os cientistas enfrentaram foi o pequeno tamanho dos sistemas nervosos. Em 1873, Golgi descobriu uma solução, agora chamada de mancha de Golgi, que faz com que os neurônios se tornem coloridos em sua totalidade. Em seguida, Cajal usou a mancha de Golgi para fornecer uma descrição detalhada das células nervosas e conduziu a doutrina do neurônio, a qual proclama que os neurônios 
individuais são os blocos de construção elementares do sistema nervoso [Bear et al., 2007, Kandel et al., 2000].

\subsubsection{Classificação de neurônios}

Como foi mencionado antes, os neurônios podem ser classificados dependendo da forma, função ou atividade bioquímica que possuem. A primeira e mais conhecida maneira de classificar neurônios é usar a distribuição espacial de seus componentes. Esse método de classificação é conhecido como classificação morfológica, dado que essencialmente são avaliadas as formas de seus componentes. Segundo essa classificação, os neurônios podem ser separados em três grandes grupos: unipolar, bipolar e multipolar [Kandel et al., 2000].

Os neurônios unipolares se caracterizam por terem apenas corpo celular e uma estrutura em forma de árvore que desempenha ambas funções, de dendritos e de axônio. Esse tipo de células são muito comuns no sistema nervoso de invertebrados. Os neurônios bipolares possuem uma estrutura mais complexa, com duas estruturas em forma de árvore saindo do corpo celular, que por sua vez tem forma oval. Neste tipo de neurônio a árvore dendrítica recebe as informações e as transporta para o soma, enquanto que o axônio transporta as informações desde o soma para a medula espinhal ou diretamente para alguma área do cérebro. Esse tipo de neurônio é comum nos órgãos sensoriais como olfato e visão [Bear et al., 2007, Kandel et al., 2000]. Já os neurônios multipolares são os mais comuns no sistema nervoso humano e se encaixam perfeitamente na descrição do neurônio proporcionada na Seção 2.2.1.1.1.

É importante notar que essa é apenas a classificação morfológica mais simples que foi proposta inicialmente por Cajal. As imagens de neurônios que todos temos foram criadas por ele com fins didáticos e essa é uma classificação ensinada até nossos dias. No entanto, existem muitas subclassificações e nomenclaturas que são exploradas em trabalhos mais recentes, que levam em consideração muitos outros aspetos. 
Figura 2.1: Classes de neurônios segundo sua forma

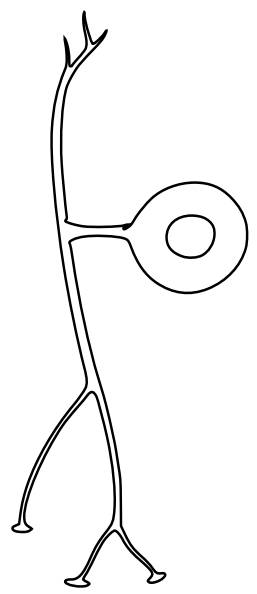

Unipolar

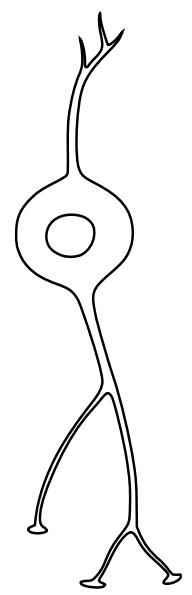

Bipolar

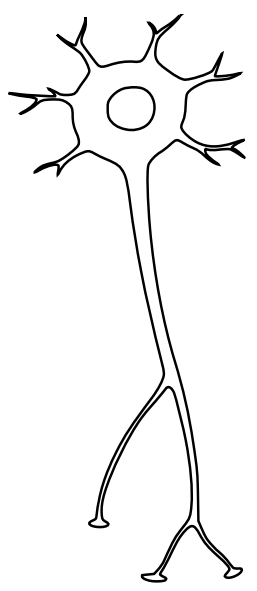

Multipolar

Fonte: adaptação de ilustração de Holly Fischer, distribuída sob licença de Creative Commons Attribution 3.0 Unported.

\subsubsection{Classificação automática de neurônios}

Tradicionalmente, o problema da classificação de neurônios tem tido uma abordagem qualitativa, mas sempre com várias divergências entre os pesquisadores. Nos últimos anos, as abordagens quantitativas automáticas foram popularizadas devido, principalmente, ao surgimento de entidades como a NIF (Neuroscience Information Framework), que promove a cultura de compartilhamento das informações de neurônios entre pesquisadores de diferentes partes do mundo. Sob o impulso de eventos como a competição DIADEM 2010 [Liu, 2011] que publicou imagens de neurônios e suas correspondentes reconstruções digitais, o crescimento de bancos de dados que compartilham informações tem sido acentuado [Nanda et al., 2015, Parekh e Ascoli, 2013, Parekh et al., 2015]. Projetos como o NeuroMorpho.Org [Ascoli et al., 2007] investiram esforços na automação da reconstrução digital, tendo como resultado o incremento acelerado tanto de dados quanto de trabalhos de pesquisa em diversas áreas.

NeuroMorpho.Org é um repositório de neurônios reconstruídos digitalmente que está constantemente coletando e compartilhando suas informações (Veja a tela principal do site oficial na Figura 2.2) e que oferece acesso gratuito ao seu banco de dados tentando sempre motivar o compartilhamento de dados na comunidade de neurociências. Este projeto foi iniciado em 2006 e atualmente é mantido pelo Grupo de Neuroanatomia Computacional no 
Figura 2.2: Site oficial do Neuromorpho.Org

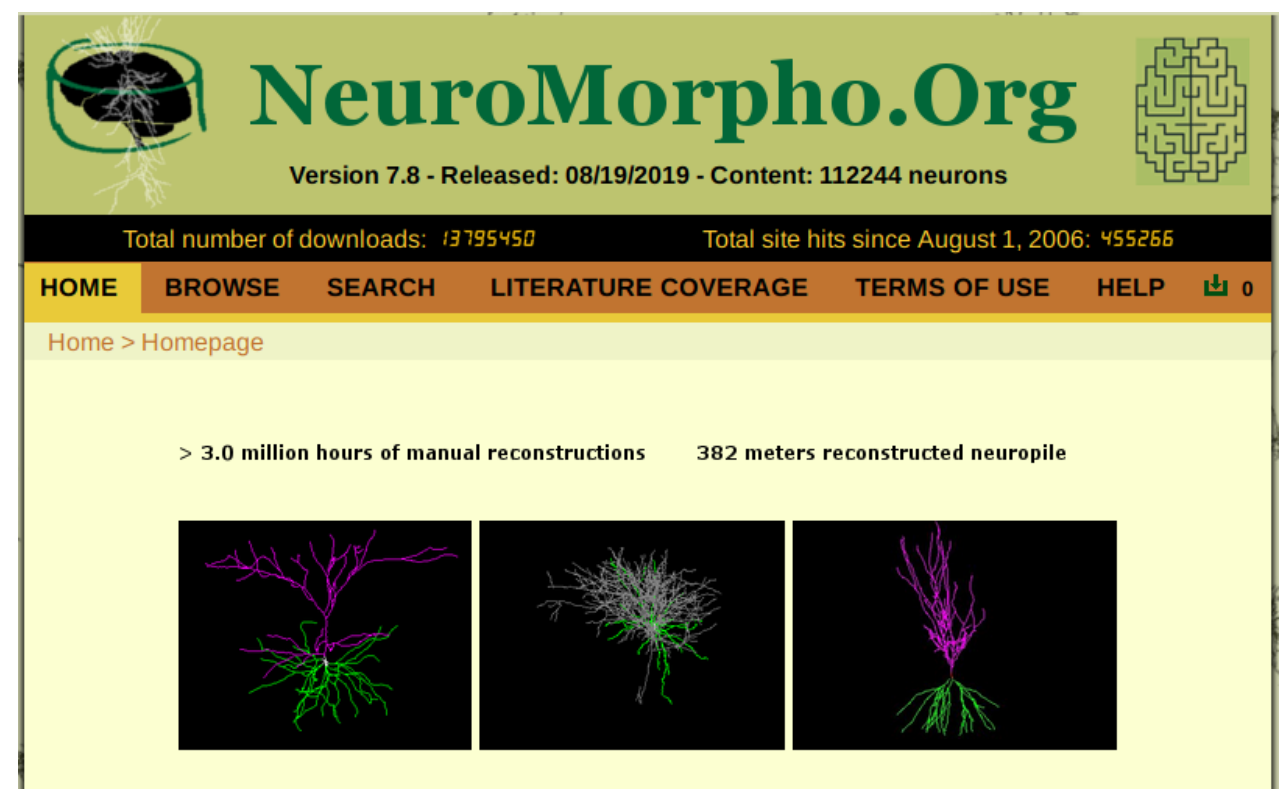

Fonte: Captura de tela do Neuromorpho.Org.

Instituto Krasnow para Estudos Avançados, Universidade George Mason, e dirigido pelo Prof. Giorgio Ascoli, PhD. Atualmente conta com a colaboração de vários laboratórios ao redor do mundo. A Figura 2.3 mostra a evolução do tamanho do banco de dados do NeuroMorpho.Org no tempo.

Figura 2.3: Evolução no tempo do banco de dados do NeuroMorpho.org

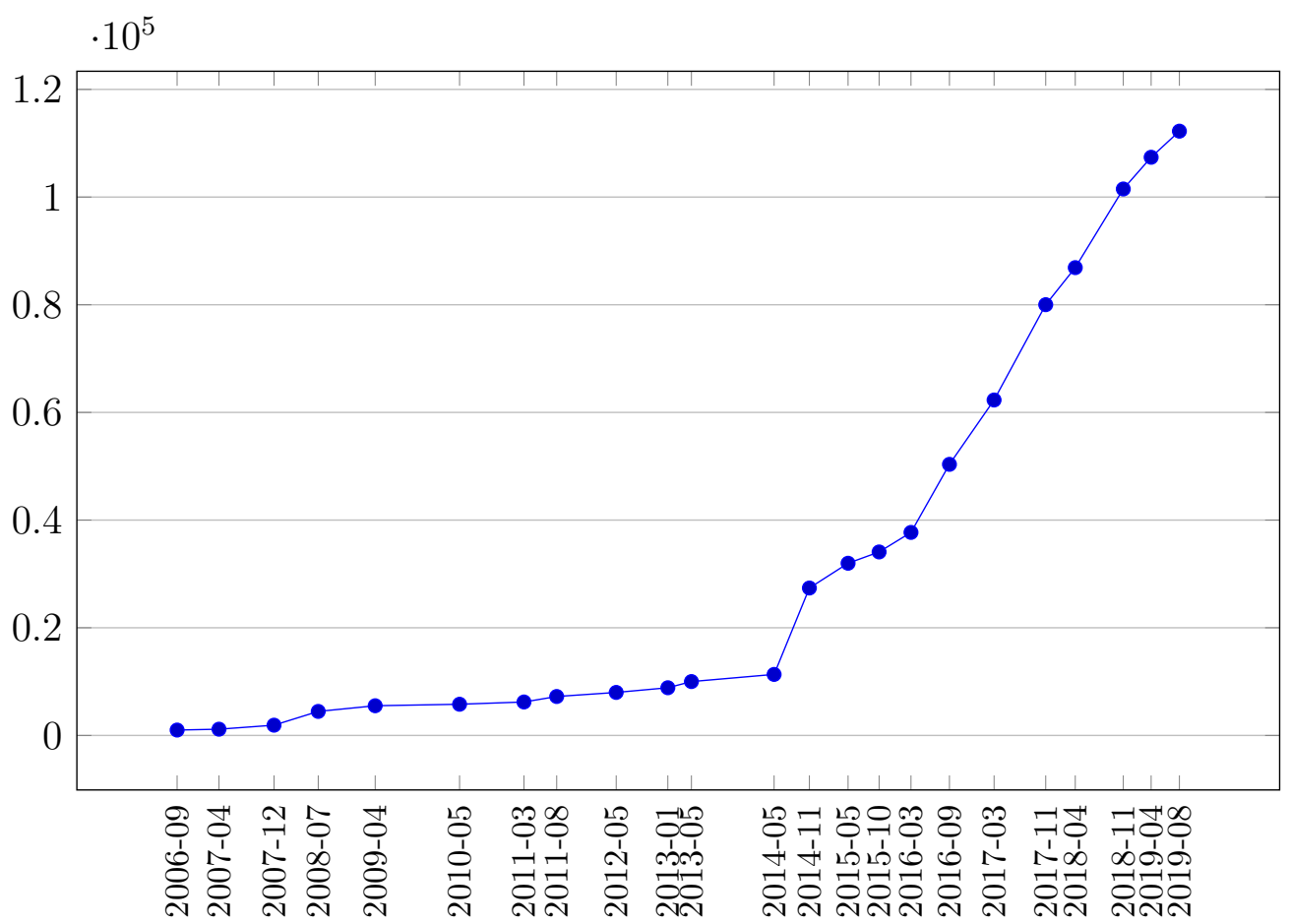


O termo "classificação" em ciência da computação é usado para se referir a dois tipos de análises. A primeira implica em dividir um conjunto de neurônios em grupos previamente conhecidos. O segundo uso implica na identificação das próprias classes [Armañanzas e Ascoli, 2015]. Essa pesquisa, analisa a classificação automática de neurônios a partir de medidas quantitativas no primeiro significado. Neste sentido, ao longo dos anos, várias propostas surgiram para classificar os neurônios com base na análise das estruturas previamente descritas na Seção 2.2.1.1.1.

As primeiras tentativas para automatizar a classificação de neurônios se caracterizavam por implementar processos complexos que implicavam em aquisição de dados diretamente no cérebro das espécies analisadas, medição de atividade elétrica, visualização das células, para finalmente conseguir adquirir algumas medidas morfológicas como área ou perímetro e implementar métodos de aprendizado de máquina para classificar neurônios ou em geral identificar padrões [Cesar Jr e da Fontoura Costa, 1998, da F Costa e Velte, 1999, Karagiannis et al., 2009].

Armañanzas e Ascoli [2015] fizeram uma revisão sistemática dos métodos de classificação de neurônios que usam aprendizado de máquina. As propostas consideradas nesse estudo exploram ambas estruturas de axônios e dendritos, basicamente porque existem também estudos que comprovam a profunda relevância destas estruturas na transmissão do impulso nervoso, integração, conectividade e na detecção de patologias [Parekh e Ascoli, 2015, Zippo e Biella, 2015]. Embora as primeiras análises tenham sido baseadas em dados, posteriormente, foram aprofundadas, envolvendo um conjunto de pareceres de especialistas para criar Multiredes Bayesianas [López-Cruz et al., 2014], com informações biológicas previamente conhecidas [Guerra et al., 2011, Santana et al., 2013].

A análise Sholl é uma técnica bem conhecida em estudos sobre neurônios que consiste na extração de características morfológicas de neurônios utilizando circunferências concêntricas (com centro no soma) para quantificar o número de interseções com as árvores dendríticas [Sholl, 1953]. Métodos semelhantes ao proposto por Sholl são comuns entre pesquisadores que utilizam reconstruções digitais de neurônios para calcular nelas algumas medidas, permitindo estabelecer algum critério de similaridade [Polavaram et al., 2014]. 
Usando NeuroMorpho.org [Ascoli et al., 2007] como banco de dados e o software Lmeasure [Scorcioni et al., 2008] para calcular medidas morfológicas sobre as árvores dendríticas, Lu et al. [2015] adotaram um algoritmo harmônico para agrupar os neurônios em grupos e subgrupos e ao mesmo tempo identificar padrões para agrupamento hierárquico. Santana et al. [2013] propuseram um algoritmo de agrupamento chamado propagação por afinidade para identificar tipos neuronais combinando um conjunto de características morfológicas e fisiológicas. Vasques et al. [2016] testaram um conjunto de classificadores usando como características medidas morfológicas calculadas sobre um conjunto de neurônios.

A densidade do neurônio é uma das características que mais atraiu o olhar de alguns pesquisadores, como no caso de Teeter e Stevens [2011], que abordaram o problema da classificação usando a densidade das árvores dendríticas e axonais junto com a área de território ocupada por essas estruturas. Sümbül et al. [2014a] abordaram o problema de maneira semelhante, mas incluíram a posição relativa da árvore dendrítica em relação a outras células. A sobreposição de densidade entre as árvores dendríticas foi proposta por Zhao e Plaza [2014] para expressar a semelhança entre os neurônios.

Por outro lado Sophie Laturnus e colaboradores mostram no seu artigo [Laturnus et al., 2019] que uma mistura de mapas de densidade junto com características morfológicas se mostraram mais eficientes na classificação de neurônios. Resultados semelhantes foram obtidos usando-se apenas reconstruções parciais de neurônios. Este trabalho foi desenvolvido usando informações tanto dos dendritos quanto dos axônios, eles afirmam que os axônios forneceram melhores informações do que os dendritos em células de tipo bipolares da retina e interneurônios corticais.

Lin e Zhen [Lin e Zheng, 2019] usaram recentemente redes neurais profundas para classificar neurônios, eles usaram 43 características morfológicas extraídas com a ferramenta L-measure para treinar dois modelos de redes profundas cumulativas conectadas os testes foram feitos em duas especies (Caenorhabditis elegans e peixe-zebra) e obtiveram resultados com acurácias acima de $72 \%$.

O desafio de comparar estruturas com forma de árvores é abordado por Gillette e seus 
colaboradores [Gillette e Grefenstette, 2009], no artigo eles utilizam e avaliam o método tree-edit-distance restringido, que permite fazer uma comparação direta entre árvores, para comparar morfologia de células neuromusculares, tal como originalmente foi proposto por Heumann e Wittum [Heumann e Wittum, 2009] quando usaram o método para comparar dendritos de células do hipocampo.

Uma abordagem diferente foi a apresentada por Gillette e Ascoli [2015] que codifica as árvores axonais e dendríticas em sequências de caracteres que representam bifurcações para permitir medições de similaridade, definidas para comparar sequências de genes, com a finalidade de identificar padrões nessas árvores. 


\subsection{Conceitos básicos}

A mistura entre a biologia, neurologia e a computação gerou a fascinante área de pesquisa conhecida como neurociência computacional, a qual usa métodos computacionais para tentar entender o complexo sistema de nervoso. Particularmente, o cérebro e a coluna vertebral que são os encarregados de perceber estímulos externos, processá-los e permitir a geração de movimento, pensamento, lembrança, conhecimento, sentimento, emoção, etc. Neste capítulo são introduzidos conceitos básicos do ponto de vista da biologia e da computação.

Serão descritos os principais componentes do sistema nervoso do ponto de vista da biologia, para depois, numa análise hierárquica, estudar as unidades fundamentais do sistema nervoso, os neurônios. Neste sentido, é preciso entendermos os processamentos que os neurônios fazem em suas diversas partes constituintes. São descritas também as funções das diferentes partes dos neurônios. De maneira semelhante, do ponto de vista da computação, são descritos alguns dos conceitos e métodos usados neste trabalho para analisar, modelar e classificar neurônios.

Neste documento, são apresentados conceitos simplificados. Estudos mais detalhados do ponto de vista biológico podem ser encontrados nos livros do Kandel [Kandel et al., 2000], Bear [Bear et al., 2007] e Cuntz, Remme e Torben [Cuntz et al., 2014]. Para um estudo mais detalhado do ponto de vista da computação, podem ser usados os livros do Ascoli [Ascoli, 2002] e do Capowski [Capowski, 2012].

\subsubsection{Princípios de neurociência}

O termo neurociência é definido como o estudo científico do sistema nervoso [Kandel et al., 2000]. É uma ciência interdisciplinar que combina conhecimento e técnicas de áreas como a biologia, química, matemática, psicologia entre outras, sendo o escopo dela bastante amplo. 


\subsubsection{Sistema Nervoso}

O sistema nervoso, nos seres humanos, é uma rede complexa formada por um conjunto de células (mais de 100 bilhões) encarregadas de levar e trazer informações das diferentes partes do corpo para o cérebro e para a coluna vertebral e vice-versa [Kandel et al., 2000]. É composto pelos sistema nervoso central (SNC) e sistema nervoso periférico (SNP). O SNC por sua vez é composto pelo cérebro e pela medula espinhal. Já o SNP é composto pela rede de nervos distribuída por todo o corpo humano [Bear et al., 2007]. Dentre eles o cérebro é considerado o órgão mais importante do sistema nervoso porque exerce o papel de centro de controle.

2.2.1.1.1 Neurônio Um neurônio ou célula nervosa é a unidade funcional básica do sistema nervoso. É uma célula eletricamente excitável que tem a capacidade de processar e transmitir informações através de conexões especializadas chamadas sinapses. Um neurônio convencional tem três componentes principais: (1) o corpo celular, (2) dendritos, e (3) axônio. Cada componente tem seu próprio papel no processo transmissão do sinal elétrico ou impulso nervoso. O corpo celular, também chamado soma, é a parte onde está o núcleo que contém as informações genéticas. Sua principal função é metabólica. O axônio é uma estrutura exclusiva dos neurônios, que não pode ser encontrada em outros tipos de células. É um ramo maior que sai do soma cuja função é transportar o sinal elétrico para outros neurônios através de pontos de contato chamados sinapses [Bear et al., 2007, Kandel et al., 2000]. É importante mencionar também que a região do axônio que entra em contacto com outros neurônios é chamada de terminal axônico.

Os dendritos são estruturas ligadas ao corpo celular. O termo déndrom significa árvore em grego, descrevendo um conjunto de ramos curtos que se estendem a partir do soma. O conjunto dos dendritos de um neurônio são chamados de árvore dendrítica. A principal função desta estrutura é receber o sinal elétrico de outros neurônios e transportá-lo para o soma [Cuntz et al., 2014].

O sistema nervoso, nos seres humanos, é composto por bilhões de neurônios com diferentes funções e formas. A morfologia dos dendritos é diversificada, e até neurônios de 
um mesmo tipo podem possuir árvores dendríticas diferentes. Os pesquisadores tentam entender o porquê desta grande variedade observando as funções identificadas nessas estruturas. Primeiro, observando sua função como componente de um circuito. Sua forma é definida pelo circuito e ao mesmo tempo define o circuito ao qual pertence, devido às ligações que estabelece com outros neurônios para receber o impulso nervoso através das sinapses. Portanto, a morfologia do dendrito é importante para estabelecer a conectividade requerida pelo sistema nervoso.

Em estudos da morfologia do neurônio são levados em conta aspectos relacionadas à sua função na conectividade e na computação do impulso nervoso. Como podemos observar, a morfologia dos dendritos tem uma grande relevância na morfologia e função do neurônio completo e, em muitos casos, tem um papel importante em patologias como doenças neurodegenerativas, autismo, epilepsia, Parkinson, Alzheimer e muitas outras associadas a mudanças na morfologia dos dendritos e axônios [Cuntz et al., 2014].

Na Figura 2.4 temos uma representação visual dos principais componentes de um neurônio. É importante notar que as partes finais dos axônios que entram em contato com os dendritos do próximo neurônio são chamados de terminais axonais.

Figura 2.4: Principais componentes de um neurônio

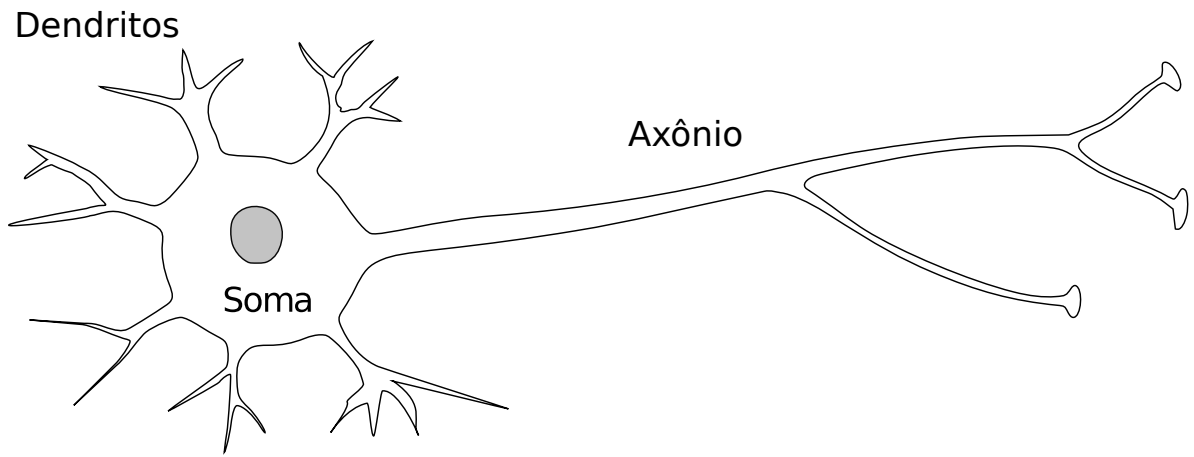

Fonte: adaptação da ilustração de Holly Fischer, distribuída sob licença Creative Commons Attribution 3.0 Unported.

\subsubsection{Dendritos}

Os dendritos são extensões que vão do corpo da célula, tendo como função principal o transporte do impulso nervoso do ambiente ou de outro neurônio para o corpo celular. Representam portanto a fronteira pela qual as informações entram no neurônio. O con- 
tato com o neurônio vizinho é feito nas sinapses. A sinapse tem duas partes: pré-sinapses, formadas por terminais axonais do neurônio precedente e pós-sinapses, formadas por um dendrito. A transferência de informações entre um neurônio e outro é chamada de transmissão sináptica [Bear et al., 2007].

A Figura 2.5 mostra a direção na qual viaja o impulso nervoso através do neurônio. É possível observar que os dendritos recebem o impulso e o transmitem para o soma. Ao contrário dos axônios, que conseguem transmitir o impulso intacto desde o soma até os terminais os dendritos causam uma atenuação do impulso nervoso, sendo o tamanho das ramificações muito importante no desempenho de sua função na transmissão do impulso.

Figura 2.5: Direção do impulso nervoso

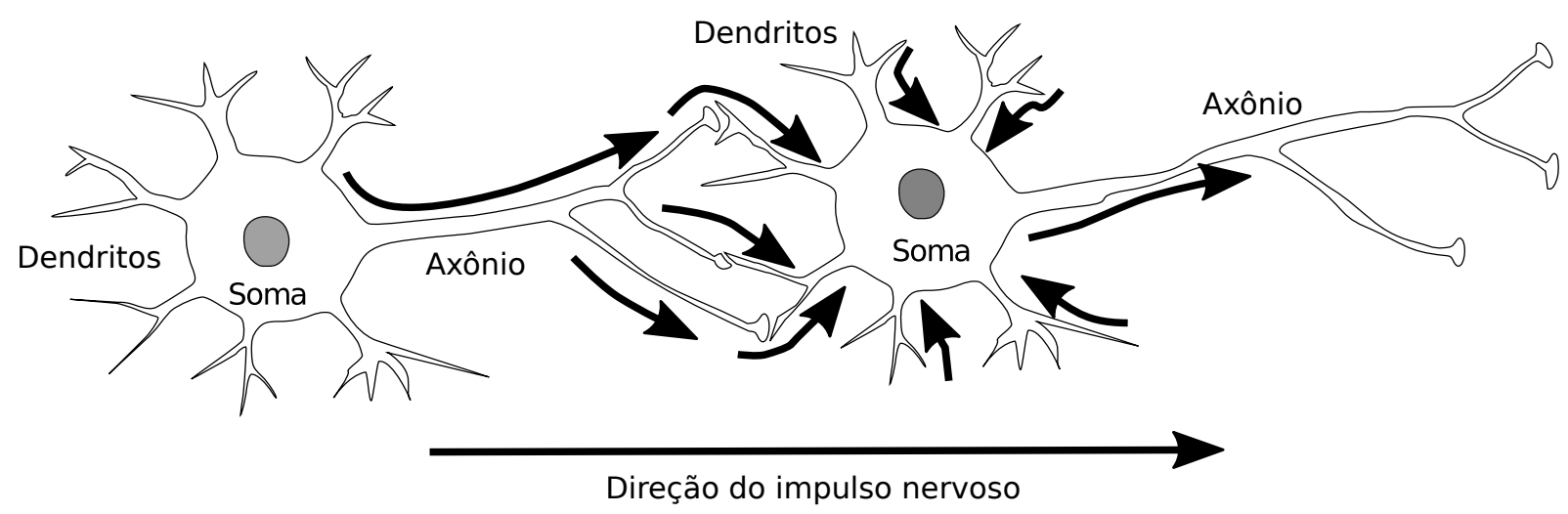

Fonte: adaptação da ilustração de Holly Fischer, distribuída sob licença Creative Commons Attribution 3.0 Unported.

2.2.1.2.1 Morfologia do dendrito Os dendritos possuem formas semelhantes a ramos de árvores assim o conjunto de dendritos de um neurônio é chamado de árvore dendrítica. A morfologia das árvores dendríticas pode variar amplamente de um tipo de neurônio para outro. Por outro lado, a complexidade das árvores dendríticas pode variar dependendo de sua localização. O significado funcional dessas diferenças morfológicas tem sido mostrado desde as origens da neurociência [Bear et al., 2007]. Adicionalmente, a grande diversidade das árvores dendríticas faz com que sejam comumente usadas para classificar neurônios.

A estrutura de árvore dos dendritos e axônios tem profundas implicações na conectividade da rede de neurônios, na comunicação sináptica na integração do sinal que é transmitido [Parekh e Ascoli, 2015]. Portanto, é fundamental entender como os neurônios 
elaboram seus dendritos durante o desenvolvimento para estabelecer sua morfologia dendrítica final. Segundo a descrição do Götz e do Huttner [Götz e Huttner, 2005], durante o desenvolvimento do cérebro, os novos neurônios são gerados pela divisão simétrica ou assimétrica dos neurônios progenitores neurais.

A morfogênese do dendrito ocorre de maneira altamente dinâmica, envolvendo complexos mecanismos que permitem a produção de ramos que atingem um nível de estabilidade e formam sinapses, e outros que não atingem a dita estabilidade e se retraem. Esses mecanismos podem ser influenciados por dois tipos de aspectos [Lefebvre et al., 2015]: (1) Fatores genéticos o que significa que desde o nascimento de um novo neurônio existe um plano inicial da forma que possuirá sua árvore dendrítica. Neste sentido, foi reportada a predeterminação genética da propensão do neurônio para ramificações dendríticas, responsividade a sinais ou inibição de crescimento por fatores externos. (2) Fatores extracelulares; neste caso, os neurônios geneticamente determinados para responder fatores externos ou ambientais seguem pistas moleculares para determinar seu desenvolvimento. Dentre elas, temos pistas de orientação em direção ao neurônios vizinhos com os quais podem ser estabelecidas novas conexões, auto-evitação de dendritos para espaçamento e cobertura ideais e poda e remodelação dendrítica para evitar ou para eliminar o excesso de ramos.

\subsubsection{Princípios da neuroanatomia computacional}

É difícil responder quando foi criado o primeiro computador, devido às diversas definições de computador existentes. Assim, dentre os primeiros, pode-se mencionar o Z1 que criado por Konrad Zuse entre 1936 e 1938. Por outro lado, o ENIAC (as siglas em inglês de Electronic Numerical Integrator And Computer) é considerado o primeiro computador eletrônico de uso geral criado em 1946, impulsionado pela necessidade de cálculos de trajetórias balísticas durante a Segunda Guerra Mundial. Naquela época os computadores eram demasiado caros e difíceis de manipular para fazer parte de um laboratório de pesquisa em biologia. Somente no final da década de 1960 os computadores podiam fazer parte do orçamento dos laboratórios de pesquisa em biologia. É neste momento que as 
duas áreas, biologia e computação, começaram a trabalhar juntas representado assim os primórdios da neurociência.

A neuroanatomia computacional, é uma área emergente dentro da neurociência, combinando a neuroanatomia com o poder computacional do hardware, software e computação gráfica. Acredita-se que a neuroanatomia está dando os passos iniciais conceituais e técnicos para a compreensão da complexa estrutura e funcionamento do sistema nervoso [Ascoli, 2002].

\subsubsection{Modelagem e representação de neurônios}

O rastreamento do neurônio é o procedimento pelo qual um neurônio é transferido de sua forma original no tecido para uma forma, com a finalidade de evitar algumas limitações de visualização. O rastreamento inicialmente era feito observando a célula no microscópio e desenhando-se na mão segundo o que estava sendo observado. Mesmo assim estas novas representações ainda possuíam limitações. Medições, por exemplo, precisavam ser feitas na imagem desenhada. O passo seguinte na evolução da representação envolveu o computador. Com a representação digital, programas podiam fazer medições automatizadas e gerar diversos tipos de visualizações [Capowski, 2012].

Pela estrutura que os neurônios possuem, a representação mais natural na memória de um computador pode ser feita utilizando a estrutura de dados abstrata chamada grafo extraído da teoria de grafos.

2.2.2.1.1 Grafos Formalmente um grafo é um par ordenado $G=(V, E)$ formado por um conjunto de vértices ou nós $v_{i} \in V$ e um conjunto de aresta $e_{i} \in E$ que relaciona um par de vértices [West et al., 1996]. A Figura 2.6 mostra a maneira muito natural na qual um neurônio pode ser representado utilizando um grafo. No exemplo, os segmentos do neurônio são representados por arestas delimitadas pelos vértices que representam o início e fim do segmento.

Os grafos podem ser dirigidos ou não dirigidos. Um grafo dirigido é aquele no qual suas arestas têm orientação, portanto, a aresta $\left(v_{a}, v_{b}\right) \neq\left(v_{b}, v_{a}\right)$. Nos grafos não dirigidos as arestas não possuem orientação, portanto, a aresta $\left(v_{a}, v_{b}\right)=\left(v_{b}, v_{a}\right)$. 
Figura 2.6: Representação natural do neurônio (lado esquerdo) como um grafo (lado direito), os segmentos do neurônio são representados por arestas.
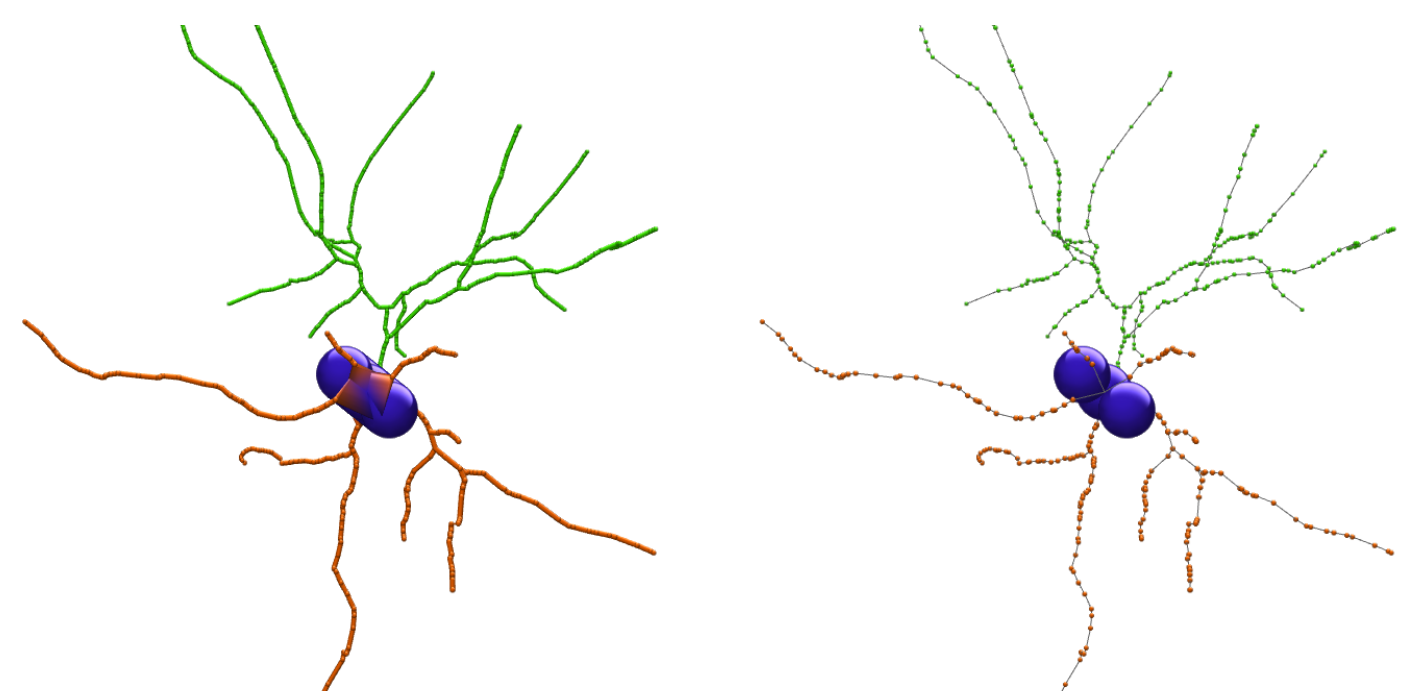

2.2.2.1.2 Árvore Uma árvore é um grafo não dirigido em que quaisquer pares de vértices estão conectados por unicamente um caminho. $\mathrm{O}$ caminho entre dois vértices $v_{0}$ e $v_{k}$ está formado pela sequência de vértices e arestas $v_{0}, e_{0}, v_{1}, e_{1} \ldots, v_{k-1}, e_{k-1}, v_{k}$ em que todos os vértices $v_{i}$ são diferentes.

Na ciência da computação, uma árvore binária é uma estrutura hierárquica que possui um vértice raiz e todos os vértices têm no máximo dois vértices filhos. Esse tipo de estrutura gera sua hierarquia baseada na distância de cada vértice para o vértice raiz. Consequentemente, existem níveis de profundidade. Portanto, o pai de cada vértice está um nível acima e o filho está um nível abaixo [Skiena, 1998].

Numa observação detalhada do neurônio da Figura 2.6 podemos notar que apenas o vértice representando o soma, na cor azul, tem mais do que duas arestas ligadas a ele, todas as outras arestas possuem no máximo três ligações, pelo qual poderia ser utilizada uma outra estrutura chamada de árvore binária.

\subsubsection{Reconstrução de neurônios}

A reconstrução é o processo pelo qual é determinado o caminho dos processos neuronais, os axônios e os dendritos do neurônio. Através da reconstrução é possível gerar uma representação digital do neurônio, na qual sua morfologia pode ser analisada qualitativa e quantitativamente, a partir de uma imagem do microscópio. 
Diversos métodos são adotados para efetuar a tarefa de reconstrução do neurônios. Dentre eles existem os métodos manuais que geram reconstruções 3D baseadas em desenhos à mão do neurônio. Embora existam algumas ferramentas que auxiliam neste processo ele é realmente laborioso. Por outro lado, os métodos automáticos de reconstrução comumente envolvem (i) pré-processamento da imagem do microscópio (ii) alinhamento de várias imagens de dependendo do tipo de microscópio usado, (iii) segmentação do soma, (iv) segmentação de estruturas ramificadas [Meijering, 2010]. A desvantagem deste tipo de método é o erro de precisão em estruturas complexas. Finalmente, os métodos que dão os melhores resultados atualmente são os responsáveis pelo crescimento dos bancos de dados de reconstruções de imagens são os semiautomáticos. Eles usam métodos automáticos seguidos por métodos manuais que avaliam e corrigem erros gerados pelo processo prévio.

A Figura 2.7 mostra uma imagem de neurônio como é observada no microscópio e uma reconstrução 3D dela, gerada usando o método semiautomático fornecido pela ferramenta Vaa3D-Neuron por fim uma representação do neurônio baseada em grafos.

Figura 2.7: Reconstrução do neurônio: (a) imagem original do microscópio [fonte:celltypes.brain-map.org], (2) reconstrução $3 D$ fornecida pelo Allen Brain Atlas utilizando o método de reconstrução semiautomático da ferramenta Vaa3D-Neuron, (c) representação do neurônio como grafo.

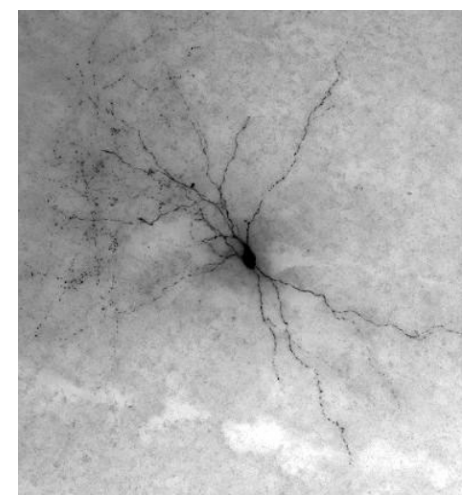

(a)

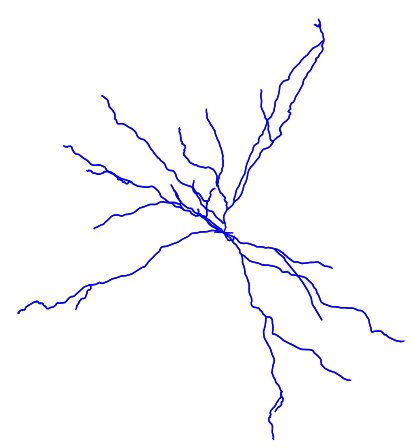

(b)

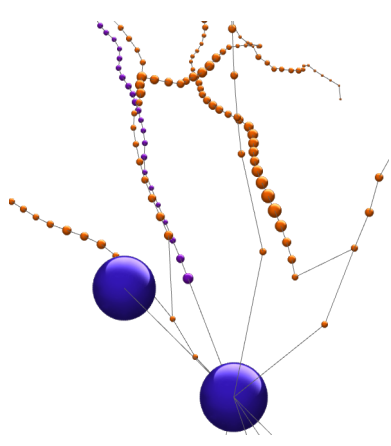

(c)

2.2.2.2.1 Armazenamento O armazenamento das reconstruções digitais é essencial para o compartilhamento. Dependendo da riqueza de informações geradas podem ser adotados métodos complexos de armazenamento. Uma maneiras mais simples, e que é usada neste trabalho, é o formato SWC, que armazena estruturas topológicas conectadas sequen- 
cialmente http://www.neuronland.org/NLMorphologyConverter/MorphologyFormats/SWC/ Spec.html.

No formato SWC, os dados são organizados em um conjunto de linhas de texto contendo um identificador único, um tipo, as coordenadas de um ponto no espaço tridimensional, um raio, e o identificador a outro ponto ao qual está conectado. Na Figura 2.8 é apresentada uma representação gráfica das informações que o arquivo SWC armazena.

Figura 2.8: Representação gráfica de uma segmento de neurônio representado no formato $S W C$

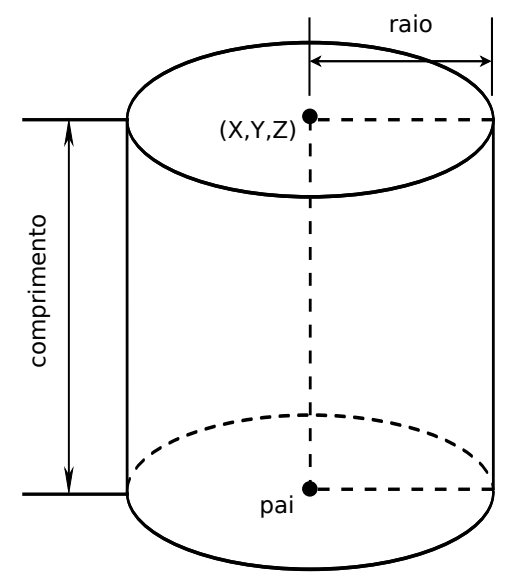

O índice é um identificador único para cada ponto atribuído de maneira sequencial, iniciando no soma em direção aos terminais dendríticos e axonais. O tipo pode tomar os seguintes valores: (1) se for um ponto pertencente ao soma, (2) se o ponto pertencer ao axônio e (3) ou (4) se for dendrito. Se for parte do dendrito basal tem valor (3) e se for parte do dendrito apical tem valor (4). X, Y e Z representam as coordenadas do ponto no espaço tridimensional. O raio do segmento entre o ponto atual e o ponto indicado pelo "pai" é o último dado informado em cada linha. No caso do primeiro ponto pertencente ao soma, o valor do "pai" é de -1. Na Tabela 2.1 e na Figura 2.9 é apresentado um pequeno exemplo de um arquivo SWC e sua correspondente representação gráfica 2D. 
Tabela 2.1: Exemplo de arquivo $S W C$

\begin{tabular}{|c|c|c|c|c|c|c|}
\hline Index & Tipo & $\mathrm{X}$ & $\mathrm{Y}$ & $\mathrm{Z}$ & Raio & Pai \\
\hline 1 & 1 & 0.0 & 0.0 & 0.0 & 2.555 & -1 \\
2 & 1 & 0.0 & 11.55 & 0.0 & 2.555 & 1 \\
3 & 1 & 0.0 & -11.56 & 0.0 & 2.555 & 1 \\
4 & 3 & 11.12 & 3.99 & 2.62 & 1.885 & 1 \\
5 & 3 & 19.8 & 5.28 & 1.53 & 1.885 & 4 \\
6 & 3 & 27.17 & 15.17 & 2.47 & 1.885 & 5 \\
7 & 3 & 49.56 & 27.46 & -1.78 & 1.23 & 6 \\
8 & 3 & 63.6 & 23.4 & -1.78 & 0.82 & 7 \\
9 & 3 & 55.94 & 32.16 & -1.78 & 1.23 & 7 \\
10 & 3 & 25.64 & 37.99 & -1.68 & 1.39 & 6 \\
11 & 3 & 4.04 & 12.27 & -0.63 & 1.885 & 1 \\
12 & 3 & 6.28 & 42.25 & -0.93 & 1.555 & 11 \\
13 & 3 & 26.63 & 69.2 & -4.0 & 1.64 & 12 \\
14 & 3 & -4.04 & 59.74 & -0.88 & 1.64 & 12 \\
15 & 3 & 5.43 & 69.63 & -0.22 & 1.065 & 14 \\
16 & 3 & -19.32 & 67.89 & 0.03 & 0.575 & 14 \\
\hline
\end{tabular}

Figura 2.9: Representação gráfica do arquivo $S W C$

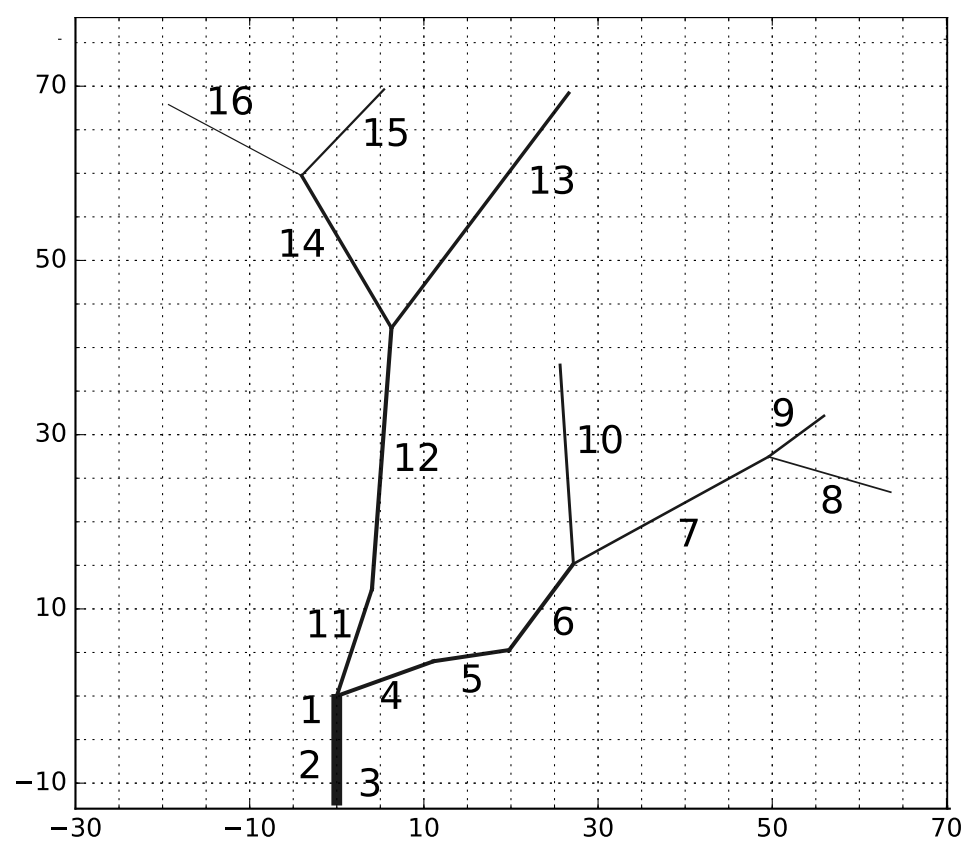




\subsubsection{Aprendizado de máquina}

Dentro do tópico de aprendizado de máquina existe uma ampla variedade de problemas abordados, esses problemas podem ser organizados nas seguintes categorias maiores:

- Classificação: os métodos de classificação atribuem uma categoria a cada um dos elementos estudados, o número de categorias pode ou não ser fornecido.

- Regressão: Os métodos de regressão atribuem valores reais a cada um dos elementos estudados.

- Agrupamento: Os métodos abordam o problema de agrupar elementos em regiões homogêneas dependendo de algum critério.

Existem três principais cenários de aprendizado dependendo do uso de exemplos rotulados ou não rotulados no processo de aprendizado: (a) o aprendizado supervisionado aprende a partir de um conjunto de exemplos rotulados (b) aprendizado não supervisionado aprende a partir de exemplos não rotulados (c) o aprendizado semisupervisionado aprende a partir de ambos exemplos rotulados e não rotulados [Armañanzas e Ascoli, 2015].

2.2.2.3.1 Aprendizado supervisionado O aprendizado supervisionado é um mecanismo que aprende uma função de mapeamento de entradas em saídas baseado em um conjunto de exemplos de treinamento formado por pares (entrada, saída) [Mohri et al., 2018].

Dados $N$ exemplos de treinamento $\left\{\left(x_{1}, y_{1}\right), \ldots,\left(x_{N}, y_{N}\right)\right\}$, em que $x_{i} \in X$ é uma entrada comumente representada por um vetor de características e $y_{i} \in Y$ é uma classe ou categoria, existe uma função ideal desconhecida $f: X \rightarrow Y \operatorname{com} y_{i}=f\left(x_{i}\right)$ em que $X$ é o espaço de entrada contendo todas as possíveis entradas e $Y$ é o espaço de saída contendo todas as possíveis saídas. O algoritmo de aprendizado procura uma função $g: X \rightarrow Y$ que melhor aproxima $f$ baseado no conjunto de exemplos. A função $g$ é escolhida dentre um conjunto de funções candidatas chamado de conjunto de hipótese $H$ [Abu-Mostafa et al., 2012]. 
2.2.2.3.2 Máquinas de vetor de suporte (SVM) As máquinas de vetor de suporte são uma contribuição da teoria da aprendizagem estatística que tem sido adotada em diversas áreas. São algoritmos de aprendizado supervisionado que podem ser usados tanto para classificação quanto para regressão.

Os modelos SVM [Cortes e Vapnik, 1995] representam os dados de entrada, como vetores de características, como pontos no espaço e constroem hiperplanos que permitem fazer uma separação entre as classes. A escolha do melhor hiperplano de separação é feita maximizando a distância do hiperplano para os pontos de treinamento mais próximos dele.

No caso da classificação binária, o aprendizado supervisionado com SVM inicia com um conjunto de dados de treinamento, consistindo de $m$ amostras rotuladas, definidas como:

$$
E_{m}=\left(x_{i}, y_{i}\right) \in R^{n}, x=\{-1,+1\}, i=1, \ldots, m
$$

Cada $x_{i}$ é um vetor de características na dimensão $d . y_{i} \in\{-1,+1\}$ e indica se o ponto pertence à classe $(+1)$ ou à classe $(-1)$ que o classificador aprenderá a reconhecer.

Baseado nesses dados o classificador SVM procura um hiperplano nas $d$ dimensões, o qual é uma superfície $(d-1)$-dimensional definida como:

$$
f(x)=w \cdot x+b=0
$$

sendo que w denota o vetor normal ao hiperplano e $\cdot$ denota o produto interno.

\subsubsection{Avaliação de resultados}

A avaliação da acurácia dos classificadores é a tarefa que permite determinar quão confiável é o classificador. Nesse sentido, duas das medidas mais comumente usadas são as chamadas precisão e revocação. Para entender melhor estas duas medidas, é preciso conhecer primeiro a tabela de confusão criada a partir da comparação dos valores esperados com os resultados obtidos pelo classificador. Para exemplificar as medidas de cálculo 
de acurácia vamos novamente usar o caso da classificação binária. Na seguinte tabela são contabilizados os resultados obtidos:

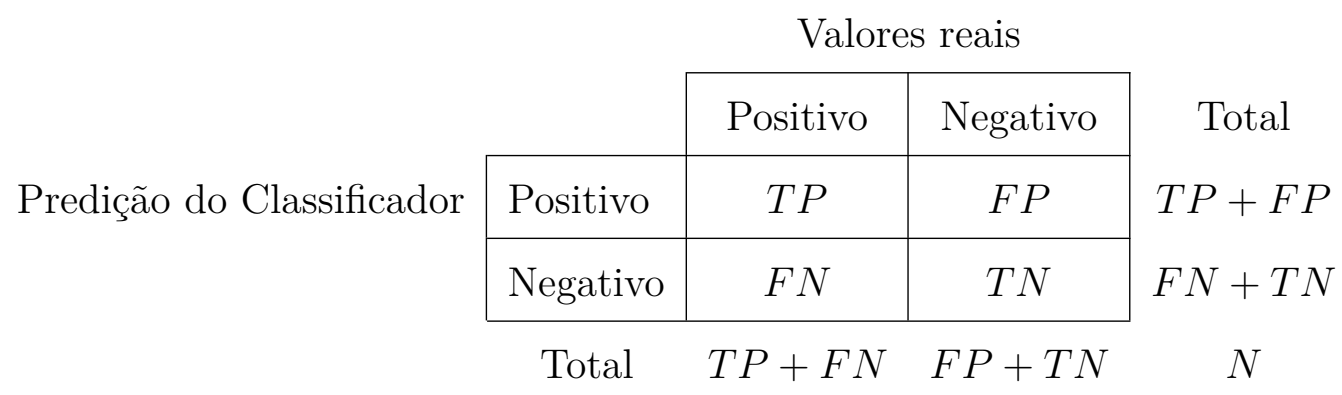

A predição do classificador pode ser positiva $(T)$ ou negativa $(F)$ para a classe que esta sendo avaliada. Se a predição for correta é considerada verdadeira positiva $(T P)$. Se a predição for falsa é contabilizada como falsa positiva (FP). De maneira análoga, se a predição for corretamente negativa, e considerada verdadeira negativa $(T N)$ e se for incorreta, é considerada falsa negativa $(F N)$.

Usando a contagem da tabela de confusão são calculadas as medidas de precisão, revocação e a medida-F. A precisão mede a proporção de verdadeiros positivos dentre todos os elementos que foram classificados como positivos. Portanto, usando a tabela acima, podemos calcular da seguinte maneira [Olson e Delen, 2008]:

$$
\text { Precisão }=\frac{T P}{T P+F P}
$$

A revocação é a proporção de verdadeiros positivos dentre os elementos que realmente são positivos, podendo ser calculada da seguinte maneira:

$$
\text { Revocação }=\frac{T P}{T P+F N}
$$

Uma medida que associa as duas medidas prévias é chamada de Medida-F. Essa medida é essencialmente a média harmônica da precisão e revocação.

$$
\text { Medida-F }=\frac{2 \times \text { precisão } \times \text { revocação }}{\text { precisão }+ \text { revocação }}
$$




\section{Capítulo 3}

\section{Metodologia}

Neste capítulo é descrito o método adotado para representar os neurônios, e também são detalhados os mecanismos implementados para decompor os neurônios baseado na hierarquia. Por fim é relatado o método de classificação utilizado junto com as características morfológicas que são levadas em conta nesse estudo.

\subsection{Proposta}

Na Figura 3.1 mostramos uma representação gráfica do método proposto neste trabalho. O estudo é composto por três etapas: a primeira envolve a gestão, o armazenamento e a manipulação dos arquivos SWC - que são os arquivos que contêm as reconstruções digitais dos neurônios - sendo também implementados métodos de decomposição dos neurônios. Na segunda etapa, é abordado o processo de classificação quando são computadas as medidas morfológicas dos neurônios. Estas medidas são normalizadas e submetidas a um processo de seleção de características para, finalmente, construir os modelos de classificação que serão testados com nossos dados.

Na última etapa, os diversos resultados obtidos da classificação são comparados para determinar as partes das árvores dendríticas relevantes para a classificação morfológica. Posteriormente são detalhados os passos envolvidos no método.

A seguir são descritas detalhadamente essas três etapas. 
Figura 3.1: Uma visão da proposta deste trabalho dividida em três etapas: Na etapa de decomposição de neurônios, o neurônio foi decomposto sistematicamente nas diferentes hierarquias dos ramos. Na segunda etapa, foi efetuada a classificação supervisionada de neurônios depois de um processo de normalização e seleção de características. Por fim, na última etapa, foi feita uma análise comparativa, baseada na acurácia, dos resultados obtidos nos diferentes processos de classificação.

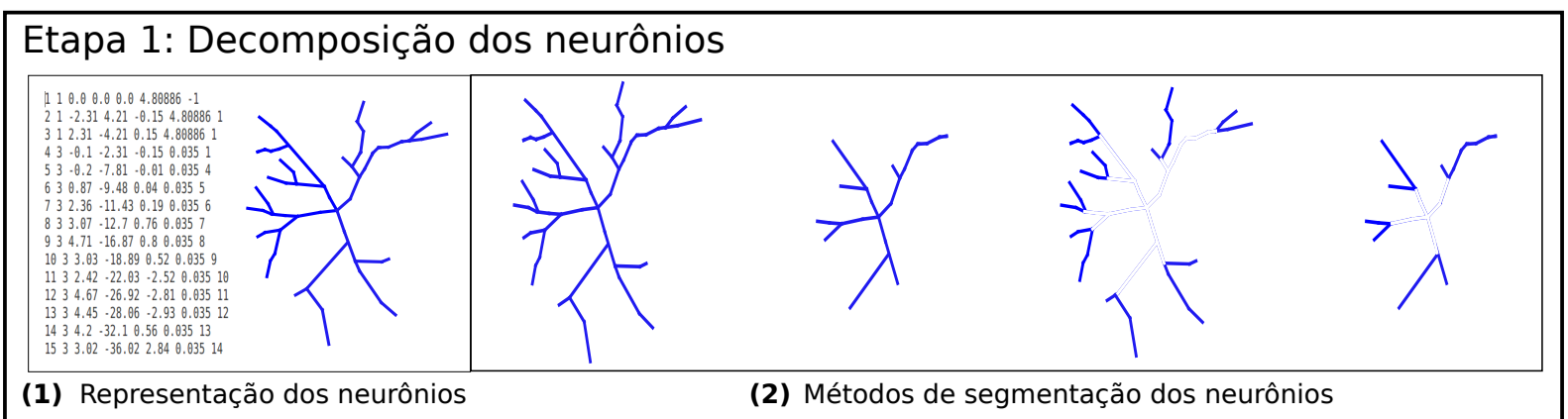

Etapa2: Classificação morfológica de neurônios

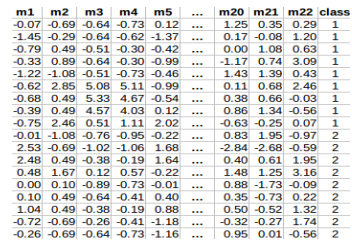

(3) Extração de características com L-measure

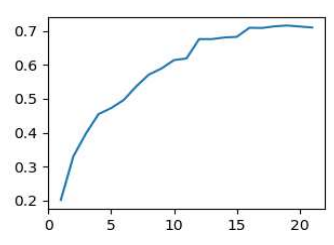

(4) Seleção de características

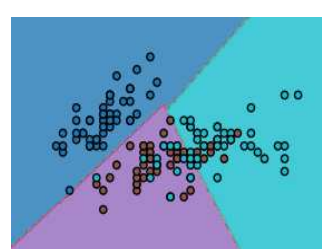

(5) Resultados da classificação

Etapa 3: Análise comparativa dos resultados

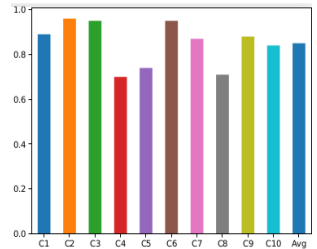

(6) Classificação de neurônios inteiros

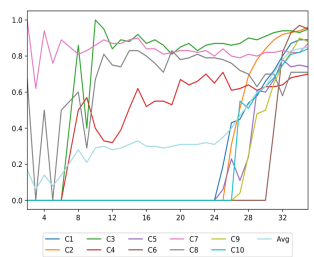

(7) Classificação por altura

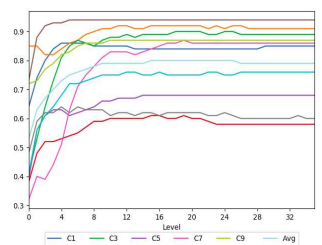

(8) Classificação por profundidade

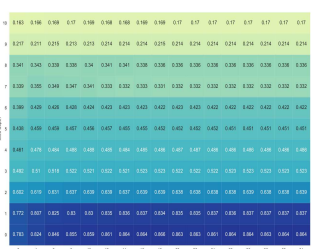

(9) Classificação por fatía

\subsection{Decomposição de neurônios}

Esta etapa foi dividida em duas subetapas. A primeira delas permite a leitura dos arquivos contendo as reconstruções digitais dos neurônios e a implementação de uma estrutura abstrata que possibilita a manipulação da reconstrução.

\subsubsection{Representação digital do neurônio}

Conforme mencionado anteriormente, um formato amplamente conhecido para armazenamento de reconstruções digitais de neurônios é o SWC. Esse é um formato de texto 
simples que permite armazenar pontos num espaço tridimensional e ligações entre esses pontos.

Uma vez identificado o formato do arquivo de entrada e as características a serem avaliadas, foi implementado um procedimento que permite ler automaticamente arquivos SWC e recriar a representação 3D da reconstrução digital do neurônio. Analisando o formato SWC e as estruturas do neurônio descritas no Capítulo 2, observamos que seria interessante implementar uma estrutura de dados que permita armazenar os dados do arquivo e também identificar partes estruturais dos neurônios como soma, dendritos, axônios entre outros. A Figura 3.2 mostra os componentes representados.

Figura 3.2: Representação dos componentes do neurônio.

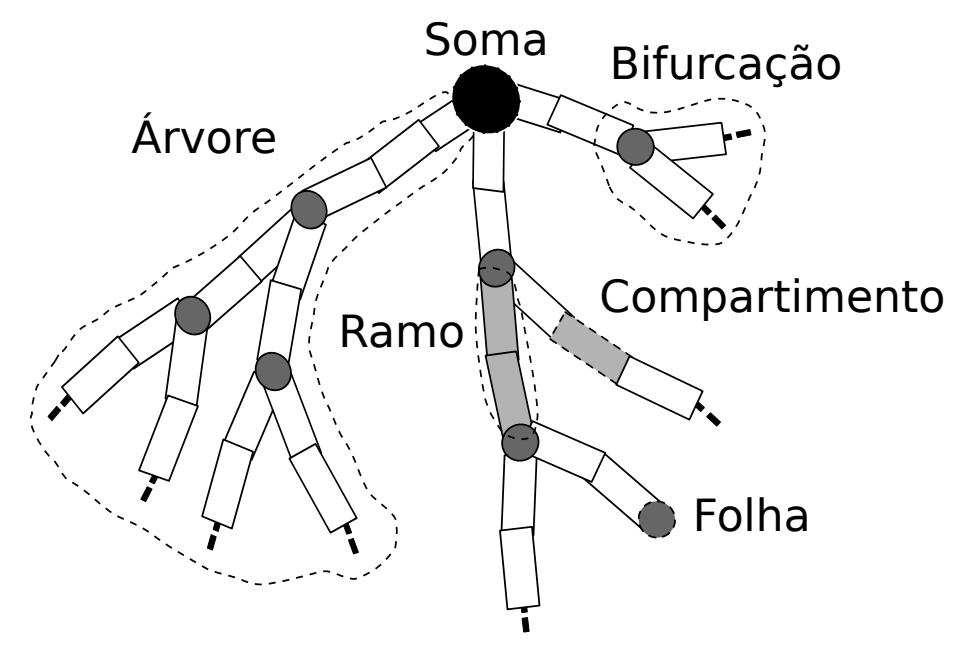

No trabalho foi usada como referência a estrutura proposta por [Torben-Nielsen, 2014]. Essa estrutura representa de maneira intuitiva o neurônio como uma árvore.

O neurônio é representado por uma árvore, cuja raiz representa o soma e os ramos da árvore, conectados ao soma, são árvores binárias. Essa estrutura é apresentada na Figura 3.3. Foi adicionado um novo atributo, na estrutura proposta por [Torben-Nielsen, 2014], para armazenar o nível de profundidade de cada nó com relação ao nó raiz, e também foram criados novos métodos de busca e desmembramento da árvore. Na Figura 3.3 é possível observar que o nó raiz (destacado com a cor azul) pode possuir mais de dois filhos enquanto todos os outros nós podem ter no máximo dois filhos. 
Figura 3.3: Estrutura de árvore usada para armazenar os dados do neurônio, (figura baseada na estrutura proposta em [Torben-Nielsen, 2014]). A cor azul foi usada para destacar o nó raiz.

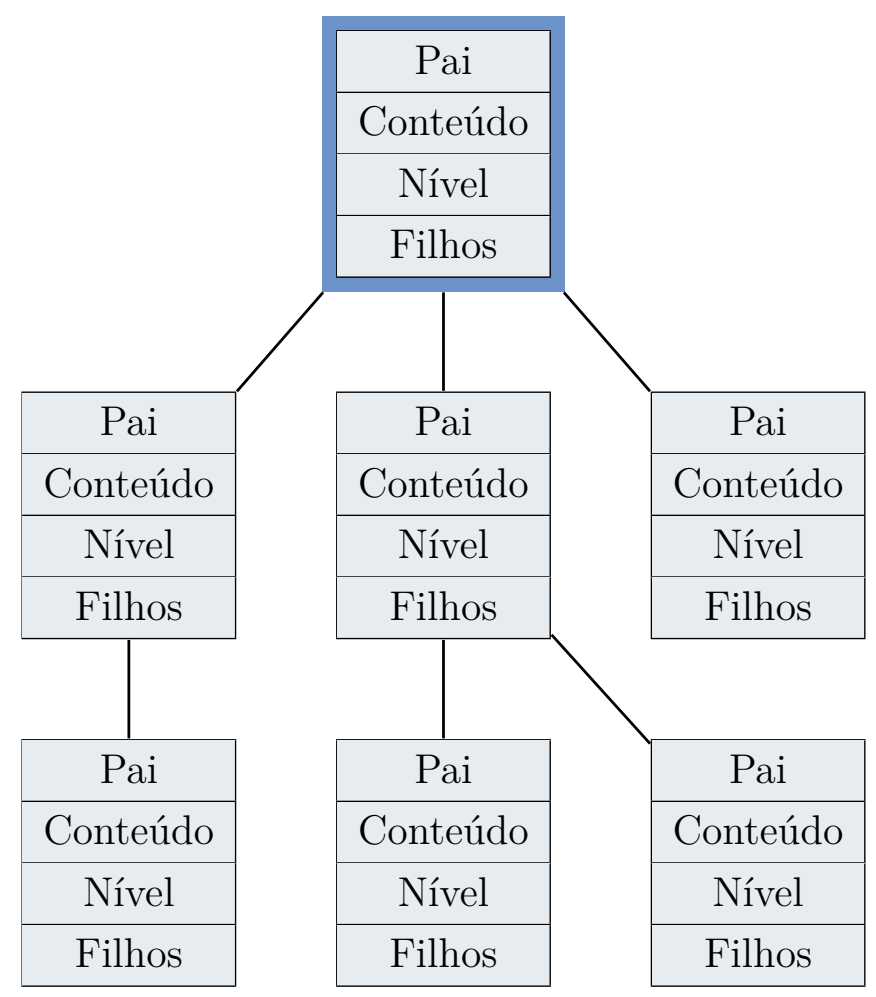

\subsection{Decomposição do neurônio}

O termo decomposição, nesse trabalho, é usado para descrever o processo de separação dos elementos componentes da árvore dendrítica de um neurônio. Na Figura 3.4, é mostrada uma abordagem simples de decomposição de neurônio baseada no número de ramos principais. No exemplo, o neurônio foi decomposto em sete partes, sendo cinco delas dendritos, um axônio e o soma. Existem diversas maneiras de decompor uma estrutura. Neste caso, estamos interessados apenas em analisar a árvore dendrítica. Por isso, em todos os casos serão desconsiderados os axônios dos neurônios. A seguir, apresentamos quatro abordagens usadas neste trabalho para decompor a árvore dendrítica.

Um ponto de interesse neste trabalho, é avaliar o efeito de usar diferentes partes dos neurônios para classificá-los utilizando suas características morfológicas. Como foi mencionado antes, a árvore dendrítica de um neurônio pode ser entendida como um conjunto de árvores. É, portanto, possível decompor estas estruturas em subárvore de acordo com os níveis de profundidade distintos. 
Figura 3.4: Um exemplo de decomposição do neurônio baseado na estrutura da árvore dendrítica.

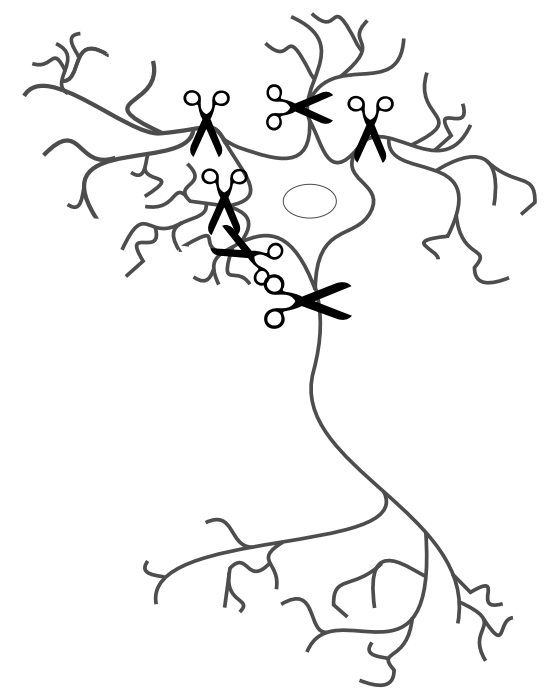

!h

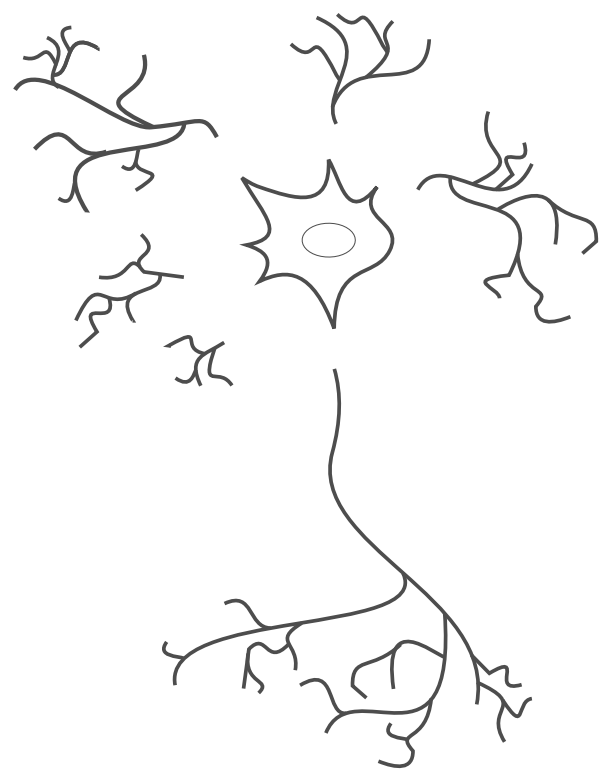

A profundidade definida como o número de bifurcações ao longo do caminho da raiz (isto é, o soma) até os ramos terminais. Assim, a maior profundidade (max-depth) será alcançada no ramo mais distante da raiz. A altura de um nó é definida como a diferença entre o máximo de profundidade e a profundidade do nó atual. Assim, a altura é zero no ramo mais distante a partir da raiz e atinge seu valor máximo (max-height) na raiz. Figura 3.5 mostra como profundidade e altura estão relacionados neste trabalho. Note-se que a nossa definição de profundidade e altura é diferente da definição padrão de profundidade e altura de um nó de teoria dos grafos

O presente trabalho, desenvolve a partir da estrutura proposta em [Torben-Nielsen, 2014] para representar as árvores dendríticas utilizando uma estrutura de árvore abstrata. Com essa estrutura, é possível representar todos os componentes neuronais. O soma é armazenado como a raiz, e cada dendrito conectado ao soma é representado por uma árvore binária anexado a raiz. Além disso, dois campos são usados para armazenar a profundidade e a altura de cada ramo. Os termos utilizados para descrever os componentes dos neurônios são suportados pela ferramenta L-measure [Scorcioni et al., 2008]. 
Figura 3.5: Ilustração da altura e profundidade de ramos dendríticas em uma árvore. A profundidade de um ramo representa o número de bifurcações indo ao longo do caminho da raiz até os ramos terminais. A altura é o complemento da profundidade. Note-se que, de acordo com a nossa definição, ramos terminais não necessariamente tem altura igual a zero.
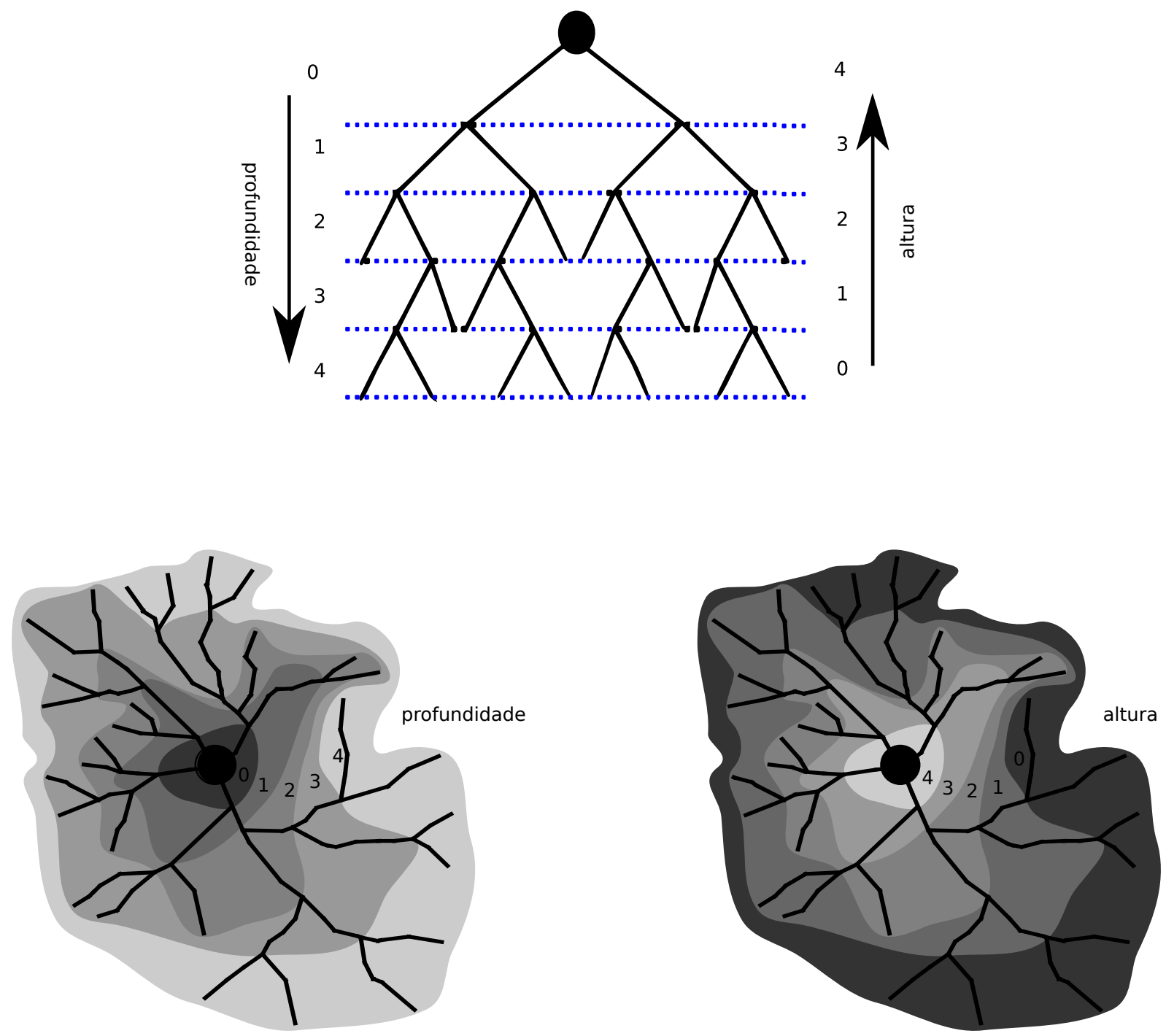

\subsubsection{Decomposição baseada nos ramos principais da árvore den-} drítica

Este método é semelhante ao apresentado em [Cervantes et al., 2016]. Nessa abordagem a reconstrução digital do neurônio foi antes mapeada na estrutura de árvore descrita previamente. É importante notar, que chamaremos esta estrutura de neurônio embora o axônio esteja sendo desconsiderado. Posteriormente são identificados todos os ramos principais da árvore dendrítica. Um novo neurônio é criado para cada ramo principal identificado e o soma do neurônio original é usado como soma de cada um dos novos 
neurônios. No algoritmo 1 mostramos o pseudo código do procedimento de decomposição por ramos principais. O método OBTER_RAMOS_PRINCIPAIS(neurônio) recebe o neurônio e devolve o conjunto de ramos principais identificados. O método REMOVER_RAMOS(novo_neurônio, ramo) remove todos os ramos principais diferentes do ramo do neurônio. O método

SALVAR_NOVO_NEURONIO(novo_neurônio) salva o novo neurônio no formato SWC.

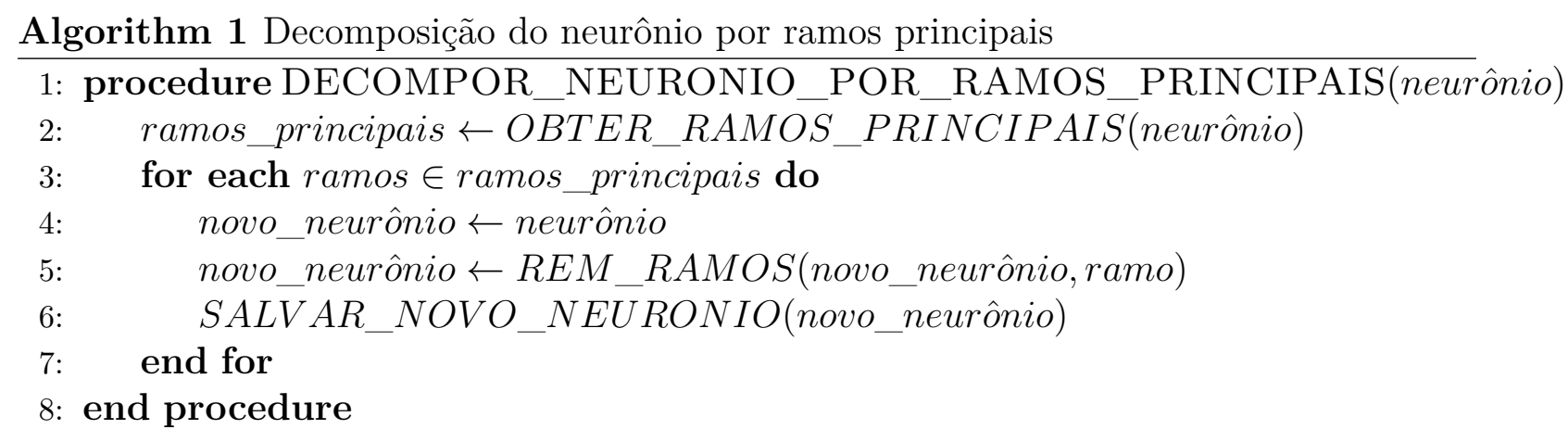

Esse procedimento cria $n$ novos neurônios onde $n$ é o número de ramos principais do neurônio original. Cada um desses novos neurônios permite fazer uma análise individual, o que no fundo significa analisar cada ramo do neurônio independentemente. Na Figura 3.6(a) podemos observar um neurônio com 4 ramos principais e em 3.6(b) os 4 ramos decompostos que poderão ser tratados como neurônios independentes.

Figura 3.6: (b) 4 neurônios criados usando o método de decomposição por ramos principais aplicado sobre o neurônio em (a).

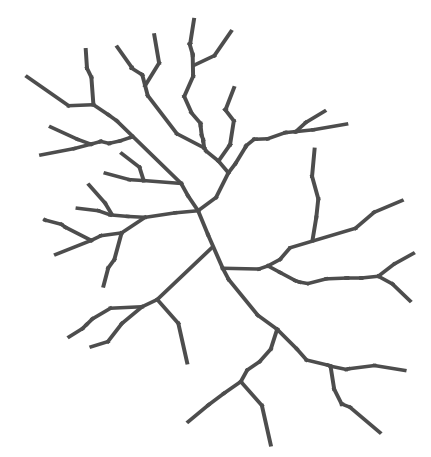

(a)

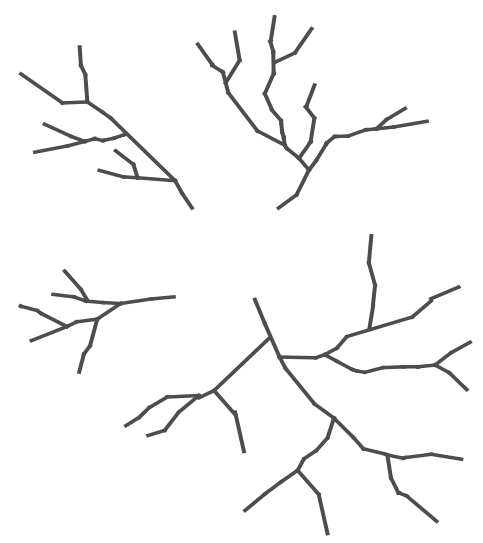

(b) 


\subsubsection{Decomposição baseada na profundidade de árvore dendrí- tica}

A presente abordagem, é levada em conta a profundidade de cada ramo da árvore dendrítica. No processo de criação do neurônio é preenchido o campo chamado "profundidade" da estrutura pelo qual cada ramo tem associado a ele uma profundidade. Então, o procedimento principal implica em remover todos os ramos com profundidade maior do que uma profundidade dada.

No Algoritmo 2 é mostrado o procedimento, onde o método OBTER_PROFUNDIDADE_MAXIMA(neurônio) obtém a profundidade máxima atingida pela folha mais distante da raiz da árvore dendrítica do neurônio em questão. Então é criada uma cópia no neurônio original da qual são removidos todos os ramos maiores pertencentes a níveis mais profundos do que um dado nível de profundidade pelo procedimento REM_POR_PROFUNDIDADE(novo_ne urônio, ível). Esse procedimento é repetido para cada um dos níveis entre 0 e a profundidade máxima. O método SALVAR_NOVO_NEURONIO(novo_neurônio) salva o novo neurônio no formato SWC. Com esse procedimento serão criados $p$ novos neurônios onde $p$ é a profundidade máxima da árvore dendrítica do neurônio original.

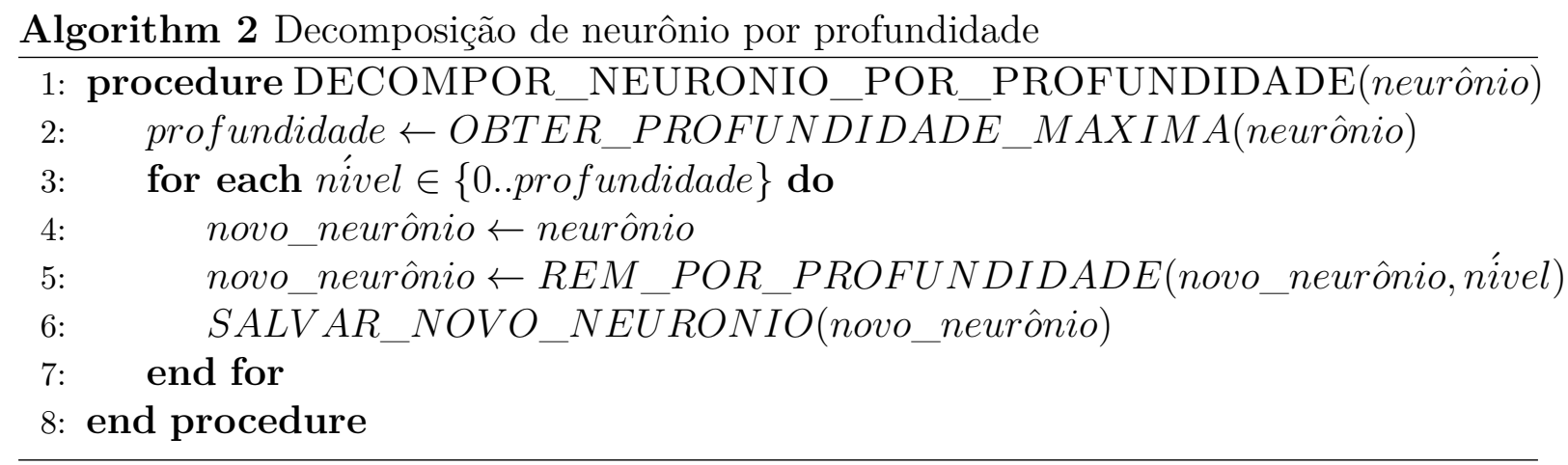

Na Figura 3.7 é mostrado um exemplo do resultado obtido ao submeter um neurônio com profundidade 4 ao algoritmo de decomposição de neurônio. Foram criados quatro novos neurônios um para cada nível de profundidade. Na Figura 3.7(a) temos o soma no neurônio mais todos os ramos com profundidade 0 , quer dizer ramos até antes da primeira bifurcação. Na Figura 3.7(b) temos o neurônio de profundidade 0 mais os ramos 
com profundidade 1, isto é ramos até antes da segunda bifurcação, e assim por diante. É importante notar que o neurônio correspondente ao nível de profundidade 4 (3.7(e)) é igual ao neurônio original. Cabe ressaltar que o soma no neurônio original é mantido intacto em todos os novos neurônios criados. Em resumo, esse procedimento vai adicionando em cada iteração um nível de profundidade à árvore dendrítica e com isto tentaremos avaliar a influência de cada nível na caracterização do neurônio.

Figura 3.7: cinco neurônios criados usando o procedimento de decomposição baseado na profundidade da árvore dendrítica. (a) neurônio com profundidade 0, (b) neurônio com profundidade 1, (c) neurônio com profundidade 2, (d) neurônio com profundidade 3 e (e) neurônio com profundidade 4, esse último neurônio é igual ao neurônio original.

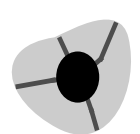

(a)

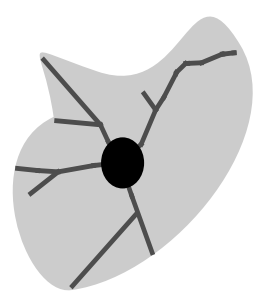

(b)

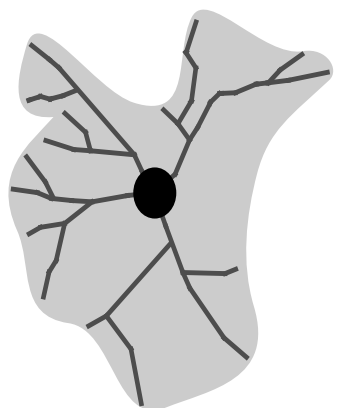

(c)

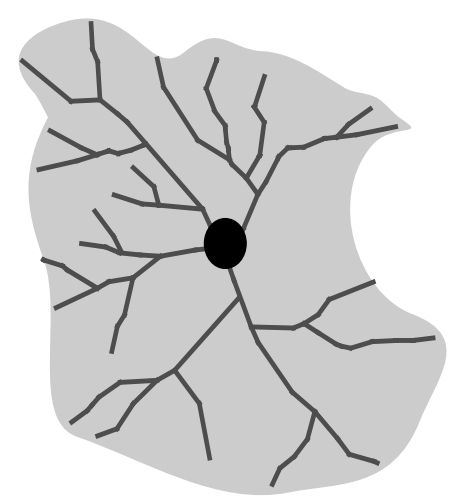

(d)

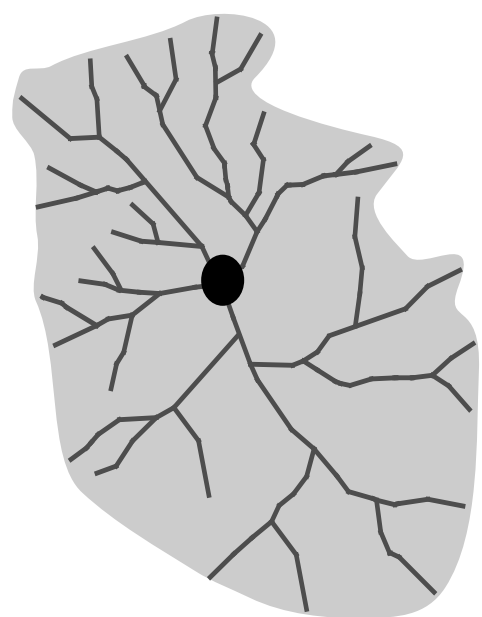

(e) 


\subsubsection{Decomposição baseada na altura da árvore dendrítica}

Essa abordagem é semelhante à baseada em profundidade, mas nesse caso vamos adicionar um nível de altura, em cada iteração, começando pelas folhas mais profundas da árvore dendrítica original. Para este algoritmo, precisa-se definir a altura de cada ramo e será usada como referência a profundidade que já foi calculada durante a criação da árvore. Logo, se definirá a altura de um ramo como a diferença entre a profundidade máxima da árvore menos a profundidade do ramo atual. Após se aplicará o Algoritmo 3 para a decomposição o neurônio por altura. É importante destacar, que a altura começa com o valor de 0 nas folhas e vai aumentando, em uma unidade, nas bifurcações em direção à raiz da árvore. Portanto, a altura máxima e a profundidade máxima de nossas árvores dendríticas serão iguais, apenas a contagem é feita de maneira invertida.

O método OBTER_ALTURA_MAXIMA(neurônio) obtém o valor da altura máxima da árvore dendrítica original, e para cada nível de altura entre 0 e a altura máxima, é criada uma cópia do neurônio original do qual são removidos os ramos com alturas maiores à altura que está sendo avaliada. Vale a pena salientar, que o método REM_POR_ALTURA(novo_neurônio, nível) além de remover os ramos com alturas maiores a um dado nível, deve criar uma ligação entre a raiz da árvore original e os ramos no nível dado, que no caso é o nível de maior altura no novo neurônio criado. Finalmente o novo neurônio é salvo pelo método $S A L V A R \_N O V O \_N E U R O N I O($ novo_neurônio).

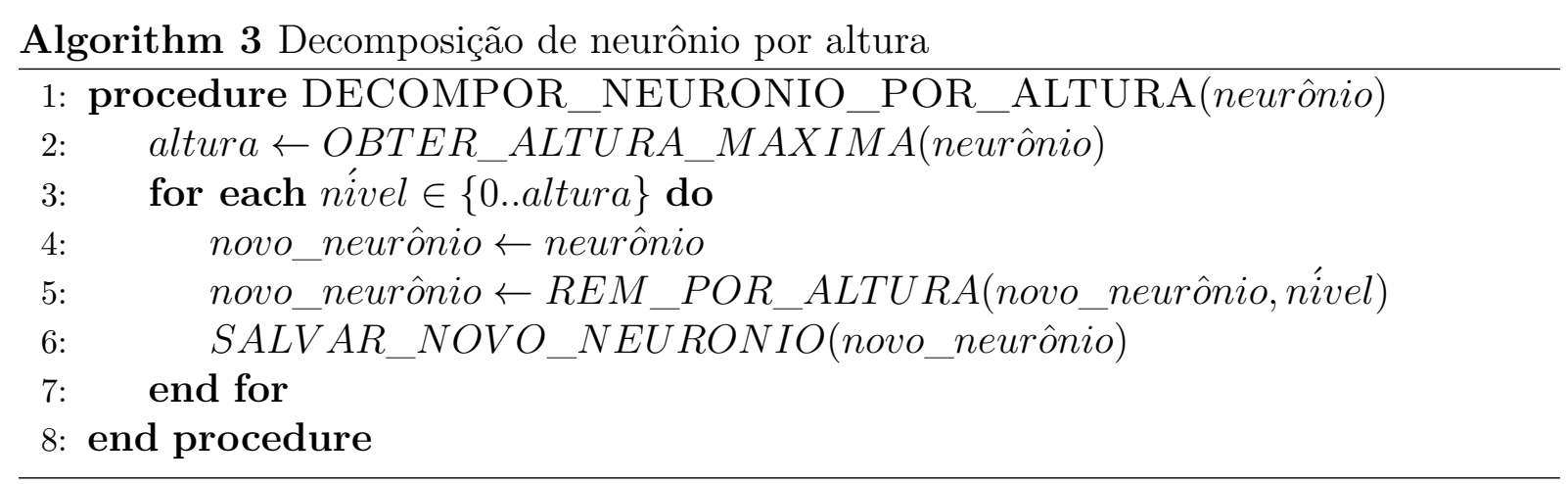

Na Figura 3.8 é apresentado o resultado da aplicação do método de decomposição baseado na altura num neurônio cuja árvore dendrítica possui altura 4. Assim, para cada nível de altura, é criado um novo neurônio. Na Figura 3.8(a) se observa o neurônio criado 
considerando apenas ramos pertencentes à altura 0 junto com o soma do neurônio original. Os ramos na cor amarela são removidos pelo método $R E M \_P O R \_A L T U R A$. Na Figura 3.8(b) temos o novo neurônio que é formado pelos ramos com altura 0 , os ramos com altura 1 e o soma do neurônio original, e assim por diante para cada nível de altura. No exemplo, foram criados 4 novos neurônios dado que o último neurônio 3.8(e), é igual ao original. Em resumo estamos acumulando com cada iteração cada vez mais ramos começando nas folhas em direção à raiz da árvore. Com isto, se pretende avaliar como a altura dos ramos das árvores dendríticas influem na caracterização do neurônio.

Figura 3.8: 4 novos neurônios criados usando o método de decomposição por altura num neurônio com altura 4. Os ramos na cor amarela são desconsiderados em todos os casos. (a) neurônio com altura 0, (b) neurônio com altura 1, (c) neurônio com altura 2, (d) neurônio com altura 3 e (e) neurônio com altura 4, esse último neurônio é igual ao neurônio original.

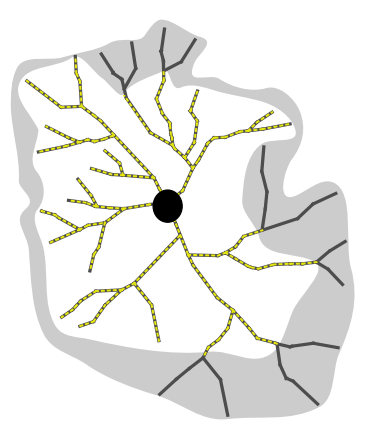

(a)

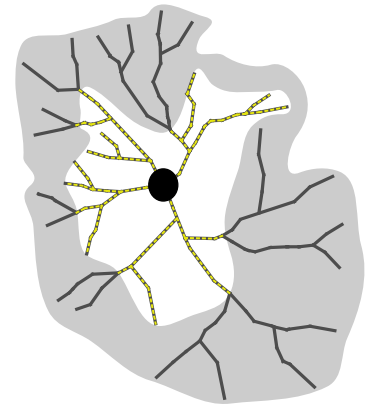

(b)

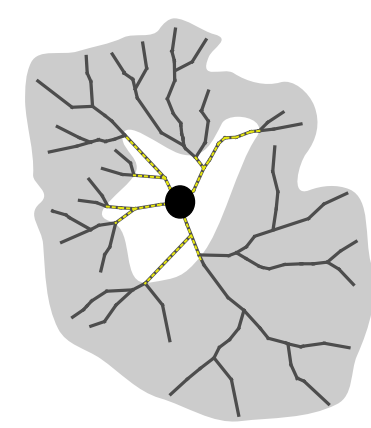

(c)

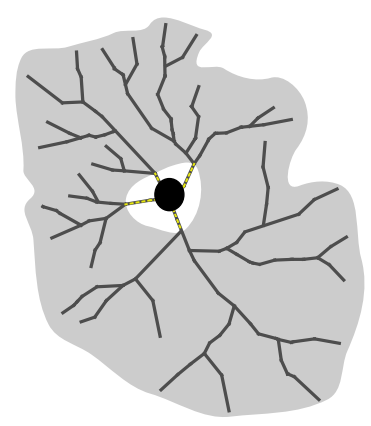

(d)

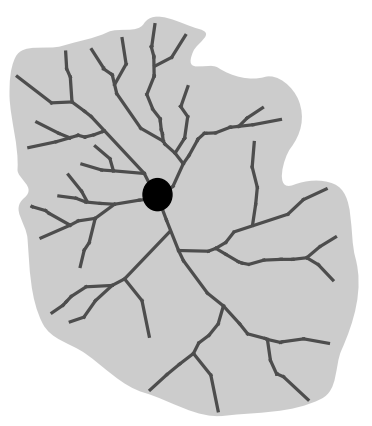

(e)

\subsubsection{Decomposição baseada em fatia da árvore dendrítica}

Nessa última abordagem, de modo geral serão levados em conta dois parâmetros que permitirão definir uma fatia da árvore dendrítica. Esses parâmetros representam 
o limite superior e o limite inferior da fatia em termos de profundidade. Nesse caso é preciso testar com todas fatias possíveis pelo qual serão testadas todas as combinações de pares de profundidades entre 0 e a profundidade máxima. Depois, o procedimento deve aplicar os métodos REM_POR_PROFUNDIDADE( novo_neurônio, linf) e REM_POR_ALTURA(novo_neurônio, linf), descritos nos Algoritmos 1 e 2, respetivamente para remover os ramos que estão fora dos limites da fatia.

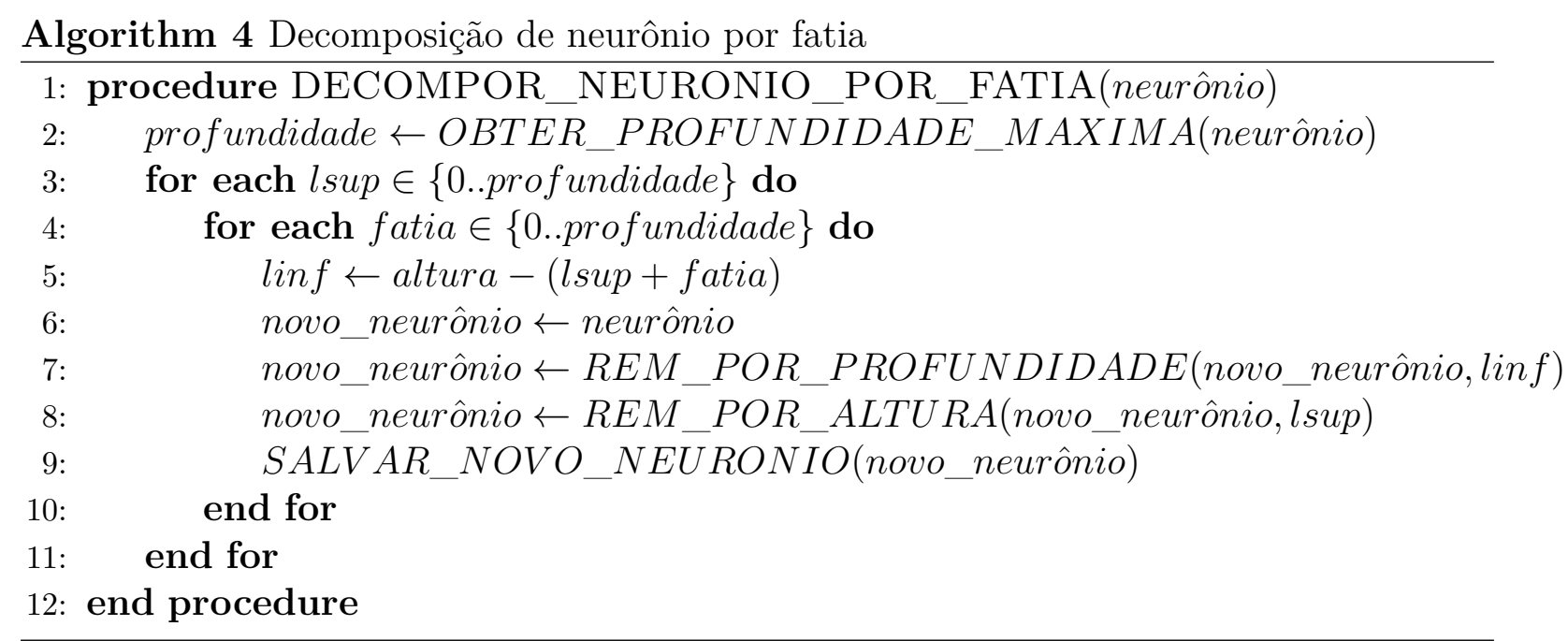

Na Figura 3.9 são apresentados alguns exemplos de neurônios gerados aplicando o método de decomposição por fatias. Os ramos em amarelo são desconsiderados em todos os casos. Na Figura 3.9(a) temos o neurônio de fatia com limite superior 2 e limite inferior 3; na Figura 3.9(b) fatia com limite superior 1 e limite inferior 3; na Figura 3.9(c) fatia com limite superior 2 e limite inferior 4; na Figura 3.9(d) fatia com limite superior 1 e limite inferior 4. Lembrando que o limite superior e o limite inferior são dados em termos de profundidade da árvore dendrítica original.

\subsection{Classificação morfológica de neurônios}

A classificação morfológica de um conjunto de $k$ neurônios observados, cada um deles descrito por $(n+1)$ variáveis, em que as $n$ primeiras variáveis são medidas morfológicas calculadas sobre os neurônios e a última variável é usada para indicar a classe do neurônio. Classificar neurônios significa encontrar uma função $f$ que atribui as classes às 
Figura 3.9: Neurônios criados aplicando o método de decomposição por fatia. (a) o neurônio de fatia com limite superior 2 e limite inferior 3, (b) fatia com limite superior 1 e limite inferior 3, (c) fatia com limite superior 2 e limite inferior 4, (d) fatia com limite superior 1 e limite inferior 4.

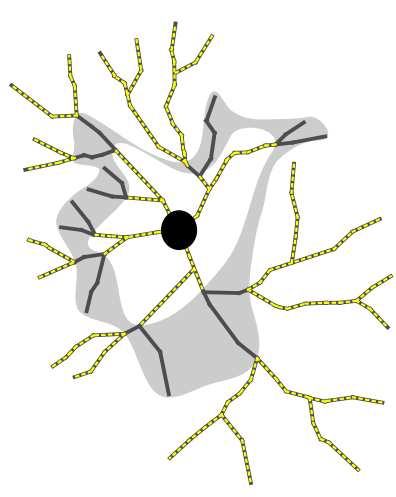

(a)

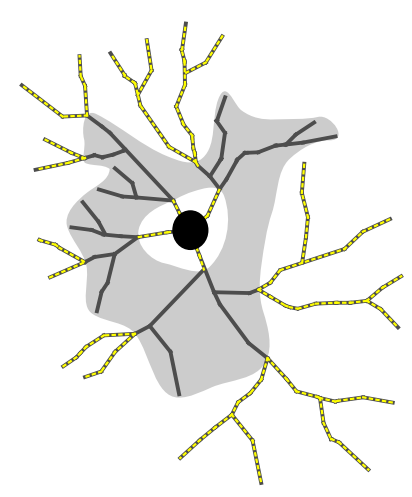

(b)

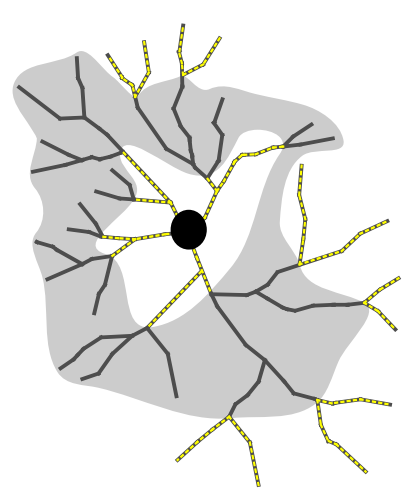

(c)

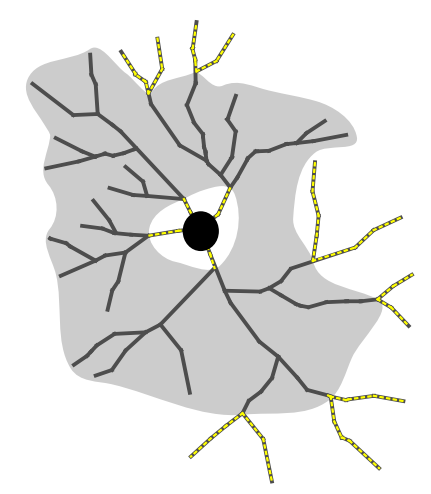

(d)

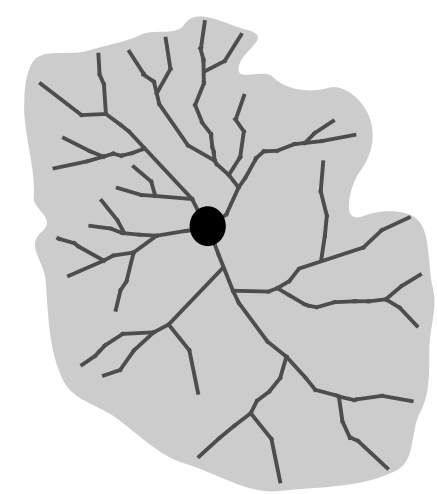

(e)

observações:

$$
f:\left(x_{1} \ldots x_{n}\right) \rightarrow\{1,2, . . m\}
$$

onde $x=\left(x_{1}, \ldots, x_{n}\right)$ contém todas as medidas de um neurônio particular e $\{1,2, . . \mathrm{m}\}$ são as possíveis classes às quais o neurônio pode pertencer, sendo que a classe real do neurônio está dentro desse domínio [Armañanzas e Ascoli, 2015]. Neste sentido, existem três principais categorias de propostas para classificação: os métodos supervisionados que requerem ambas informações, as $n$ características e as etiquetas das classes; os métodos não supervisionados que somente requerem as $n$ características; e os métodos semisupervisionados, que requerem, as $n$ características e apenas algumas mas não todas as etiquetas das classes. [Guerra et al., 2011] apresentaram um estudo de caso no qual foi comparado o desempenho dos métodos supervisionados e não supervisionados. Foi mostrado que os métodos supervisionados superam os não supervisionados na capacidade de distinguir 
diferentes tipos de neurônios utilizando medidas morfológicas.

\subsubsection{Medidas morfológicas}

O software L-Measure[Scorcioni et al., 2008] está sendo utilizado para computar as medidas morfológicas das reconstruções digitais dos neurônios. Com esta ferramenta é possível extrair um grande número de medidas, mas neste trabalho foram escolhidas 22 medidas que são mostradas na Tabela 3.1. A escolha dessas medidas foi baseada nas referências bibliográficas sobre análise morfológica assim como um análise de avaliação de medidas vinculadas com a morfologia dos dendritos.

As medidas morfológicas apresentadas na Tabela 3.1 serão usadas como características. Entre as características, temos a área de superfície do soma cuja importância reside na resistência exercida sobre o impulso trazido de outros neurônios pelos dendritos [Rall, 2011]. O número de troncos ou ramos principais quantifica os ramos que estão diretamente conectados ao soma. Esse número é muito importante para um dos testes deste trabalho. O número de bifurcações representa o grau de liberdade permitido à árvore dendrítica. Quanto maior é esse valor, mais complexa é a forma da árvore dendrítica. Da característica 4 até a 12 são medidas relacionadas com o tamanho do neurônio, como a extensão do neurônio que tem relação direta com o número de sinapses [Jan e Jan, 2010, Poirazi e Mel, 2001, Scott e Luo, 2001], e o diâmetro e cumprimento dos dendritos que têm influência direta na transmissão do impulso de entrada.

Em geral as medidas relacionadas ao tamanho da árvore dendrítica são importantes porque o impulso nervoso sofre algum tipo de atenuação nessa estrutura, o que não acontece no axônio [Koch, 2004]. A fragmentação quantifica o número de subdivisões que cada ramo tem. A assimetria topológica quantifica a diferença entre o número de folhas dos ramos direito e esquerdo para cada bifurcação. Para quantificar o Rall power existe uma equação $D_{p}^{n}=D_{a}^{n}+D_{b}^{n}$ onde $D_{p}$ é o diâmetro do ramo pai, $D_{a}$ e $D_{b}$ são os diâmetros dos ramos filhos. Essa medida é computada para cada bifurcação, e representa o valor $n$ que se adapta melhor com a equação [Rall, 1962]. A média dos ângulos entre os ramos em cada bifurcação é quantificada pela medida do ângulo local enquanto que o 
ângulo remoto quantifica o ângulo considerando os terminais dos ramos das bifurcações. A dimensão fractal quantifica a relação entre a distância euclidiana e o caminho entre os terminais dos ramos [Marks e Burke, 2007].

É possível obter mais informações sobres as medidas no artigo [Ascoli, 2002], no site oficial da ferramenta L-Measure (http://cng.gmu.edu:8080/Lm) e também no site do projeto FARSIGHT (http://farsight-toolkit.org/wiki/L_Measure_functions).

Tabela 3.1: Medidas morfológicas consideradas para caracterização do neurônio.

\begin{tabular}{|c|c|c|c|}
\hline Noo & Descrição da medida & No & Descrição da medida \\
\hline 1 & Área de superfície de soma & 11 & Volume total de arborização \\
\hline 2 & $\begin{array}{l}\text { Número de ramos principais } \\
\text { (árvores) anexadas ao soma }\end{array}$ & 12 & $\begin{array}{l}\text { Distância máxima euclidiana } \\
\text { entre o soma e as folhas }\end{array}$ \\
\hline 3 & Número de bifurcações & 13 & Caminho máximo \\
\hline 4 & Número de ramos & 14 & Ordem de ramificação máxima \\
\hline 5 & $\begin{array}{l}\text { Altura neuronal, diferença entre o má- } \\
\text { ximo e o mínimo nas coordenadas x }\end{array}$ & 15 & Tamanho médio dos ramos \\
\hline 6 & Largura neuronal, diferença entre o má- & 16 & Contração média \\
\hline & ximo e o mínimo nas coordenadas y & 17 & Fragmentação total \\
\hline 7 & Profundidade neuronal, diferença entre & 18 & Assimetria topológica média \\
\hline & máximo e o mínimo nas coordenadas z & 19 & Rall power média \\
\hline 8 & Diâmetro médio dos ramos & 20 & Ângulo médio de bifurcação local \\
\hline 9 & Comprimento total da arborização & 21 & Ângulo médio de bifurcação remota \\
\hline 10 & Área total de arborização & 22 & Dimensão fractal \\
\hline
\end{tabular}

\subsubsection{Aprendizagem supervisionada}

Neste trabalho são usados métodos de classificação supervisionada. Os vetores de características foram previamente padronizados removendo a média de cada característica e escalando à variância unitária [Costa e Cesar Jr, 2009] como método de seleção de características foi usado o RFECV (do inglês recursive feature elimination and cross-validated selection) o qual basicamente faz uma eliminação recursiva de características usando crossvalidation para determinar o número ótimo de características. Para a avaliação é usada a medida-F (F-measure) dos resultados obtidos comparados com o ground-truth que é a classe original do neurônio no banco de dados do NeuroMorpho.Org.

Finalmente escolhemos o melhor classificador levando em conta o desempenho em termos de medida-F e tempo de execução. A Figura 3.10 mostra a medida-F de cada 
classificador para cada uma das 10 classes consideradas.

Figura 3.10: Medida-F dos classificadores testados.

\begin{tabular}{|c|c|c|c|c|c|c|c|c|c|c|c|}
\hline Vizinho mais próximo & 0.85 & 0.92 & 0.92 & 0.69 & 0.57 & 0.94 & 0.93 & 0.59 & 0.9 & 0.79 & 0.81 \\
\hline SVM linear & 0.89 & 0.96 & 0.95 & 0.7 & 0.74 & 0.95 & 0.87 & 0.71 & 0.88 & 0.84 & 0.85 \\
\hline SVM polinomial & 0.24 & 0.03 & 0.69 & 0.46 & 0.02 & 0.76 & 0.82 & 0.07 & 0.19 & 0.12 & 0.34 \\
\hline SVM radial & 0.86 & 0.84 & 0.68 & 0.38 & 0.6 & 0.86 & 0.58 & 0.6 & 0.73 & 0.69 & 0.68 \\
\hline Árvore de decisão & 0.57 & 0.77 & 0.76 & 0.39 & 0.59 & 0.9 & 0.66 & 0.54 & 0.63 & 0.33 & 0.61 \\
\hline Random forest & 0.78 & 0.82 & 0.85 & 0.43 & 0.66 & 0.93 & 0.8 & 0.63 & 0.79 & 0.72 & 0.74 \\
\hline Rede neural & 0.91 & 0.94 & 0.95 & 0.72 & 0.7 & 0.95 & 0.92 & 0.69 & 0.9 & 0.83 & 0.85 \\
\hline AdaBoost & 0.36 & 0.43 & 0.44 & 0.18 & 0.39 & 0.83 & 0.33 & 0.47 & 0.37 & 0.42 & 0.42 \\
\hline Naive Bayes & 0.79 & 0.87 & 0.84 & 0.51 & 0.62 & 0.92 & 0.71 & 0.33 & 0.69 & 0.71 & 0.7 \\
\hline \multirow[t]{2}{*}{$\begin{array}{r}\text { Análise discrimante } \\
\text { quadrático }\end{array}$} & 0.76 & 0.78 & 0.92 & 0.61 & 0.62 & 0.93 & 0.75 & 0.24 & 0.61 & 0.54 & 0.67 \\
\hline & $\mathrm{C} 1$ & C2 & C3 & C4 & C5 & $\begin{array}{l}\text { C6 } \\
\text { Classe }\end{array}$ & C7 & C8 & C9 & $\mathrm{C} 10$ & avg \\
\hline
\end{tabular}

O melhor resultado foi obtido usando o classificador C-Support Vector Classifier (SVC) com kernel linear e suporte multiclasses [Vapnik, 2013] e foi adotado para executar os testes posteriores. Como método de validação foi usado o cross-validation com 10 folds. A medida-F é usada para apresentar os resultados.

$$
F-\text { measure }=2 *(\text { precision } * \text { recall }) /(\text { precision }+ \text { recall })
$$

Dado um conjunto de vetores de treinamento $x_{i} \in R^{n}$ com $i=1, \cdots, l$ em duas classes e o vetor $y \in R^{l}$ tal que $y \in\{1,-1\}$. O classificador SVM procura um hiperplano ideal separação, destas duas classes, nas $n$ dimensões, o qual é uma superfície $(d=n-1)$ dimensional definida como:

$$
f(x)=\mathbf{w} \cdot x-b=0
$$

em que $\mathbf{w}$ denota o vetor normal ao hiperplano e $\cdot$ denota o produto interno. Na Figura 3.11 mostramos um exemplo da maneira como o SVM identifica o hiperplano de separação ideal. 
Figura 3.11: Um exemplo do hiperplano de separação ideal entre duas classes, identificado pelo SVM.

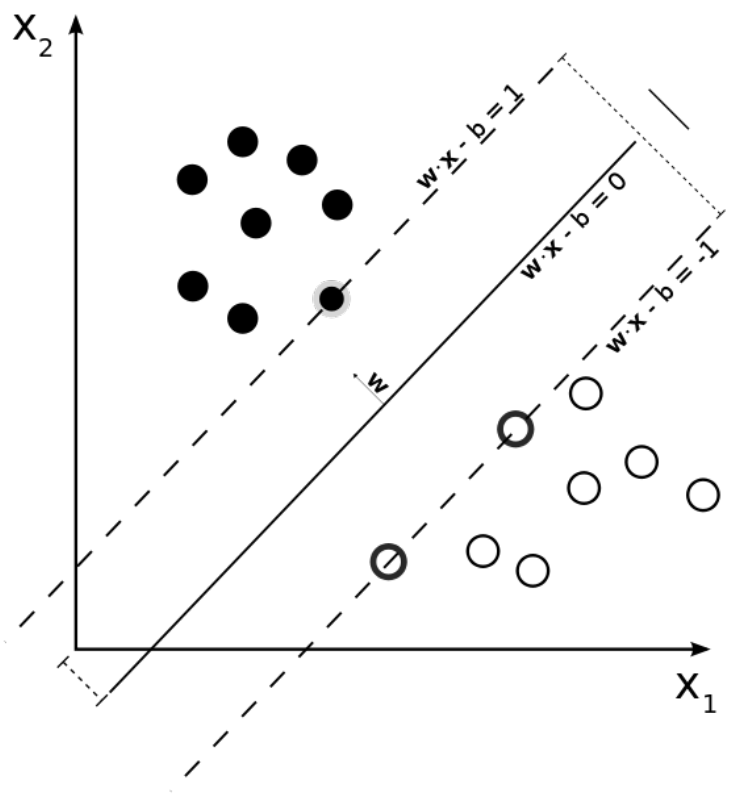

Fonte: distribuída sob domínio público por Creative Commons. 


\section{Capítulo 4}

\section{Experimentos e resultados}

Durante o desenvolvimento deste projeto foram realizados diversos testes envolvendo variadas classes de neurônios. Neste capítulo é apresentado o conjunto de dados usado na Seção 4.1. Também são apresentados os resultados obtidos utilizando o método de classificação descrito no Capítulo 3. Nas Seções 4.3, 4.4, 4.5 e 4.6 são apresentados e discutidos os resultados obtidos da classificação morfológica com diversos níveis hierárquicos.

\subsection{Conjunto de dados}

Para nossos testes foram usadas reconstruções digitais de neurônios obtidas do banco dados do NeuroMorpho.org [Ascoli et al., 2007]. O repositório fornece uma ampla variedade de arquivos SWC, contendo a descrição da estrutura dos neurônios. O teste envolvendo a maior quantidade de células utiliza um total de 5.000 neurônios pertencentes a dez classes biológicas. Os neurônios escolhidos pertencem às espécies humana e animais de espécies como rato, camundongo e chimpanzé. A Tabela 4.1 mostra o conjunto de dados usados junto com o identificador que foi atribuído a cada classe.

Na Figura 4.1 mostramos alguns exemplos de neurônios aleatoriamente escolhidos para cada classe. É possível observar que é um conjunto bastante heterogêneo. Os neurônios foram obtidos no formato SWC do site do NeuroMorpho.Org e a escolha das classes foi principalmente guiada pelo número de ramos, foram escolhidas classes de neurônios com uma média de ramos principais maior ou igual a 1. As classes de neurônios escolhidas para 
Tabela 4.1: Lista de classes de neurônios consideradas neste estudo.

\begin{tabular}{|l|l|l|l|}
\hline Id & Classe de neurônio & Id & Classe de neurônio \\
\hline C1 & principal piramidal de chimpanzé & C6 & interneurônio nitrérgico de rato \\
C2 & principal piramidal de humano & C7 & principal piramidal do hipocampo de rato \\
C3 & principal ganglionar de camundongo & C8 & principal piramidal do neocortex de rato \\
C4 & principal piramidal de camundongo & C9 & vários, principal granular \\
C5 & interneunônio gabaérgico de rato & C10 & vários, principal da espinha média \\
\hline
\end{tabular}

serem estudadas são principalmente piramidais e interneurônios pertencentes à espécies de chimpanzé, rato, camundongo e humano. Adicionalmente foram incluídos neurônios do tipo granulado e espinhoso.

Nossos testes foram executados sempre considerando o mesmo número de neurônios para cada classe, escolhidos aleatoriamente com uma probabilidade de uniforme, com a finalidade de descartar a influência do desbalanço de classes na classificação.

Figura 4.1: Dez exemplos de reconstruções digitais de neurônios pertencentes às diferentes classes utilizadas em nossos testes.

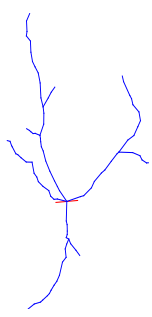

$\mathrm{C} 1$

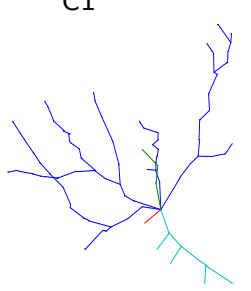

C6

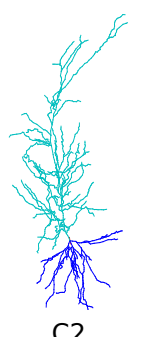

$\mathrm{C} 2$

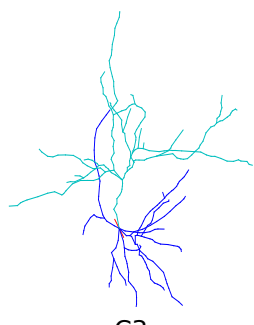

C3
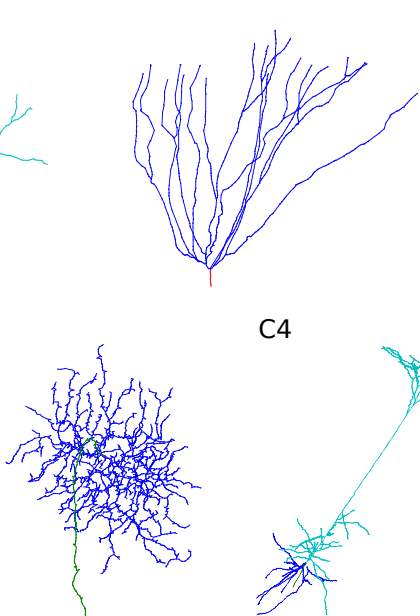

C8
C4

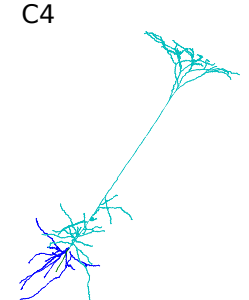

C9

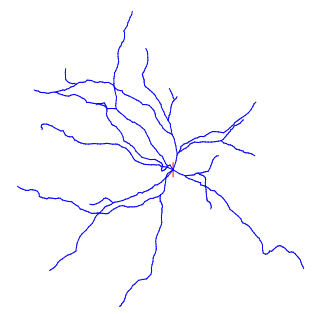

C5

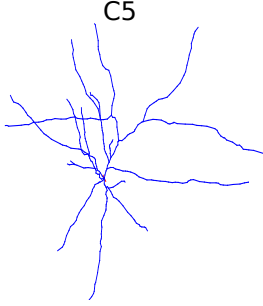

$\mathrm{C} 10$

Foi necessária a realização de alguns testes adicionais, com subconjuntos destas dez classes. Na respectiva seção de resultados serão descritos.

Na Tabela 4.2 é apresentado um resumo contendo a média o desvio padrão para cada uma das 22 medidas morfológicas apresentadas na Tabela 3.1 e para cada uma das dez classes maiores consideradas nesse estudo e mostradas na Tabela 4.1. Pode-se observar que em todos os casos foram escolhidos neurônios com mais de dois ramos (medida 2). Observando as medidas relacionadas com o tamanhos (medidas entre 4 e 12), aparentemente existem classes com tamanhos característicos e diferenciados entre si. Por outro 
lado, a dimensão fractal de todas as classes é semelhante.

Tabela 4.2: Média e desvio padrão das medidas usadas como características para cada uma das dez classes consideradas.

\begin{tabular}{|c|c|c|c|c|c|}
\hline & $\mathrm{C1}$ & $\mathrm{C} 2$ & C3 & $\mathrm{C} 4$ & C5 \\
\hline 1 & $13339.21(7675.1)$ & 26208.84 (19333.69) & 49363.49 (372271.97) & $87005.31(230902.85)$ & 8793.75 (4971.9) \\
\hline 2 & $4.43(1.18)$ & $6.07(1.41)$ & $3.82(2.48)$ & $5.97(2.46)$ & $4.85(1.67)$ \\
\hline 3 & $15.78(6.28)$ & $25.82(7.58)$ & $81.18(43.54)$ & $30.21(20.62)$ & $21.62(13)$ \\
\hline 4 & $35.98(12.97)$ & $57.71(15.7)$ & $166.15(86.47)$ & $66.38(42.11)$ & $48.08(26.38)$ \\
\hline 5 & $156.95(58.31)$ & 318.47 (80.88) & $213.17(100.75)$ & $303.07(285.79)$ & $201.83(71.8)$ \\
\hline 6 & $234.97(81.97)$ & $308.94(88.51)$ & $250.53(120.04)$ & $425.39(232.65)$ & $307.17(102.66)$ \\
\hline 7 & $70.69(25.21)$ & $115.13(42.76)$ & $24.85(19.07)$ & $52.3(57.79)$ & $14.06(8.63)$ \\
\hline 8 & $0.67(0.26)$ & $0.96(0.24)$ & $1.29(0.91)$ & $1.2(1.48)$ & $0.15(0.06)$ \\
\hline 9 & $1420.09(690.69)$ & $3902.28(1233.15)$ & $4453.37(1709.84)$ & $3606.76(2498.89)$ & $1892.93(731.86)$ \\
\hline 10 & 3225.68 (1493.66) & $11203.64(3834.89)$ & 20490.88 (22804.19) & $13812.34(18734.68)$ & $1033.39(360.94)$ \\
\hline 11 & $4176.94(2494.52)$ & $10841.91(5911.31)$ & $23507.47(101371.86)$ & $30838.31(75524.25)$ & $2208.33(1242.76)$ \\
\hline 12 & $175.97(62.7)$ & $265.86(64.26)$ & $191.41(80.77)$ & $373.14(201.23)$ & $228.97(74.73)$ \\
\hline 13 & $206.93(69.26)$ & $328.85(80.84)$ & $277.99(115.85)$ & $453.94(251.66)$ & $269.05(85.97)$ \\
\hline 14 & $2.57(1.84)$ & $2.69(1.79)$ & $6.48(4.44)$ & $3.15(3.84)$ & $2.97(2.73)$ \\
\hline 15 & $817.04(587.67)$ & $1139.34(569.25)$ & 29902.43 (26938.97) & 19619.55 (46806.98) & $2001.96(1864.28)$ \\
\hline 16 & $0.92(0.02)$ & $0.9(0.04)$ & $0.86(0.05)$ & $0.88(0.08)$ & $0.93(0.02)$ \\
\hline 17 & $334.35(170.5)$ & $431.05(185.63)$ & $5037.31(3775.43)$ & $3253.65(5228.12)$ & $732.65(465.23)$ \\
\hline 18 & $0.47(0.11)$ & $0.42(0.08)$ & $0.51(0.07)$ & $0.5(0.11)$ & $0.51(0.11)$ \\
\hline 19 & $9.8(5.73)$ & $4.82(4.37)$ & $5.84(13.93)$ & $12.35(16.88)$ & $0(0)$ \\
\hline 20 & $63.97(8.62)$ & $66.86(7.99)$ & $60.6(29.22)$ & $70.81(14.7)$ & $75.92(10.92)$ \\
\hline 21 & $58.76(8)$ & $57.13(7.18)$ & $74.95(10.5)$ & $60.55(11.94)$ & $61.83(11.94)$ \\
\hline \multirow[t]{2}{*}{22} & $1.03(0.01)$ & $1.04(0.02)$ & $1.05(0.02)$ & $1.05(0.04)$ & $1.02(0.01)$ \\
\hline & C6 & $\mathrm{C} 7$ & $\mathrm{C} 8$ & C9 & C10 \\
\hline 1 & $7224.39(3863.12)$ & 45289.61 (97973.91) & $9101.39(4387.26)$ & $9856.12(19336.21)$ & $10147.9(8106.11)$ \\
\hline 2 & $2.67(0.8)$ & $4.45(2.57)$ & $5.19(1.77)$ & $1.55(0.96)$ & $5.07(2.04)$ \\
\hline 3 & $2.93(1.97)$ & $64.26(34.53)$ & $30.32(17.48)$ & $9.33(5.03)$ & $16.16(8.58)$ \\
\hline 4 & $8.53(4.17)$ & $132.89(70.19)$ & $65.84(35.11)$ & $20.22(10.27)$ & $37.38(18.17)$ \\
\hline 5 & $46.59(29.85)$ & $839.23(3716.46)$ & $170.23(58.78)$ & $121.25(106.01)$ & $172.94(63.37)$ \\
\hline 6 & $110.58(54.94)$ & $497.25(236.48)$ & $302.84(86.46)$ & $168.6(84.04)$ & $178.28(59.27)$ \\
\hline 7 & $6.18(4.06)$ & $139.79(164.41)$ & $14.25(7.07)$ & $50.93(54.66)$ & $78.94(37.6)$ \\
\hline 8 & $1.85(0.66)$ & $0.96(0.44)$ & $0.15(0.08)$ & $1.37(1.3)$ & $0.66(0.43)$ \\
\hline 9 & $226.1(142.88)$ & 7832.8 (6152.09) & $1991.41(734.74)$ & $1156.92(1156.97)$ & $1722.9(759.21)$ \\
\hline 10 & $1008.94(350.42)$ & $21805.05(15773.14)$ & $1073.53(343)$ & $4953.44(5481.79)$ & $3834.31(2824.21)$ \\
\hline 11 & $1983.81(1007.15)$ & $18231.28(26402.36)$ & $2284.88(1097.79)$ & $4356.23(6082.51)$ & $3405.48(2330.93)$ \\
\hline 12 & $77.23(41.3)$ & $493.87(218.93)$ & $258.24(77.09)$ & $192.65(97.83)$ & $160(49.33)$ \\
\hline 13 & $82.77(43.07)$ & $654.52(360.39)$ & $304.62(86.68)$ & 227.89 (121.33) & $214.7(59.53)$ \\
\hline 14 & $0.69(0.90)$ & $6.80(6.28)$ & $3.57(4.02)$ & $3.37(2.02)$ & $2.24(1.707744)$ \\
\hline 15 & $31.97(53.62)$ & $17959.83(27395.09)$ & $4070.23(3610.42)$ & $1861.1(3066.99)$ & $2277.89(2843.58)$ \\
\hline 16 & $0.97(0.02)$ & $0.89(0.09)$ & $0.93(0.03)$ & $0.91(0.04)$ & $0.85(0.04)$ \\
\hline 17 & $47.01(31.29)$ & $2417.02(2761.26)$ & $997.63(696.56)$ & $614.3(888.87)$ & $1027.93(1013.08)$ \\
\hline 18 & $0.57(0.23)$ & $0.55(0.08)$ & $0.54(0.1)$ & $0.5(0.16)$ & $0.45(0.11)$ \\
\hline 19 & $1.43(1.62)$ & $35(37.86)$ & $0(0.03)$ & $7.01(7.93)$ & $7.4(9.63)$ \\
\hline 20 & $78.83(39.19)$ & $67.92(13.13)$ & $75.23(9.23)$ & $68.89(17.24)$ & $78.47(11.82)$ \\
\hline 21 & $51.72(32.86)$ & $52.25(13.62)$ & $62.74(10.59)$ & $42.98(14.57)$ & $67.11(12.47)$ \\
\hline 22 & $1.01(0.01)$ & $1.03(0.1)$ & $1.02(0.01)$ & $1.02(0.12)$ & $1.05(0.02)$ \\
\hline
\end{tabular}

Com a finalidade de facilitar a visualização dos dados, foi executadas as técnica de redução de dimensionalidade conhecida como PCA [Jolliffe, 2002] (Análise do Componentes Principais, tradução do Inglês, Principal Components Analysis) e t-SNE [Maaten e Hinton, 2008] (do ingles t-Distributed Stochastic Neighbor Embedding (t-SNE)). Com essa técnica 
foi reduzida a dimensionalidade de 22 para 2 dimensões e o resultado é apresentado na Figura 4.2. Nesta imagem a variância dos dados foi expressa em percentagem para cada um dos componentes. Também é possível observar nessa projeção que majoritariamente, diferentes classes ocupam diferentes regiões no espaço. Além disso, pode-se observar a existência de sobreposição de várias classes a qual era esperada dada a complexidade do problema que estamos enfrentado. Um comportamento semelhante é apresentado utilizando o método t-SNE (ver Figura 4.3) onde é possível observar que cada classe ocupa uma região específica exceto pelas classes C4, C5, C7 e C8 que se encontram sobrepostas entre elas.

Figura 4.2: PCA das dez maiores classes envolvidas neste estudo. É possível observar a predominância de algumas classes em determinadas regiões, mas também existem regiões com sobreposição.

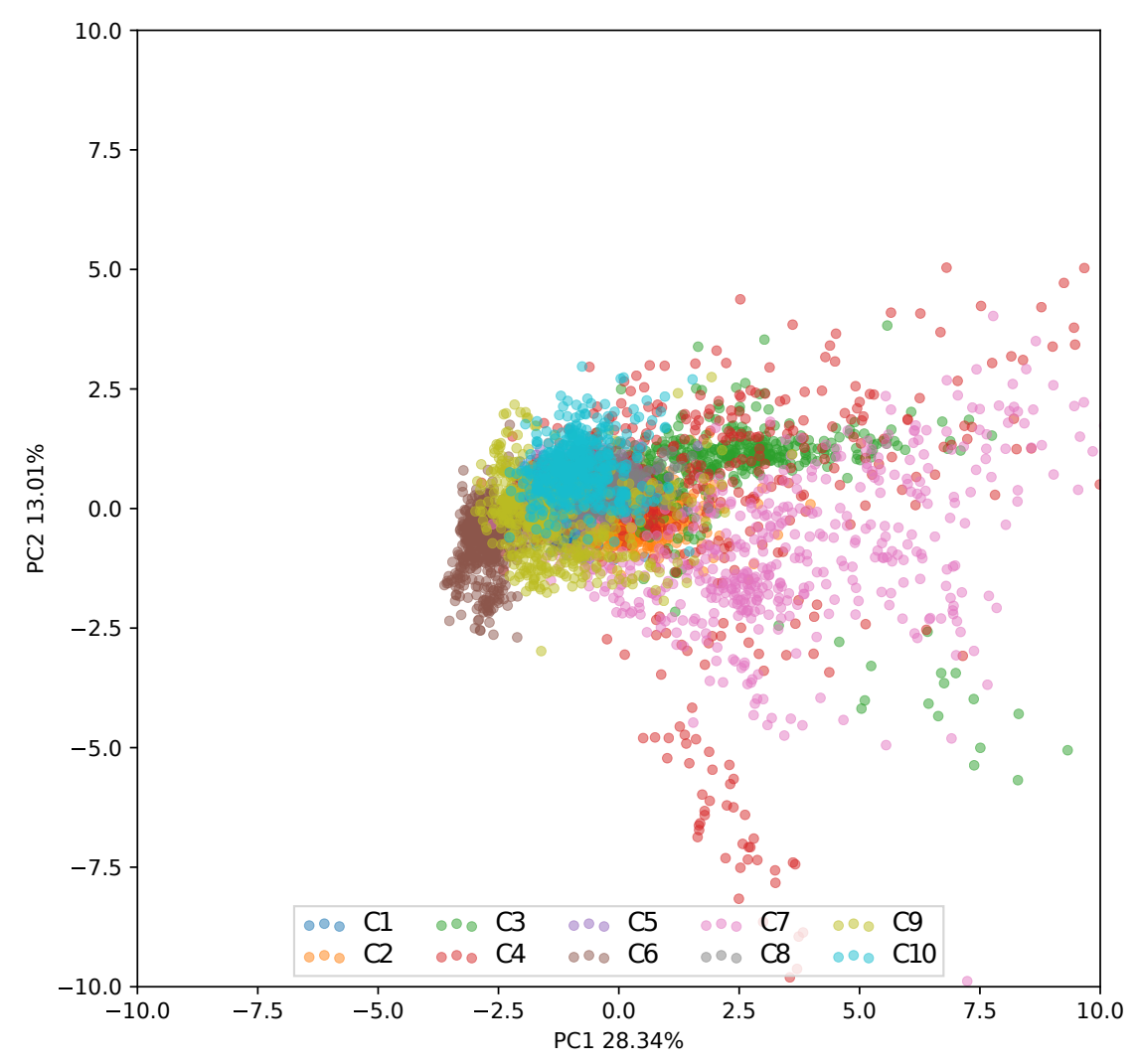


Figura 4.3: $t$-SNE das dez maiores classes envolvidas neste estudo.

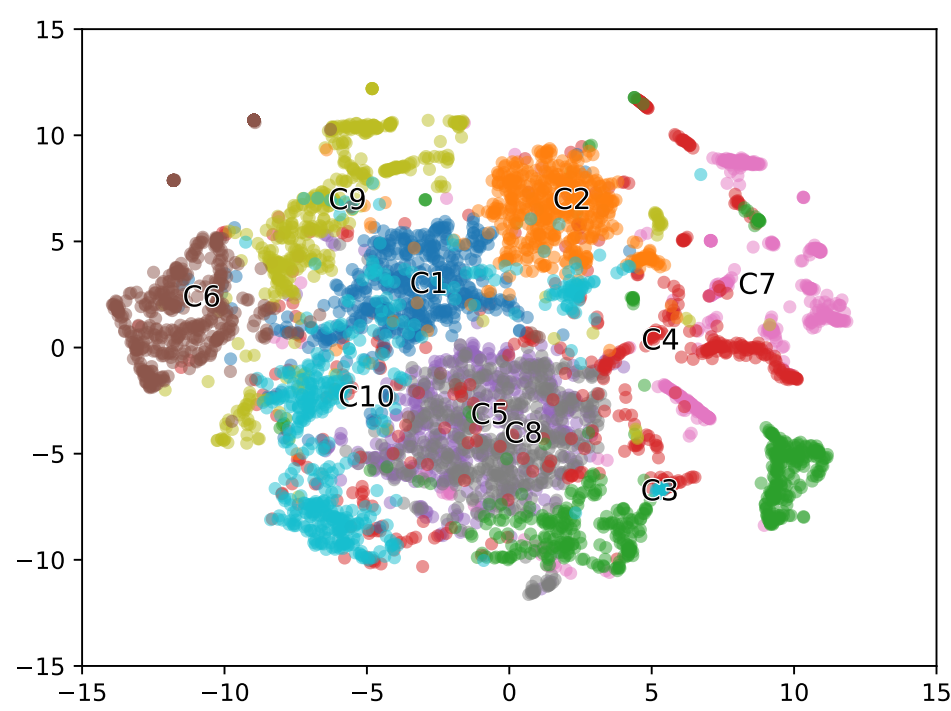

A seguir apresentamos os resultados da classificação morfológica executada depois de serem usados os métodos de decomposição de neurônios apresentados no Capítulo 3. Com a finalidade de comparar os resultados, primeiro foi criado o teste de controle e logo em seguida foi executado o procedimento descrito na Seção 3.4.

\subsection{Experimento 1: Classificação de neurônios com-} pletos

Esse primeiro teste envolve os neurônios completos, de todas as dez classes. É importante lembrar que embora neste trabalho adotemos o termo completo para descrever o neurônio que possui sua árvore dendrítica inteira, os axônios nos neurônios não estão sendo considerados.

Como passo inicial, foram computadas as medidas morfológicas de cada neurônio, para ajudar nesta tarefa foi utilizada a ferramenta L-measure [Scorcioni et al., 2008]. Tais medidas foram normalizadas e utilizadas para povoar os vetores de caraterísticas dos classificadores. Foi realizada uma seleção de caraterísticas utilizando o método RFECV e os resultados da cross-validation com 10 folds são apresentados na Figura 4.4a. O gráfico 
mostra a medida-F para cada classe e a média de todas as classes. Este resultado indica que nosso conjunto neurônios pode ser classificado em dez classes com uma medida-F de 0.86 utilizando o classificar SVM.

É possível observar que as classes C4, C5 e C8 apresentam valores baixos se comparados com os valores obtidos das outras classes. Para complementar esse resultado foi computada a scatter distance para cada par de classes e o resultado é apresentado na Figura 4.4b. Assim, observa-se que existem valores baixos, o que explica a sobreposição no PCA. A classe C4, por exemplo, apresenta valores baixos e semelhantes entre si. Disto pode se abstrair que a classe poderia estar sendo incorretamente classificada como qualquer uma das outras nove classes. Entretanto, observa-se que as distâncias com as classes C5 e C8 são baixas, e isso explica por que essas três classes têm baixa medida-F.

Figura 4.4: Medida-F obtida da classificação morfológica de neurônios inteiros e scatter distance para cada par de classes.

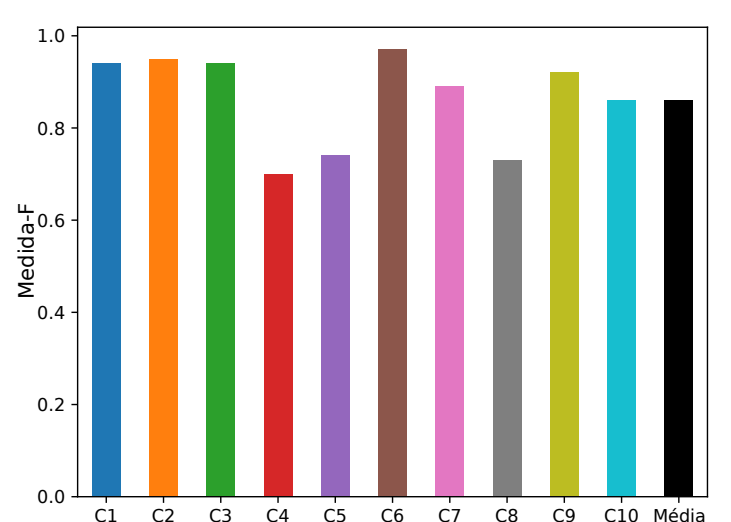

(a) Medida-F obtida na classificação morfológica utilizando neurônios inteiros.

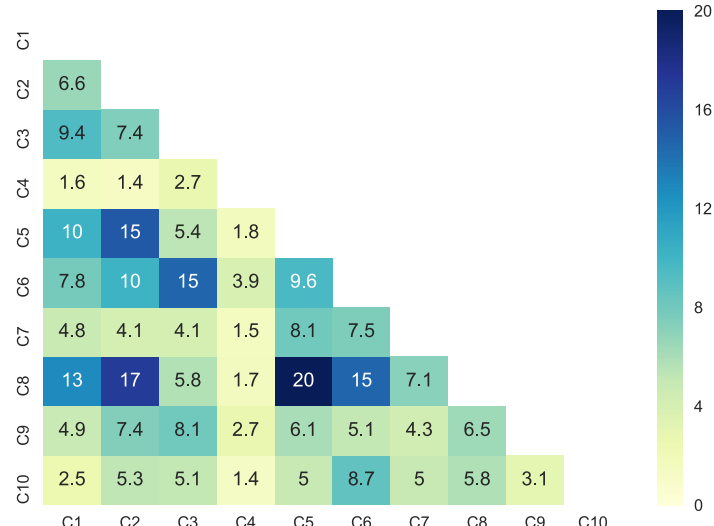

(b) Scatter distance para cada par de classes utilizando neurônios inteiros.

Adicionalmente o PCA de três dimensões foi executado e o resultado é apresentado na Tabela 4.3. A tabela contém informações do peso de cada uma das três componentes principais (na primeira coluna). Observamos que os pesos maiores estão relacionados com medidas vinculadas ao tamanho do neurônio. Assim, temos neste grupo as medidas de comprimento da árvore, distância do caminho máximo e distância euclidiana.

Com este experimento conseguimos o resultado que servirá como controle dos resultados dos experimentos seguintes. 
Tabela 4.3: A tabela contém informações do peso de cada uma dos três componentes principais (na primeira coluna) os pesos maiores estão relacionados com medidas vinculadas ao tamanho do neurônio.

\begin{tabular}{|l|r|r|r|}
\hline & PC1 & PC2 & PC3 \\
\hline Explicação de variância & $28 \%$ & $14 \%$ & $10 \%$ \\
\hline Área de superfície de soma & 0,1 & $-0,33$ & 0.35 \\
Número de ramos principais & 0,09 & 0,08 & -0.1 \\
Número de bifurcações & 0,26 & 0,31 & 0.25 \\
Número de ramos & 0,26 & 0,31 & 0.25 \\
Largura neuronal & 0,06 & $-0,03$ & -0.09 \\
Altura neuronal & 0,31 & $-0,1$ & -0.2 \\
Profundidade neuronal & 0,22 & $-0,09$ & -0.28 \\
Diâmetro & 0,02 & $-0,3$ & 0.36 \\
Comprimento da árvore & 0,36 & 0,03 & -0.07 \\
Área da árvore & 0,29 & $-0,2$ & 0.27 \\
Volume da árvore & 0,13 & $-0,35$ & 0.38 \\
Distância euclidiana & 0,33 & $-0,11$ & -0.23 \\
Distância do caminho máximo & 0,35 & $-0,06$ & -0.21 \\
Ordem de ramificação & 0,28 & 0,26 & 0.08 \\
Tamanho médio dos ramos & 0,22 & $-0,32$ & -0.26 \\
Contração & $-0,19$ & $-0,15$ & 0.04 \\
Fragmentação & 0,22 & 0,19 & 0.17 \\
Assimetria topológica & $-0,01$ & 0,08 & 0.12 \\
Rall Power & 0,09 & $-0,24$ & 0.05 \\
Ângulo de bifurcação local & $-0,07$ & 0,05 & -0.11 \\
Ângulo de bifurcação remota & 0,02 & 0,28 & 0.17 \\
Dimensão fractal & 0,08 & 0,16 & 0.05 \\
\hline
\end{tabular}

\subsection{Experimento 2: Classificação baseada em ramos}

\section{principais da árvore dendrítica}

Nesse experimento foi usado o método de decomposição da árvore dendrítica em ramos como descrito na Seção 3.3.1. Seguindo dito procedimento para cada neurônio decomposto foram criados $n$ novos neurônios, onde $n$ é o número de ramos principais do neurônio original. Cada um desses novos neurônios criados foi usado como indivíduo no qual foram computadas as medidas morfológicas para serem usadas nos vetores de características do classificador.

Na Tabela 4.4 é apresentado um resumo contendo a média o desvio padrão para cada uma das 22 medidas morfológicas apresentadas na Tabela 3.1 e para cada uma 
Tabela 4.4: Média e desvio padrão das medidas usadas como características para cada uma das dez classes consideradas no Experimento 2.

\begin{tabular}{|c|c|c|c|c|c|}
\hline & C1 & $\mathrm{C} 2$ & C3 & $\mathrm{C} 4$ & C5 \\
\hline 1 & $13489.12(7772.63)$ & $27055.06(19923.24)$ & $87775.11(549112.30)$ & $90590.71(236141.39)$ & $8994.76(4789.55)$ \\
\hline 2 & $1.00(0.00)$ & $1.00(0.00)$ & $1.00(0.05)$ & $1.00(0.00)$ & $1.00(0.00)$ \\
\hline 3 & $4.34(2.86)$ & $5.09(3.30)$ & $22.10(27.68)$ & $5.90(7.98)$ & $5.25(5.25)$ \\
\hline 4 & $9.68(5.73)$ & $11.17(6.59)$ & $45.19(55.37)$ & $12.79(15.96)$ & $11.50(10.50)$ \\
\hline 5 & $76.18(45.92)$ & $140.69(78.63)$ & $126.58(82.63)$ & $122.37(102.11)$ & $98.23(62.69)$ \\
\hline 6 & $98.21(58.46)$ & $148.33(77.21)$ & $141.25(93.98)$ & $143.28(138.12)$ & $125.33(81.61)$ \\
\hline 7 & $43.66(23.95)$ & $72.60(43.98)$ & $18.00(15.70)$ & $28.55(30.49)$ & $8.47(6.23)$ \\
\hline 8 & $1.77(1.75)$ & $3.21(3.39)$ & $1.46(1.18)$ & $2.24(3.13)$ & $0.77(0.90)$ \\
\hline 9 & 333.06 ( 245.29$)$ & $659.08(459.10)$ & $1183.66(1210.13)$ & $621.99(935.27)$ & $401.31(342.30)$ \\
\hline 10 & $1352.69(681.77)$ & $2904.04(1135.65)$ & $6590.88(11197.04)$ & $3998.72(6407.48)$ & $705.30(233.02)$ \\
\hline 11 & $3562.55(2082.85)$ & $7470.24(5122.63)$ & $24874.85(138450.62)$ & $24172.42(61907.80)$ & $2250.73(1197.19)$ \\
\hline 12 & $120.11(59.36)$ & $190.62(79.81)$ & $146.31(78.03)$ & $168.32(141.43)$ & $144.75(77.45)$ \\
\hline 13 & $143.43(68.81)$ & $232.34(101.89)$ & $202.60(108.39)$ & $204.23(171.62)$ & $168.97(89.98)$ \\
\hline 14 & $2.57(1.84)$ & $2.69(1.79)$ & $6.48(4.44)$ & $3.15(3.84)$ & $2.97(2.73)$ \\
\hline 15 & $33.48(13.26)$ & $56.67(23.30)$ & $33.33(22.12)$ & $45.36(23.99)$ & $37.03(18.30)$ \\
\hline 16 & $0.93(0.03)$ & $0.92(0.05)$ & $0.88(0.05)$ & $0.90(0.07)$ & $0.94(0.03)$ \\
\hline 17 & $77.87(58.95)$ & $73.50(57.09)$ & $1327.81(1951.24)$ & $548.04(1562.60)$ & $153.44(162.69)$ \\
\hline 18 & $0.62(0.21)$ & $0.61(0.24)$ & $0.58(0.17)$ & $0.65(0.22)$ & $0.65(0.20)$ \\
\hline 19 & $0.91(0.65)$ & $0.48(0.41)$ & $0.35(0.81)$ & $0.74(1.10)$ & $0.00(0.00)$ \\
\hline 20 & $54.60(26.71)$ & $53.10(30.48)$ & $62.81(33.67)$ & $56.72(34.69)$ & $62.06(34.46)$ \\
\hline 21 & $50.38(24.91)$ & $45.62(26.51)$ & $68.20(26.27)$ & $47.56(30.24)$ & $50.37(32.94)$ \\
\hline 22 & $1.02(0.09)$ & $1.01(0.16)$ & $1.05(0.03)$ & $1.05(0.07)$ & $1.02(0.04)$ \\
\hline & C6 & C7 & $\mathrm{C} 8$ & C9 & $\mathrm{C} 10$ \\
\hline 1 & $7407.12(3980.22)$ & $39123.36(103067.57)$ & $9361.90(4461.81)$ & $10483.72(24884.19)$ & $10646.56(8298.111550)$ \\
\hline 2 & $1.00(0.00)$ & $1.00(0.26)$ & $1.00(0.00)$ & $1.00(0.00)$ & $1.00(0.000000)$ \\
\hline 3 & $1.72(1.00)$ & $15.51(16.84)$ & $6.65(8.54)$ & $6.38(4.36)$ & $4.00(2.938472)$ \\
\hline 4 & $4.45(2.00)$ & $32.04(33.70)$ & $14.30(17.08)$ & $13.75(8.73)$ & $8.99(5.876945)$ \\
\hline 5 & $26.99(21.85)$ & $144.63(104.06)$ & $80.24(55.65)$ & $95.79(88.00)$ & $82.27(48.989056)$ \\
\hline 6 & $55.94(34.38)$ & $253.94(822.20)$ & $105.13(88.17)$ & $134.74(86.90)$ & $85.78(47.468213)$ \\
\hline 7 & $3.62(3.11)$ & $67.37(91.98)$ & $7.79(5.69)$ & $40.36(47.97)$ & $43.48(29.060836)$ \\
\hline 8 & $3.32(1.40)$ & $1.58(1.61)$ & $0.97(1.10)$ & $1.55(1.21)$ & $1.12(0.851359)$ \\
\hline 9 & $92.89(62.76)$ & $1805.12(2600.99)$ & $395.07(443.15)$ & $750.78(882.44)$ & $352.00(261.013617)$ \\
\hline 10 & $720.38(242.90)$ & $6025.32(7551.10)$ & $722.19(232.91)$ & $3406.06(4134.49)$ & $1304.23(850.619237)$ \\
\hline 11 & $1918.39(1007.47)$ & $11378.37(26270.33)$ & $2342.31(1115.49)$ & $3841.77(6803.02)$ & $2832.29(2099.980184)$ \\
\hline 12 & $57.74(34.87)$ & $244.46(193.50)$ & $121.15(86.65)$ & $165.67(107.76)$ & $110.35(49.031615)$ \\
\hline 13 & $62.18(36.81)$ & $320.49(284.86)$ & $141.92(101.68)$ & $197.51(131.36)$ & $149.39(64.235387)$ \\
\hline 14 & $0.69(0.90)$ & $6.80(6.28)$ & $3.57(4.02)$ & $3.37(2.02)$ & $2.24(1.707744)$ \\
\hline 15 & $20.93(10.10)$ & $51.97(33.32)$ & $28.07(13.27)$ & $45.29(31.93)$ & $38.58(14.248409)$ \\
\hline 16 & $0.98(0.02)$ & $0.91(0.09)$ & $0.94(0.03)$ & $0.91(0.05)$ & $0.88(0.048839)$ \\
\hline 17 & $19.49(13.06)$ & $556.53(1087.28)$ & $194.64(275.05)$ & $397.39(607.24)$ & $205.56(278.199848)$ \\
\hline 18 & $0.78(0.24)$ & $0.60(0.18)$ & $0.66(0.20)$ & $0.58(0.20)$ & $0.63(0.214473)$ \\
\hline 19 & $0.38(0.52)$ & $1.29(1.09)$ & $0.00(0.01)$ & $1.34(1.28)$ & $0.65(1.085721)$ \\
\hline 20 & $33.50(38.21)$ & $62.02(26.76)$ & $59.83(33.84)$ & $66.21(28.10)$ & $64.65(36.013558)$ \\
\hline 21 & $30.19(36.50)$ & $47.19(23.44)$ & $49.40(31.55)$ & $41.64(23.10)$ & $55.79(33.763961)$ \\
\hline 22 & $1.01(0.07)$ & $1.02(0.12)$ & $1.02(0.04)$ & $1.04(0.07)$ & $1.05(0.040411)$ \\
\hline
\end{tabular}

das dez classes consideradas nesse estudo e mostradas na Tabela 4.1. Pode-se observar que o método de decomposição gera arvores com um único ramo principal (medida 2). Observando as outras medidas e comparando elas com as das Tabela 4.2 é possível observar a diminuição de ditas medidas por causa da fragmentação do neurônio.

Os resultados desse experimento são apresentados na Figura 4.5. Pode-se observar que o fato de os neurônios estarem incompletos afeta o desempenho da classificação. Embora existam duas classes que conseguiram ser classificadas com medida-F maior a 0.7 , isso não aconteceu na maioria dos casos. Na Figura 4.6 se mostramos o PCA, onde se pode 
observar a existência de sobreposição. No mais, se for feita uma análise mais minuciosa, nota-se a presença de grupos de pontos separados ainda que pertencentes à mesma classe e isto pode estar sendo causado por alguma subclassificação das classes analisadas.

Figura 4.5: Medida-F obtida na classificação morfológica baseada nos ramos principais dos neurônios.

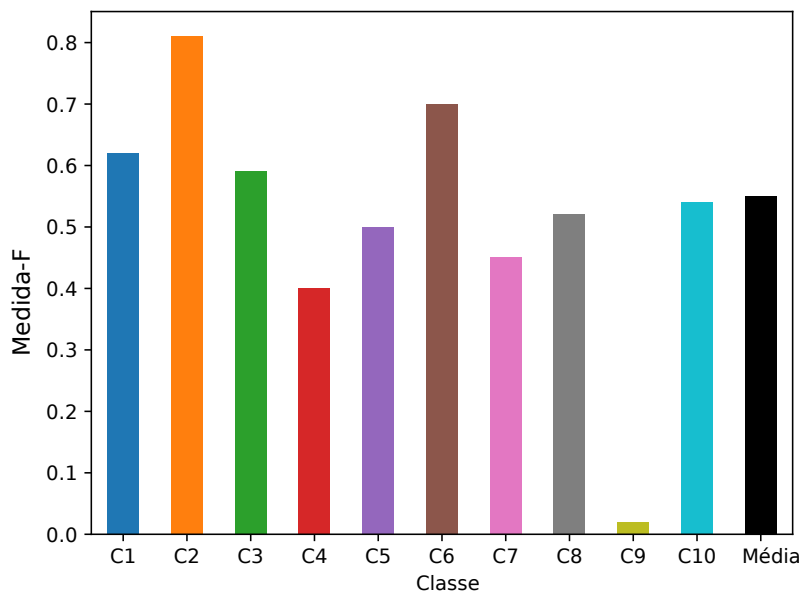

Figura 4.6: PCA das medidas morfológicas calculadas sobre os ramos principais dos neurônios.

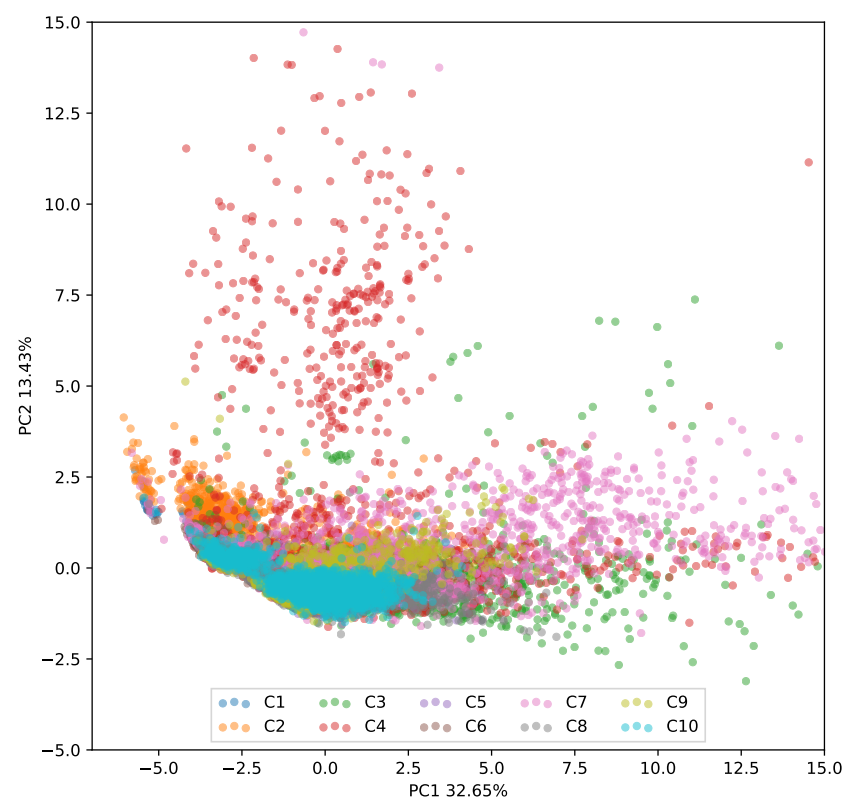

Mais uma vez o PCA de três dimensões foi executado e o resultado é apresentado na Tabela 4.5. A tabela contém informações do peso de cada uma das três componentes principais (na primeira coluna). Observamos que os pesos maiores estão relacionados com 
medidas vinculadas ao tamanho do neurônio. Assim, temos neste grupo as medidas de distância do caminho máximo, comprimento da árvore e distância euclidiana.

Tabela 4.5: A tabela contém informações do peso de cada uma dos três componentes principais (na primeira coluna) os pesos maiores estão relacionados com medidas vinculadas ao tamanho do neurônio.

\begin{tabular}{|l|r|r|r|}
\hline & PC1 & PC2 & PC3 \\
Explicação de variância & $32 \%$ & $13 \%$ & $10 \%$ \\
\hline Área de superfície de soma & 0,06 & 0,41 & $-0,16$ \\
Número de ramos principais & 0,02 & 0,03 & 0,03 \\
Número de bifurcações & 0,28 & $-0,10$ & 0,38 \\
Número de ramos & 0,28 & $-0,10$ & 0,38 \\
Largura neuronal & 0,29 & 0,10 & $-0,13$ \\
Altura neuronal & 0,12 & 0,05 & $-0,02$ \\
Profundidade neuronal & 0,21 & 0,05 & $-0,17$ \\
Diâmetro & $-0,12$ & 0,36 & 0,18 \\
Comprimento da árvore & 0,33 & 0,05 & 0,15 \\
Área da árvore & 0,25 & 0,31 & 0,06 \\
Volume da árvore & 0,07 & 0,41 & $-0,15$ \\
Distância Euclidiana & 0,32 & 0,13 & $-0,10$ \\
Distância do caminho máximo & 0,33 & 0,10 & $-0,08$ \\
Ordem de ramificação & 0,30 & $-0,14$ & 0,23 \\
Tamanho médio dos ramos & 0,20 & 0,25 & $-0,30$ \\
Contração & $-0,18$ & 0,15 & 0,11 \\
Fragmentação & 0,23 & $-0,05$ & 0,29 \\
Assimetria topológica & $-0,16$ & 0,23 & 0,31 \\
Rall Power & 0,13 & $-0,01$ & $-0,16$ \\
Ângulo de bifurcação local & 0,14 & $-0,31$ & $-0,33$ \\
Ângulo de bifurcação remota & 0,15 & $-0,32$ & $-0,22$ \\
Dimensão fractal & 0,06 & $-0,12$ & $-0,11$ \\
\hline
\end{tabular}

\subsection{Experimento 3: Classificação baseada na profun-}

\section{didade da árvore dendrítica}

O objetivo desse teste é determinar a influência da inclusão de cada nível de profundidade na performance da classificação. Para o teste foi criado um novo conjunto de dados usando o método de decomposição por profundidade descrito na Seção 3.3.2. Os novos neurônios obtidos foram agrupados por níveis de profundidade máxima atingida e então foi aplicado o método de classificação para cada grupo. 
No Apêndice A são apresentadas algumas visualizações do PCA e LDA junto com uma imagem por cada uma das 10 classes avaliadas com suas respectivas árvores dendríticas segmentadas até um determinado nível de profundidade dos sub-experimentos do Experimento 3, ditos gráficos também podem ser observados no seguinte link http: //www.vision.ime.usp.br/ epcervantes/pca_lda/apical_basal/.

Na Figura 4.7 são apresentados os resultados obtidos em termos de medida-F para cada classe e a média de todas as classes. O eixo $x$ mostra o nível de profundidade máxima atingida pelas folhas da árvore dendrítica criada. O eixo y mostra o valor da medida-F e cada classe é representada por uma linha colorida. Dado que nesse teste foram usados neurônios incompletos, o desempenho do classificador deve ser consideravelmente afetado. O gráfico da Figura 4.7(a) mostra o resultado normalizado pelo resultado obtido usando neurônios inteiros.

Figura 4.7: (a) A medida-F obtida para cada classe em função da profundidade das árvores dendríticas, (b) medida-F normalizada pelo resultado usando neurônios inteiros. Valores $x$ mais baixos estão relacionados a ramificações próximas ao soma. A acurácia aumenta primeiros níveis de profundidade até atingir a profundidade 3 na qual a medida-F se estabiliza e permanece assim até o final do gráfico.

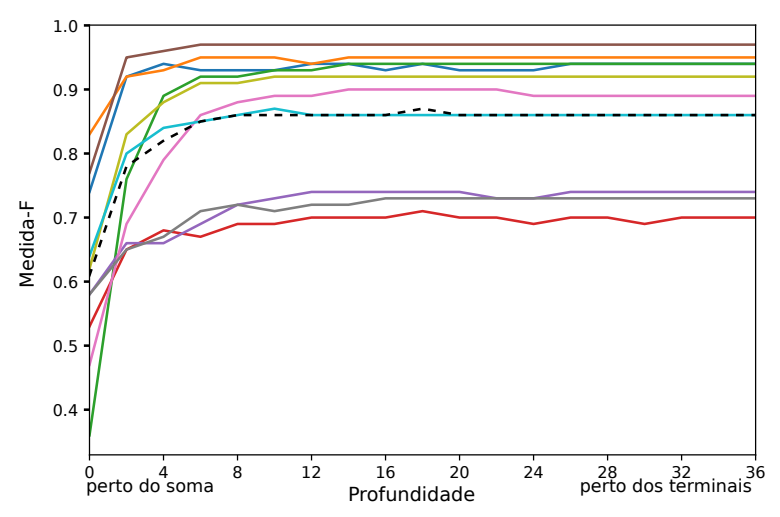

(a)

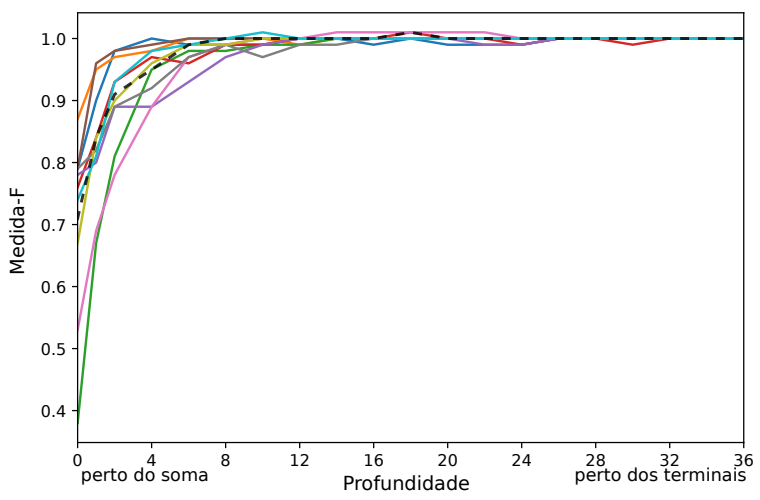

(b)

\begin{tabular}{|ll|}
\hline Principal piramidal de chimpanzé & Principal piramidal do hipocampo de rato \\
\hline Principal piramidal de humano & Principal piramidal do neocortex de rato \\
Principal ganglionar de camundongo & Vérios, principal granular \\
\hline Principal piramidal de camundongo & Vários, principal da espinha média \\
\hline Interneunônio gabaérgico de rato & - Média \\
\hline Interneurônio nitrérgico de rato &
\end{tabular}

Nota-se que com apenas o soma e os dois primeiros níveis das árvores dendríticas a performance é baixa, mas o desempenho do classificador melhora com o aumento no número de níveis considerados. Depois do nível de profundidade 8, os resultados para todas as classes tendem a estabilizar. Isto mostra que os níveis mais profundos também 
não são determinantes para a classificação da classe do neurônio. Assim, se observa que desconsiderando os níveis mais profundos são obtidos praticamente os mesmos resultados do que usando os neurônios inteiros.

Como parte de este experimento foi realizada uma separação entre dendritos apicais e basais o procedimento foi repetido. Algumas visualizações deste sub-experimento são apresentadas no Apêndice B e também podem ser acessadas nos links: http://www.vision.ime. usp.br/ epcervantes/pca_lda/apical/e http://www.vision.ime.usp.br/ epcervantes/pca_ lda/basal/. Este sub-experimento ajudou na decisão de usar tanto dendritos apicais como basais em todos os experimento dado que a separação dos mesmo levou a piorar a performance da classificação.

\subsection{Experimento 4: Classificação baseada na altura da árvore dendrítica}

O objetivo do teste é avaliar o desempenho da classificação na ausência de alguns níveis mais próximos ao soma e isso de certa maneira é o oposto à avaliação feita na Seção 4.4. Nesse caso, o interesse está em avaliar a influência da altura da árvore dendrítica na determinação da classe do neurônio. Para esse teste foi usado o método de decomposição por altura, descrito na Seção 3.3.3, para criar o conjunto de dados.

Foram agrupados os novos neurônios obtidos por níveis de altura máxima atingida e então foi aplicado o método de classificação para cada grupo. Na Figura 4.8 são apresentados os resultados obtidos em termos de medida-F. Mais uma vez, o fato de serem utilizados neurônios incompletos têm influência no resultado. Neste caso, a utilização de apenas os níveis de alturas menores a performance é baixa, mas vai aumentando com o número de níveis de altura adicionados. Os melhores resultados são obtidos quando são incluídos os níveis de altura maiores, o que implicaria que os níveis de altura baixos são irrelevantes e apenas inserem ambiguidade. Esse resultado de alguma maneira contradiz o resultado apresentado na Seção 4.4, segundo o qual os ramos mais próximos do soma inserem ambiguidade. Se forem comparadas ambas análises, realmente não é uma con- 
tradição dado que no teste nas Seção 4.4 estão sendo mantidos os nós mais próximos do soma sempre e sendo adicionados novos ramos em cada iteração. Já no presente teste, os ramos mais distantes do soma são mantidos sempre e estão sendo adicionados os ramos mais próximos do soma a cada iteração.

Figura 4.8: 9a) A medida-F obtida para cada classe em termos de altura das árvores dendríticas, (b) medida-F normalizada pelo resultado usando neurônios inteiros. Os gráficos mostram como a ausência dos níveis mais próximos ao soma afeta negativamente a acurácia, que apenas melhora à medida que esses níveis vão sendo incluídos.

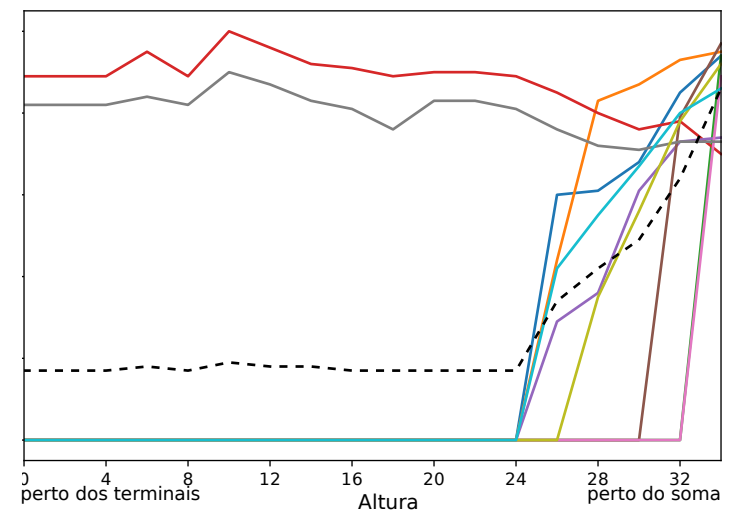

(a)

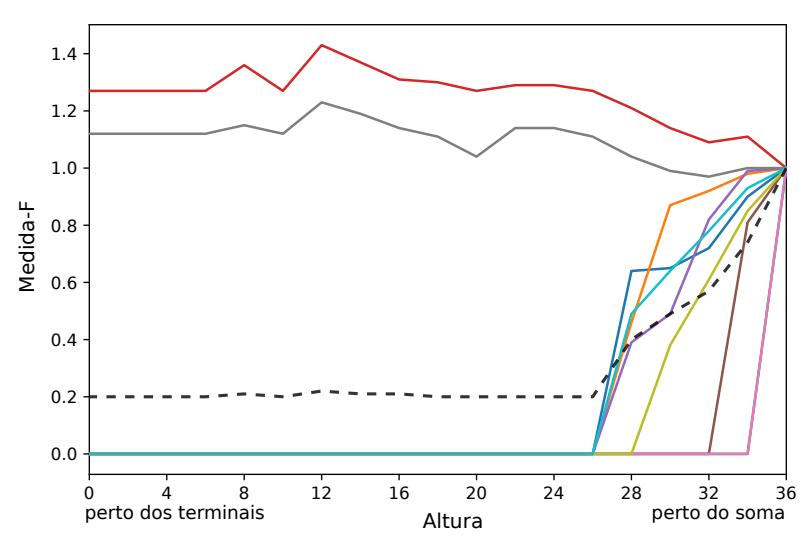

(b)

\begin{tabular}{|ll|}
\hline Principal piramidal de chimpanzé & Principal piramidal do hipocampo de rato \\
\hline Principal piramidal de humano & Principal piramidal do neocortex de rato \\
\hline Principal ganglionar de camundongo & Vários, principal granular \\
\hline Principal piramidal de camundongo & Vários, principal da espinha média \\
\hline Interneunônio gabaérgico de rato & Média \\
\hline Interneurônio nitrérgico de rato & - - \\
\hline
\end{tabular}

\subsection{Experimento 5: Classificação baseada em fatias} da árvore dendrítica

Neste ponto surgiu a seguinte questão: se aparentemente o soma, os ramos mais próximos do soma e os ramos terminais das árvores dendríticas perturbam o desempenho da classificação, então será possível identificar uma seção da árvore dendrítica, limitada por alturas lsup e $\operatorname{linf}$, que permita obter resultados, em termos de desempenho da classificação morfológica, semelhantes aos obtidos na Seção 4.2.

Para esse teste foi usado o método de decomposição por fatias da árvore dendrítica, o qual usa dois parâmetros que permitem definir os limites da fatia de árvore. Neste caso é preciso encontrar todas as possíveis fatias de cada árvore, agrupar os neurônios criados 
pelos limites considerados e então aplicar o método de classificação. Os resultados obtidos são apresentados na Figura 4.9. Como em nosso caso, o nível da profundidade máxima é 35 , teremos $35 \times 35$ resultados baseados no tamanho e a profundidade da fatia. No entanto, para melhorar a visibilidade estão sendo apresentados apenas os resultados para fatias de tamanho par e até profundidade 10.

Figura 4.9: Medidas-F média obtida para as dez classes ao decompor o neurônio por fatias e realizar a classificação morfológica. Os melhores resultados sempre contemplam os ramos com hierarquias baixas.

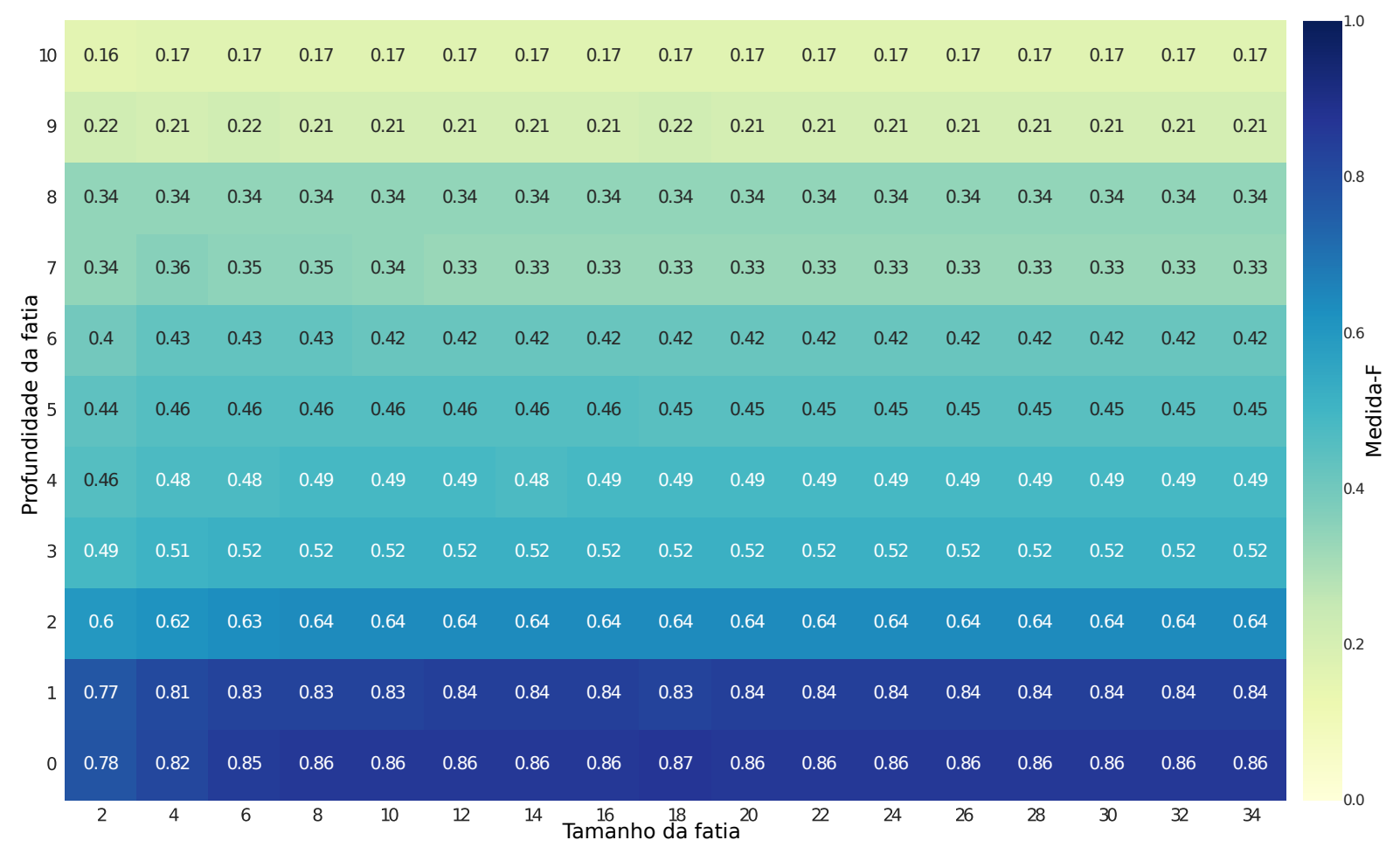

Observando os resultados da Figura 4.8, é possível notar que algumas classes têm medida-F igual a zero, isso acontece porque a altura das árvores dendríticas é irregular e pequena em muitos casos para complementar os nossos resultados na Figura 4.10 é mostrando o diagrama de caixa da ordem máxima dos ramos, que é equivalente à altura e profundidade da árvore dendrítica, de cada uma das classes estudadas. No diagrama pode ser observada a heterogeneidade em termos de profundidade das classes. Portanto, os resultados obtidos podem estar sendo influenciados de certa maneira pela quantidade de indivíduos a cada nível de profundidade.

Como exemplo adicional foi analisado um grupo de neurônios com a profundidade de suas árvores dendríticas fixa. Um subconjunto de quatro classes dentre as dez classes, 
Figura 4.10: A ordem máxima dos ramos de cada classe de neurônios, pode ser observada a heterogeneidade das profundidades.

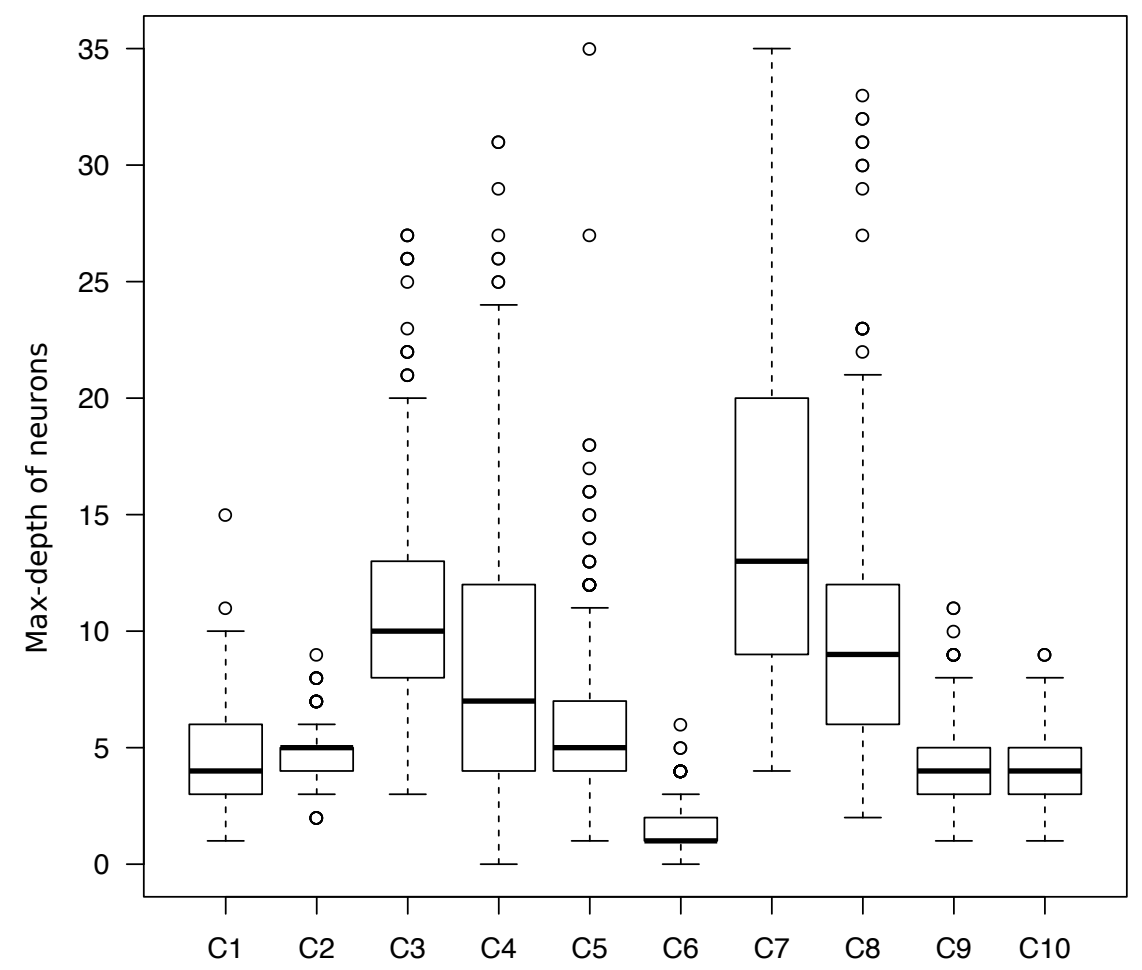

sendo 100 neurônios escolhidos com profundidade 5 para cada classe. E foi repetido o teste de classificação baseados em fatias das árvores dendríticas. Os resultados são apresentados na Figura 4.11.

O resultado mostra que efetivamente é possível classificar os neurônios usando apenas partes das árvores dendríticas com eficiência semelhante ao resultado da classificação usando os neurônios inteiros. As partes mais relevantes à classificação são mais uma vez os ramos principais e os mais próximos deles.

\subsection{Experimento 6: Classificação baseada em fatias de rato e camundongo.}

Até este ponto todos os testes foram feitos em grupos de neurônios de diferentes espécies e diferentes regiões do sistema nervoso. Neste experimento foi reduzido o conjunto de dados para apenas duas espécies, rato e camundongo. Adicionalmente algumas condições da aquisição das imagens dos neurônios foram homologadas. Foram escolhidos apenas 
Figura 4.11: Mapa de calor dos resultados obtidos usando o método de classificação por fatias com quatro classes de neurônios com profundidade de árvore dendrítica igual a 5.

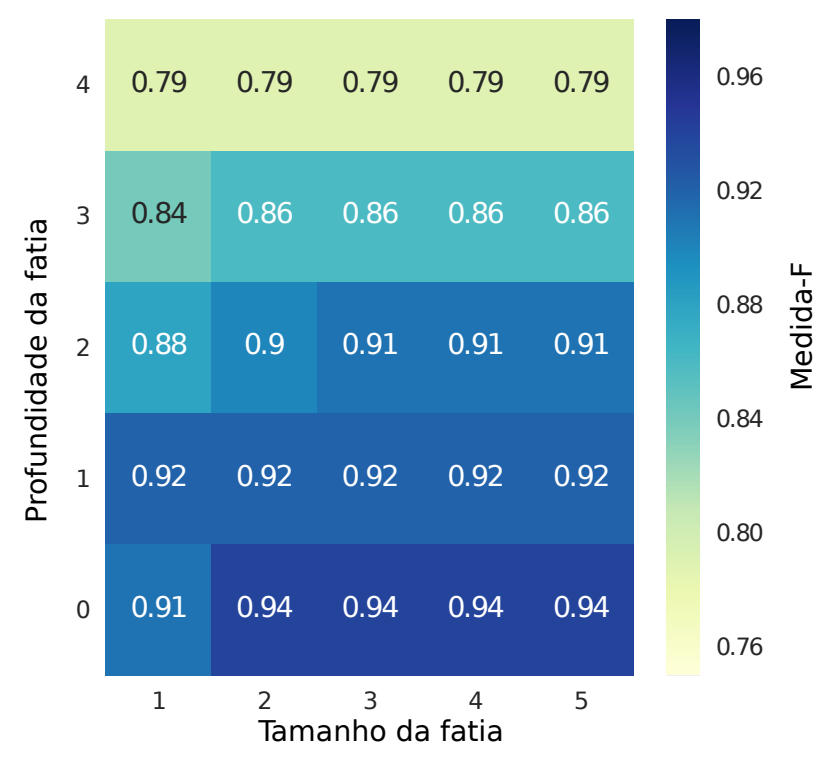

neurônios de indivíduos adultos machos pertencentes ao arquivos Lee_LJ e Henckens do repositório Neuromorpho, esses arquivos fornecem informações do diâmetro, profundidade e angulo dos neurônios. Por outro lado a região à qual pertencem os neurônios também foi reduzida, somente neurônios da região pré-frontal do neocortex foram escolhidos, especificamente aqueles pertencentes às regiões pré-límbica, camada 2-3 e região média. $\mathrm{O}$ protocolo usado na geração da reconstrução digital foi in vitro e a mancha de Golgi foi usada na coloração dos mesmos. Um total de 112 neurônios para cada uma das espécies, rato e camundongo, foram eleitos. Na Figura 4.12 podem ser observadas algumas das reconstruções de neurônios das duas espécies analisadas neste experimento. 
Figura 4.12: Representação gráfica de neurônios escolhidos aleatoriamente das classes (a) camundongo e (b) rato envolvidas neste experimento.

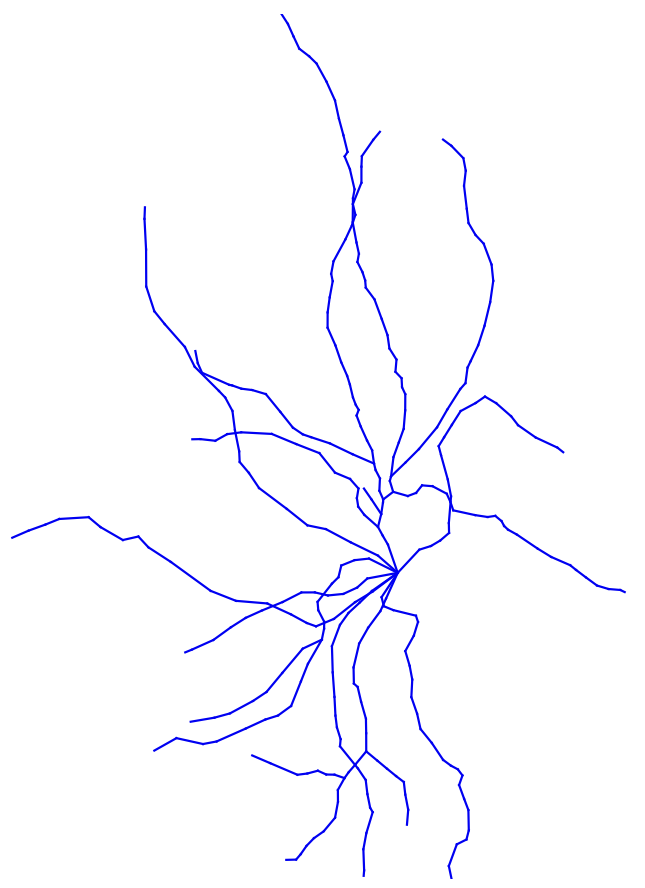

(a)

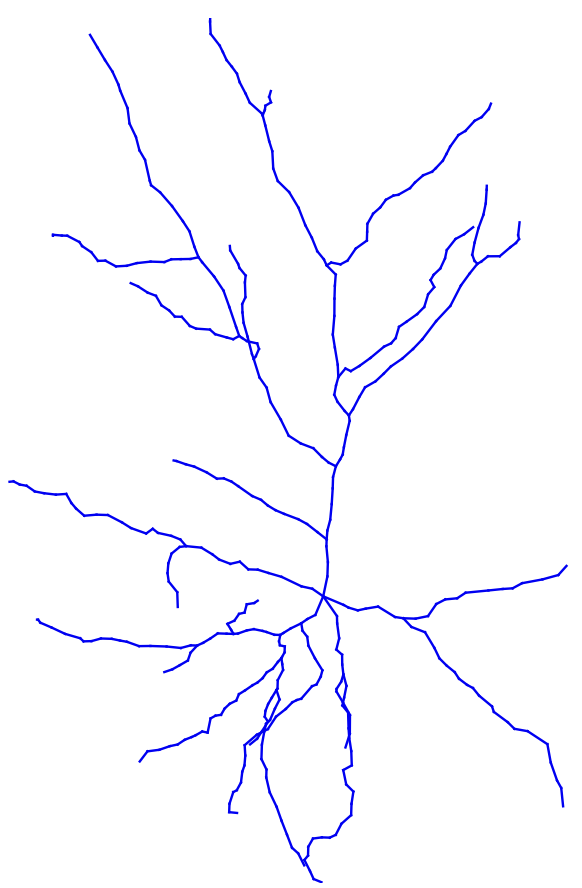

(b)

Na Tabela 4.6 é apresentada a média e desvio padrão de cada uma das 22 medidas usadas como características neste experimento. A tabela mostra medidas características de cada classe. As características de tamanho mostram que os neurônios de rato são maiores enquanto as de camundongo têm mais ramos principais e ângulos de bifurcações maiores. 
Tabela 4.6: Média e desvio padrão das medidas usadas como características as duas classes consideradas no experimento 6.

\begin{tabular}{|c|c|c|}
\hline Medida & $\begin{array}{c}\text { Rato } \\
\text { média (desvio p.) }\end{array}$ & $\begin{array}{l}\text { Camundongo } \\
\text { média (desvio p.) }\end{array}$ \\
\hline Área de superfície de soma & $26488,82(14266,63)$ & $14475,12(10812,07)$ \\
\hline Número de ramos principais & $1,03(0,16)$ & $3,78(2,76)$ \\
\hline Número de bifurcações & $17,71(5,23)$ & $10,23(4,44)$ \\
\hline Número de ramos & $36,46(10,43)$ & $24,24(9,70)$ \\
\hline Largura neuronal & $190,50(69,42)$ & $144,72(51,12)$ \\
\hline Altura neuronal & $326,84(90,74)$ & $254,21(88,50)$ \\
\hline Profundidade neuronal & $109,27(31,09)$ & $40,84(17,73)$ \\
\hline Diâmetro & $1,19(0,21)$ & $0,77(0,15)$ \\
\hline Comprimento da árvore & $2038,77(579,36)$ & $1214,03(496,64)$ \\
\hline Área da árvore & $8464,74(2230,32)$ & $3048,97(1246,51)$ \\
\hline Volume da árvore & $9267,72(3932,09)$ & $4000,46(2762,76)$ \\
\hline Distância euclidiana & $361,84(84,29)$ & $235,64(98,54)$ \\
\hline Distância do caminho máximo & $424,68(92,91)$ & $280,36(115,65)$ \\
\hline Ordem de ramificação & $8,38(2,12)$ & $4,57(2,25)$ \\
\hline Tamanho médio dos ramos & $56,84(11,04)$ & $51,68(13,16)$ \\
\hline Contração & $0,91(0,02)$ & $0,90(0,03)$ \\
\hline Fragmentação & $689,15(230,94)$ & $272,54(110,82)$ \\
\hline Assimetria topológica & $0,54(0,10)$ & $0,52(0,16)$ \\
\hline Rall Power & $2,55(0,54)$ & $1,36(1,06)$ \\
\hline Ângulo de bifurcação local & $70,97(8,80)$ & $75,79(11,22)$ \\
\hline Ângulo de bifurcação remota & $58,35(7,84)$ & $62,59(13,01)$ \\
\hline Dimensão fractal & $1,03(0,01)$ & $1,03(0,01)$ \\
\hline
\end{tabular}


Figura 4.13: PCA das medidas dos neurônios das espécies rato e camundongo envolvidas no teste do Experimento 6.

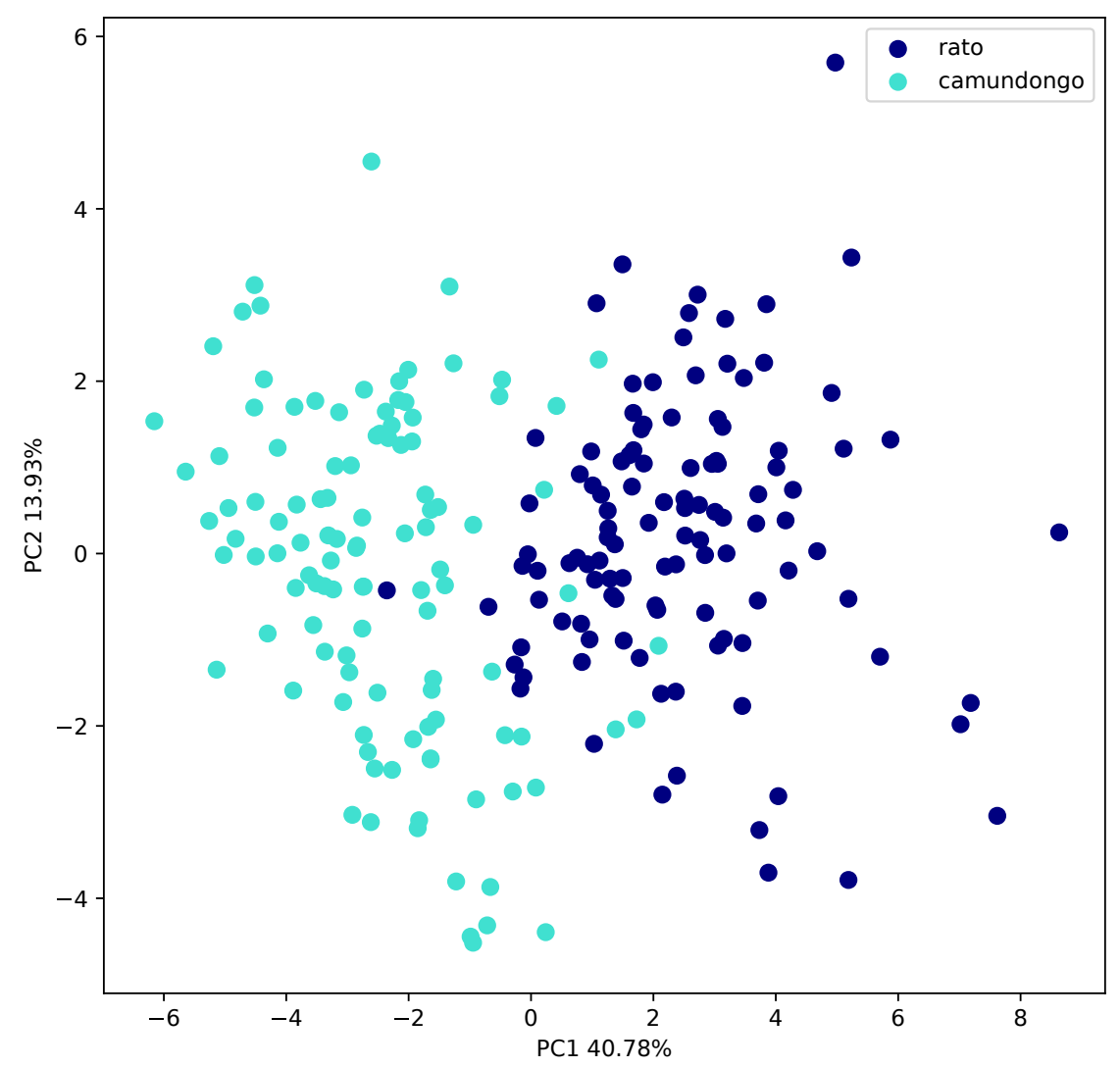

Na Figura 4.13 é mostrado o PCA das duas classes em duas dimensões, é possível notar que cada classe ocupa uma região específica do gráfico, mas existem também uma região com uma leve sobreposição de ambas classes. Para complementar este gráfico, a Tabela 4.7 são apresentados os pesos que o PCA atribui a cada medida fornecida. Pode-se observar que as medidas relacionadas com o tamanho possuem pesos maiores entre elas a área da árvore, comprimento da árvore, distância do caminho máximo e distância euclidiana.

Na Figura 4.14 são apresentados os resultados da classificação baseada no método de decomposição por fatias. Neste experimento foram utilizados neurônios principais piramidais, 112 neurônios para cada uma das espécies. O eixo $x$ mostra o tamanho da fatia e o eixo y mostra a profundidade da fatia em relação à raiz da árvore dendrítica. No gráfico são apresentados os resultados para profundidades entre 0 e 9, e tamanhos de fatias entre 1 e 11. Esses resultados confirmam o resultado obtido no experimento 5 no qual ramos de baixa ordem parecem ser mais relevantes para classificar os neurônios. 
Tabela 4.7: A tabela contém informações do peso de cada um dos três componentes principais (na primeira coluna) os pesos maiores estão relacionados com medidas vinculadas ao tamanho do neurônio.

\begin{tabular}{|l|r|r|r|}
\hline Explicação de variância & $41 \%$ & $14 \%$ & $8 \%$ \\
\hline Área de superfície de soma & 0,20 & $-0,10$ & 0,35 \\
Número de ramos principais & $-0,18$ & 0,13 & 0,06 \\
Número de bifurcações & 0,25 & 0,32 & $-0,18$ \\
Número de ramos & 0,22 & 0,36 & $-0,18$ \\
Largura neuronal & 0,19 & 0,04 & 0,00 \\
Altura neuronal & 0,23 & $-0,26$ & 0,13 \\
Profundidade neuronal & 0,25 & 0,09 & 0,03 \\
Diâmetro & 0,21 & $-0,09$ & 0,10 \\
Comprimento da árvore & 0,28 & 0,20 & $-0,04$ \\
Área da árvore & 0,31 & 0,10 & 0,05 \\
Volume da árvore & $-0,25$ & $-0,05$ & 0,30 \\
Distância Euclidiana & $-0,09$ & 0,15 & 0,25 \\
Distância do caminho máximo & 0,28 & $-0,22$ & 0,11 \\
Ordem de ramificação & 0,26 & 0,12 & $-0,13$ \\
Tamanho médio dos ramos & 0,14 & $-0,31$ & 0,24 \\
Contração & 0,09 & $-0,33$ & $-0,45$ \\
Fragmentação & 0,27 & 0,26 & $-0,03$ \\
Assimetria topológica & 0,05 & $-0,12$ & $-0,04$ \\
Rall Power & 0,16 & 0,18 & $-0,13$ \\
\hline Aimensão fractal & 0,25 & 0,09 \\
\hline
\end{tabular}

Para complementar o resultado apresentado na Figura 4.14, a média e desvio padrão de todas as medidas morfológicas usadas foram calculadas separadas por fatias (fatia 1 
de $0-8$ e fatia 2 de 4-12). Os valores obtidos são apresentados na Tabela 4.8. Observando estes resultados podemos notar que as medidas mais relevantes são aquelas diretamente relacionadas ao diâmetro dos dendritos.

Figura 4.14: Média da medida-F da classificação entre neurônios das espécies rato e camundongo. A acurácia é alta na maioria dos casos especialmente naquelas envolvendo ramos de hierarquias baixas, isto é, ramos mais próximos do corpo celular o soma

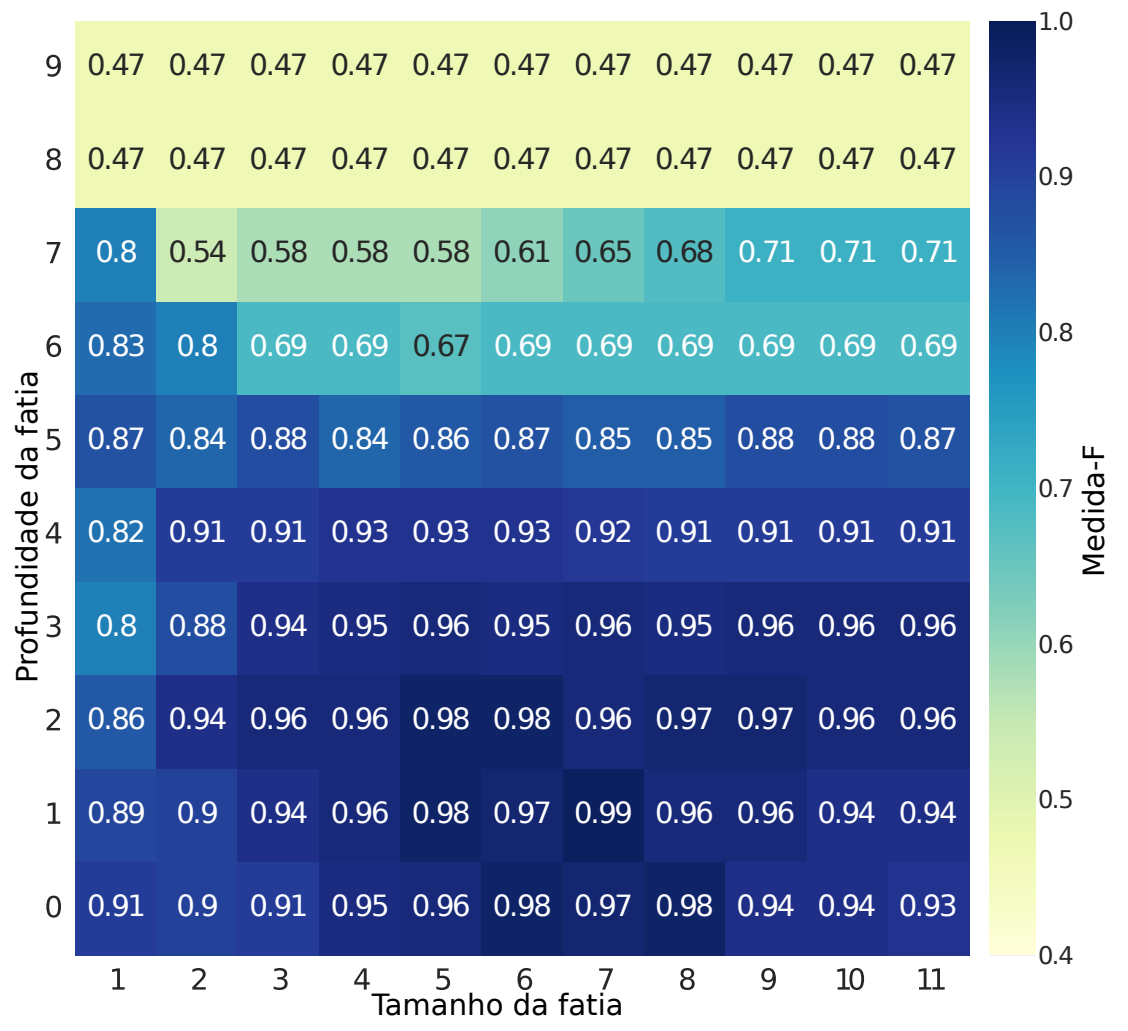


Tabela 4.8: Tabela comparativa das medidas usadas no Experimento 6, no qual foram contempladas fatias entre 0-8 e 4-12. São mostradas as médias e desvio padrão de todas as medidas para cada uma das classes em estudo.

\begin{tabular}{|c|c|c|c|c|}
\hline \multirow[b]{2}{*}{ Medidas } & \multicolumn{2}{|c|}{ Fatia $0-8$} & \multicolumn{2}{|c|}{ Fatia 4-12 } \\
\hline & $\begin{array}{c}\text { Rato } \\
\text { média(desvio p.) }\end{array}$ & $\begin{array}{l}\text { Camundongo } \\
\text { média(desvio p.) }\end{array}$ & $\begin{array}{c}\text { Rato } \\
\text { média(desvio p.) }\end{array}$ & $\begin{array}{l}\text { Camundongo } \\
\text { média(desvio p.) }\end{array}$ \\
\hline Área de superfície de soma & $14475.12(10812.07)$ & $26488.82(14266.63)$ & $12363.18(10653.21)$ & $26488.82(14266.63)$ \\
\hline Número de ramos principais & $3.78(2.76)$ & $1.03(0.16)$ & $3.13(1.8)$ & $4.7(1.87)$ \\
\hline Número de bifurcações & $10.01(4.16)$ & $15.91(4.1)$ & $3.41(2.78)$ & $10.7(5.09)$ \\
\hline Número de ramos & $23.79(9.34)$ & $32.85(8.17)$ & $9.94(5.99)$ & $26.09(10.46)$ \\
\hline Largura neuronal & $143.8(50.34)$ & $182.47(65.59)$ & $98.32(57.32)$ & $178.74(69.09)$ \\
\hline Altura neuronal & $252.21(85.74)$ & $304.69(77.29)$ & $211.08(116.26)$ & $310.86(84.52)$ \\
\hline Profundidade neuronal & $40.57(17.49)$ & $107.2(30.91)$ & $31.37(18.95)$ & $100.2(32.44)$ \\
\hline Diâmetro & $0.77(0.15)$ & $1.23(0.22)$ & $1.42(1.03)$ & $1.15(0.22)$ \\
\hline Comprimento da árvore & $1189.01(471.55)$ & $1822.8(495.46)$ & $769.99(477.22)$ & $2094.47(682.38)$ \\
\hline Área da árvore & $3001.15(1197.17)$ & $7875.18(1973.1)$ & $2070.93(1086.77)$ & $8373.26(2347.49)$ \\
\hline Volume da árvore & $3992.96(2761.85)$ & $9125.51(3816.68)$ & $3294.7(2669.53)$ & $8871.53(3741.29)$ \\
\hline Distância euclideana & $233.71(96.12)$ & $339.74(75.27)$ & $235.31(115.64)$ & $358.72(81.41)$ \\
\hline Distância do caminho máximo & $277.1(110.63)$ & $396.4(81.46)$ & $266.38(132.07)$ & $408.57(87.32)$ \\
\hline Ordem de ramificação & $4.42(1.87)$ & $7.39(0.98)$ & $1.78(1.97)$ & $4.32(1.95)$ \\
\hline Tamanho médio dos ramos & $51.61(13.09)$ & $56.24(11.47)$ & $82.67(40.12)$ & $87.56(33.7)$ \\
\hline Contração & $0.9(0.03)$ & $0.91(0.02)$ & $0.93(0.04)$ & $0.91(0.02)$ \\
\hline Fragmentação & $267.38(105.74)$ & $613.17(192.76)$ & $96.71(71.12)$ & $510.44(222.83)$ \\
\hline Assimetria topológica & $0.51(0.15)$ & $0.53(0.09)$ & $0.68(0.25)$ & $0.5(0.14)$ \\
\hline Rall Power & $1.36(1.06)$ & $2.54(0.54)$ & $0.03(0.21)$ & $2.54(1.01)$ \\
\hline Ângulo de bifurcação local & $75.91(11.24)$ & $71.28(8.81)$ & $38.67(31.36)$ & $67.36(16.47)$ \\
\hline Ângulo de bifurcação remota & $62.8(13.06)$ & $59.49(9.05)$ & $37.01(31.72)$ & $52.43(13)$ \\
\hline Dimensão fractal & $1.03(0.01)$ & $1.03(0.01)$ & $1.01(0.12)$ & $1.03(0.01)$ \\
\hline
\end{tabular}

\subsection{Experimento 7: Classificação baseada em fatias} na região neocortical.

Para concluir a parte experimental uma nova bateria de experimentos foi realizada, limitando o conjunto de dados ainda mais. Este experimento foi realizado unicamente na espécie rato, com a finalidade de homogeneizar ainda mais nosso conjunto de dados foram escolhidas apenas reconstruções de neurônios fornecidas por um único laboratório, 
tais reconstruções pertencem ao arquivo Allen Cell. Todos os neurônios usados pertencem à região neocortical de ratos adultos. Segundo o Neuromorpho.Org estes neurônios têm no domínio estrutural os dendritos, soma e axônios incompletos dos quais eles fornecem medidas como diâmetro, profundidade e ângulo. Neste caso os neurônios usados foram dos tipos piramidal e interneurônio. Para cada uma destas classes foram escolhidos 81 neurônios. Na Figura 4.15 são mostrados exemplos de reconstruções das classes envolvidas no experimento.

Figura 4.15: Representação gráfica de neurônios escolhidos aleatoriamente das classes (a) piramidal e (b) interneurônio envolvidas neste experimento.

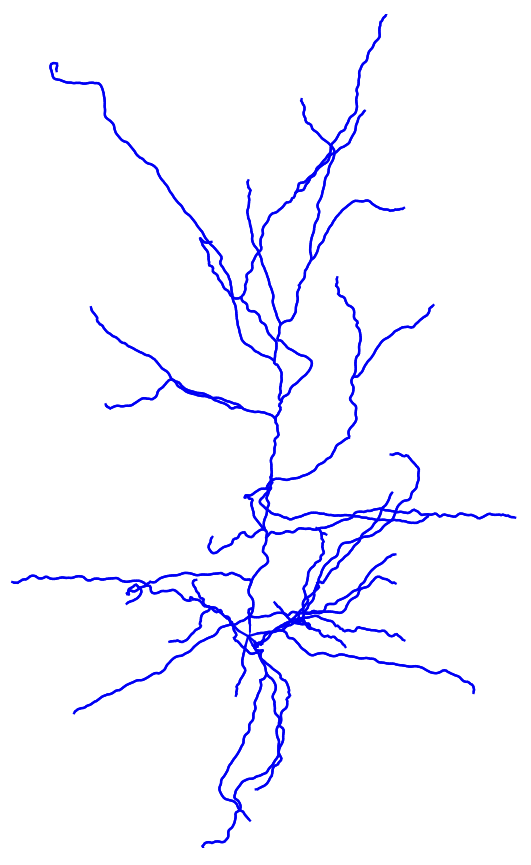

(a)

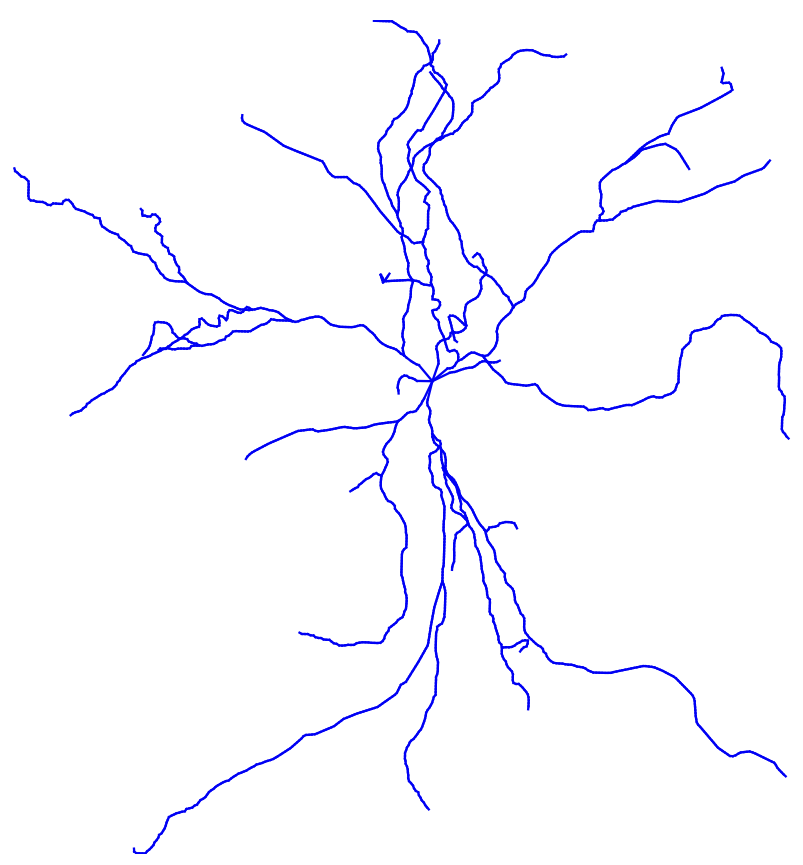

(b)

Na Tabela 4.9 é apresentada a média e desvio padrão das medidas usadas neste experimento. Neste caso as medidas mostram que os interneurônios são maiores nas medidas relacionadas ao tamanho, enquanto algumas medidas como o número de ramos principais, diâmetro, contração ou ordem de ramificação são similares. 
Tabela 4.9: Média e desvio padrão das medidas usadas no experimento 7

\begin{tabular}{|c|c|c|}
\hline Medida & $\begin{array}{l}\text { Interneurônio } \\
\text { média( desvio p.) }\end{array}$ & $\begin{array}{c}\text { Piramidal } \\
\text { média ( desvio p.) }\end{array}$ \\
\hline Área de superfície de soma & $5868,97(2875,18)$ & $4730,00(6845,19)$ \\
\hline Número de ramos principais & $7,52(2,01)$ & $6,94(1,63)$ \\
\hline Número de bifurcações & $27,11(7,25)$ & $45,70(68,44)$ \\
\hline Número de ramos & $61,74(14,96)$ & $87,60(125,14)$ \\
\hline Largura neuronal & $228,15(82,23)$ & $129,31(147,05)$ \\
\hline Altura neuronal & $467,79(160,02)$ & $254,17(216,54)$ \\
\hline Profundidade neuronal & $64,22(22,42)$ & $62,22(32,26)$ \\
\hline Diâmetro & $0,50(0,10)$ & $0,44(0,11)$ \\
\hline Comprimento da árvore & $3109,22(412,59)$ & $3050,35(4695,95)$ \\
\hline Área da árvore & $5239,43(1236,00)$ & $4329,28(4728,70)$ \\
\hline Volume da árvore & $2207,79(754,48)$ & $1464,12(2069,94)$ \\
\hline Distância euclidiana & $447,76(135,66)$ & $172,86(177,35)$ \\
\hline Distância do caminho máximo & $502,17(141,92)$ & $322,12(341,21)$ \\
\hline Ordem de ramificação & $8,46(3,57)$ & $8,41(9,61)$ \\
\hline Tamanho médio dos ramos & $52,54(11,84)$ & $45,53(21,37)$ \\
\hline Contração & $0,89(0,03)$ & $0,87(0,05)$ \\
\hline Fragmentação & $2621,40(344,88)$ & $2706,16(3989,14)$ \\
\hline Assimetria topológica & $0,49(0,11)$ & $0,53(0,10)$ \\
\hline Rall Power & $2,31(0,44)$ & $0,91(0,80)$ \\
\hline Ângulo de bifurcação local & $74,00(7,32)$ & $72,47(22,44)$ \\
\hline Ângulo de bifurcação remota & $68,53(8,96)$ & $57,50(26,40)$ \\
\hline Dimensão fractal & $1,03(0,01)$ & $1,05(0,02)$ \\
\hline
\end{tabular}

Por outro lado observando o PCA mostrado na Figura 4.16 podemos observar a região ocupada por cada classe e uma região de sobreposição.

Foi executado o mesmo procedimento dos experimentos anteriores, extração de medi- 
Figura 4.16: Representação gráfica de neurônios escolhidos aleatoriamente das classes (a) piramidal e (b) interneurônio envolvidas neste experimento.

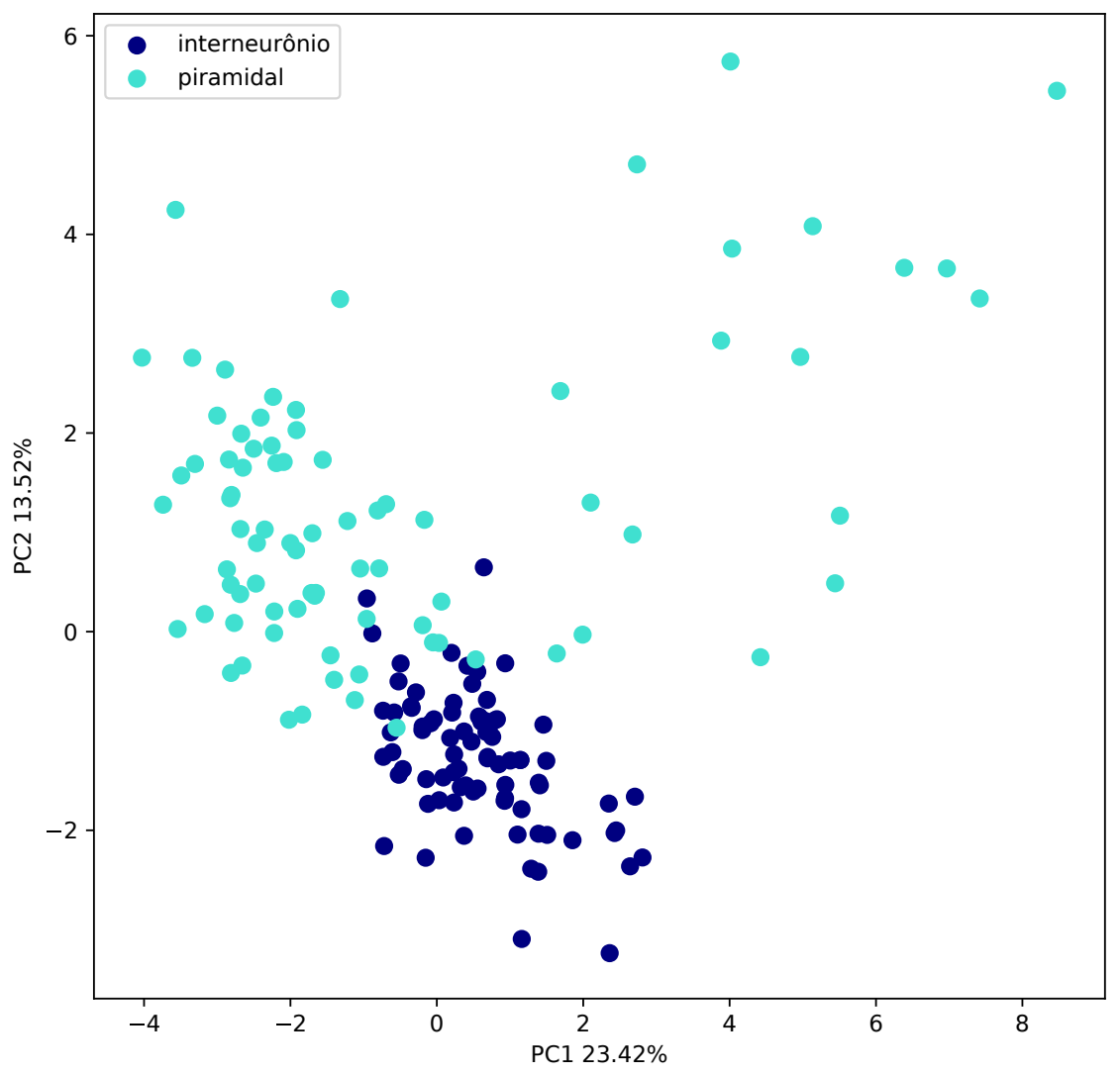

das morfológicas, normalização e classificação e os resultados são apresentados na Figura 4.17 em formato de mapa de calor da medida-F. A figura mostra a importância de ambos, profundidade e tamanho das fatias observadas.

Observando a figura pode-se notar que os maiores valores de medida-F estão localizados na região inferior direita o qual indica que fatias de tamanhos maiores a 6 tendem a apresentar melhores resultados enquanto fatias envolvendo ramos de hierarquias mais baixas apresentam menor medida-F implicando assim que nos primeiros níveis de hierarquias estão inserindo algum tipo de ambiguidade na classificação diminuindo a acurácia.

Este comportamento foi observado em vários testes com características similares a esse em que ambos os tipos de neurônios possuem morfologia muito semelhante nos primeiros níveis hierárquicos enquanto que níveis mais altos na hierarquia apresentam morfologia diferente. Também é possível observar que níveis ainda mais altos na hierarquia das árvores não contribuem para melhorar a classificação.

Na tabela 4.10 é apresentada a média e desvio padrão das medidas obtidas para os 
Figura 4.17: Média da medida-F para o experimento considerando unicamente a espécie rato, em que foram comparadas as classes de neurônios piramidais e interneurônios da região do neocortex de ratos adultos. Os maiores valores de medida-F estão localizados na região inferior direita indicando que fatias de tamanhos maiores a 6 tendem a apresentar melhores resultados enquanto fatias envolvendo ramos de hierarquias mais baixas apresentam menor medida-F. Isto acontece possivelmente por causa da semelhança entre ambas as classes nas hierarquias mais baixas.

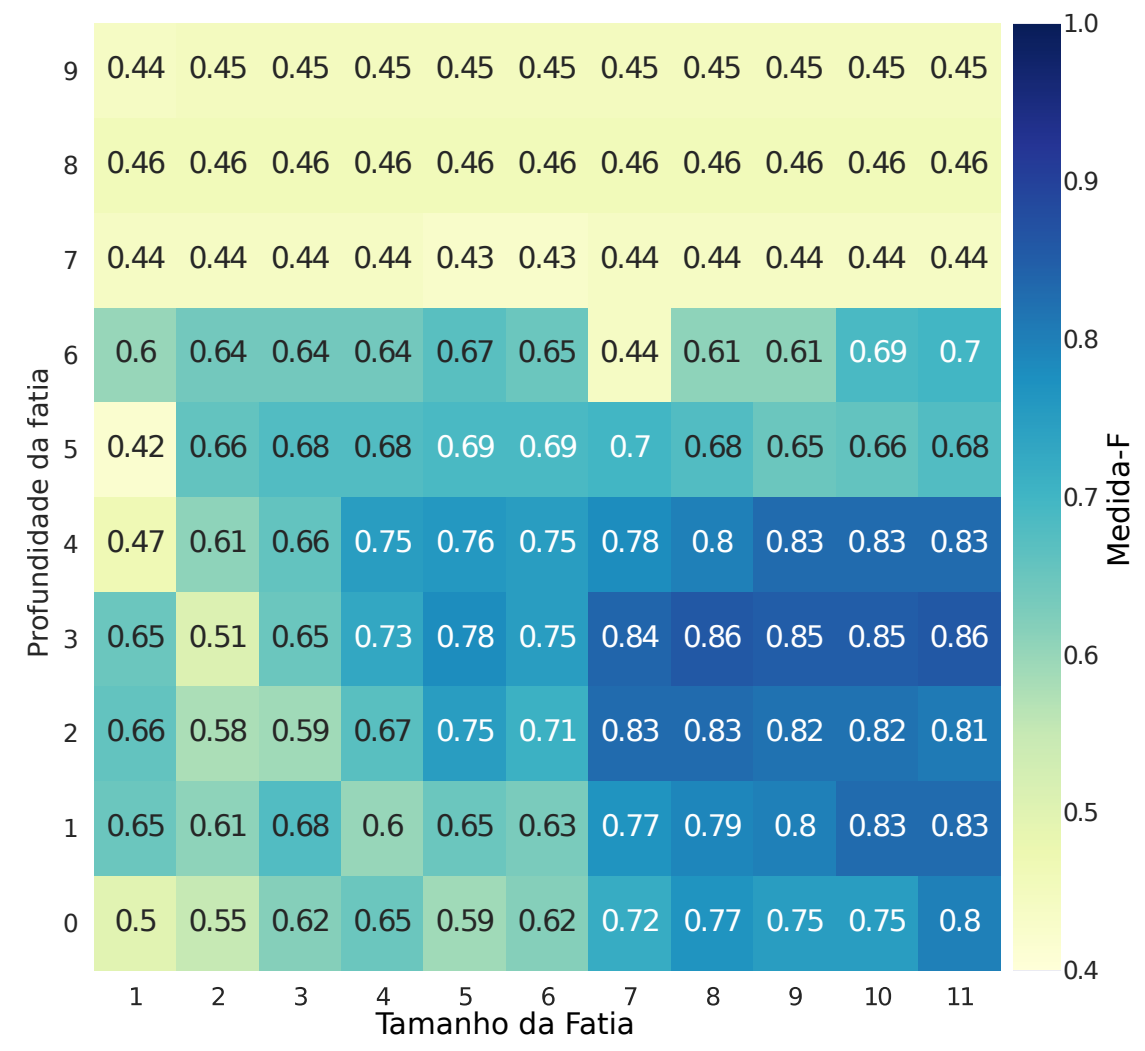

intervalos entre 0 e 6 , e 3 e 12. A tabela mostra que as medidas mais discriminativas são aquelas diretamente relacionadas com o tamanho dos dendritos, a distância de caminho e a distância euclideana.

Para entender melhor os resultados do Experimento 7 foi realizado um experimento complementar seguindo a mesma sequência de passos, desta vez foram considerados apenas os dendritos basais de ambas as classes. O resultado deste experimento complementar é apresentado na Figura 4.18. O resultado mostra a acurácia baixa do classificador esse comportamento se deve ao fato dos neurônios basais de ambas as classes serem muito semelhantes. No conjunto de neurônios escolhidos nem todos os neurônios têm dendritos apicais e basais. Além disso, os dendritos basais tendem a pertencer às hierarquias mais baixas se comparados com dendritos apicais. Por este motivo, as hierarquias baixas são menos relevantes que as hierarquias entre 3 e 12 apresentadas na Figura 4.17. 
Tabela 4.10: Tabela comparativa das medidas obtidas no Experimento 7 com fatias entre 0-6 e 3-12. A tabela mostra a média, desvio padrão para ambos os intervalos considerados.

\begin{tabular}{|c|c|c|c|c|}
\hline & \multicolumn{2}{|c|}{ Fatia 0-6 } & \multicolumn{2}{|c|}{ Fatia 3-12 } \\
\hline Medidas & $\begin{array}{l}\text { Interneurônio } \\
\text { média(desvio p.) }\end{array}$ & $\begin{array}{c}\text { Piramidal } \\
\text { média(desvio p.) }\end{array}$ & $\begin{array}{l}\text { Interneurônio } \\
\text { média(desvio p.) }\end{array}$ & $\begin{array}{c}\text { Piramidal } \\
\text { média(desvio p.) }\end{array}$ \\
\hline Área de superfície de soma & $529.4(265.86)$ & $463.39(155.71)$ & $529.4(265.86)$ & $463.39(155.71)$ \\
\hline Número de ramos principais & $6.04(1.6)$ & $6.5(1.96)$ & $9.28(5.39)$ & $9.7(4.83)$ \\
\hline Número de bifurcações & $22.28(11.5)$ & $25.43(7.4)$ & $7.52(9.5)$ & $10.29(5.2)$ \\
\hline Número de ramos & $50.6(23.11)$ & $57.35(15.28)$ & $24.32(22.27)$ & $30.27(12.82)$ \\
\hline Largura neuronal & $215.15(65.93)$ & $226.06(80.97)$ & $172.74(81.07)$ & $200.49(81.55)$ \\
\hline Altura neuronal & $331.59(103.73)$ & $396.71(137.05)$ & $278.72(135.12)$ & $418.24(140.92)$ \\
\hline Profundidade neuronal & $59.35(19.64)$ & $63.54(22.27)$ & $51.36(20.66)$ & $60.06(22.14)$ \\
\hline Diâmetro & $0.44(0.08)$ & $0.5(0.1)$ & $0.49(0.23)$ & $0.51(0.1)$ \\
\hline Comprimento da árvore & $2610.18(1037.56)$ & $2859.68(508.46)$ & $1806.68(1192.93)$ & $2146.62(626.02)$ \\
\hline Área da árvore & $4062.34(1844.32)$ & $4849.14(1103.72)$ & $2896.51(1856.69)$ & $3709.44(1117.7)$ \\
\hline Volume da árvore & $2319.53(1799.94)$ & $2152.27(734.97)$ & $2147.76(1771.26)$ & $1942.49(716.26)$ \\
\hline Distância euclidiana & $266.99(94.36)$ & $377.89(116.39)$ & $256.09(108.66)$ & $414.22(121.86)$ \\
\hline Distância do caminho máximo & $320.38(105.62)$ & $429.14(121.5)$ & $296.4(122.44)$ & $462.38(128.65)$ \\
\hline Ordem de ramificação & $5.17(1.63)$ & $7.26(1.73)$ & $2.33(2.08)$ & $4.9(2.57)$ \\
\hline Tamanho médio dos ramos & $54.09(14.7)$ & $51.98(12.54)$ & $84.87(31.62)$ & $76.76(26.43)$ \\
\hline Contração & $0.88(0.05)$ & $0.89(0.03)$ & $0.89(0.04)$ & $0.89(0.03)$ \\
\hline Fragmentação & $2227.73(951.17)$ & $2412.09(420.93)$ & $1091.49(846.97)$ & $1455.35(419.69)$ \\
\hline Assimetria topológica & $0.47(0.1)$ & $0.48(0.1)$ & $0.51(0.22)$ & $0.5(0.17)$ \\
\hline Rall Power & $2.31(0.47)$ & $2.32(0.47)$ & $1.67(1.16)$ & $2.23(0.84)$ \\
\hline Ângulo de bifurcação local & $74.54(8.86)$ & $73.86(6.95)$ & $65.26(31.43)$ & $70.85(12.31)$ \\
\hline Ângulo de bifurcação remota & $63.5(9.41)$ & $69.14(9.52)$ & $54.59(26.87)$ & $63.54(14.94)$ \\
\hline Dimensão fractal & $1.04(0.02)$ & $1.04(0.01)$ & $1.04(0.02)$ & $1.03(0.01)$ \\
\hline
\end{tabular}

Figura 4.18: Medidas-F médias obtidas após a classificação de neurônios piramidais e interneurônios das espécies de camundongos, considerando apenas os dendritos basais.

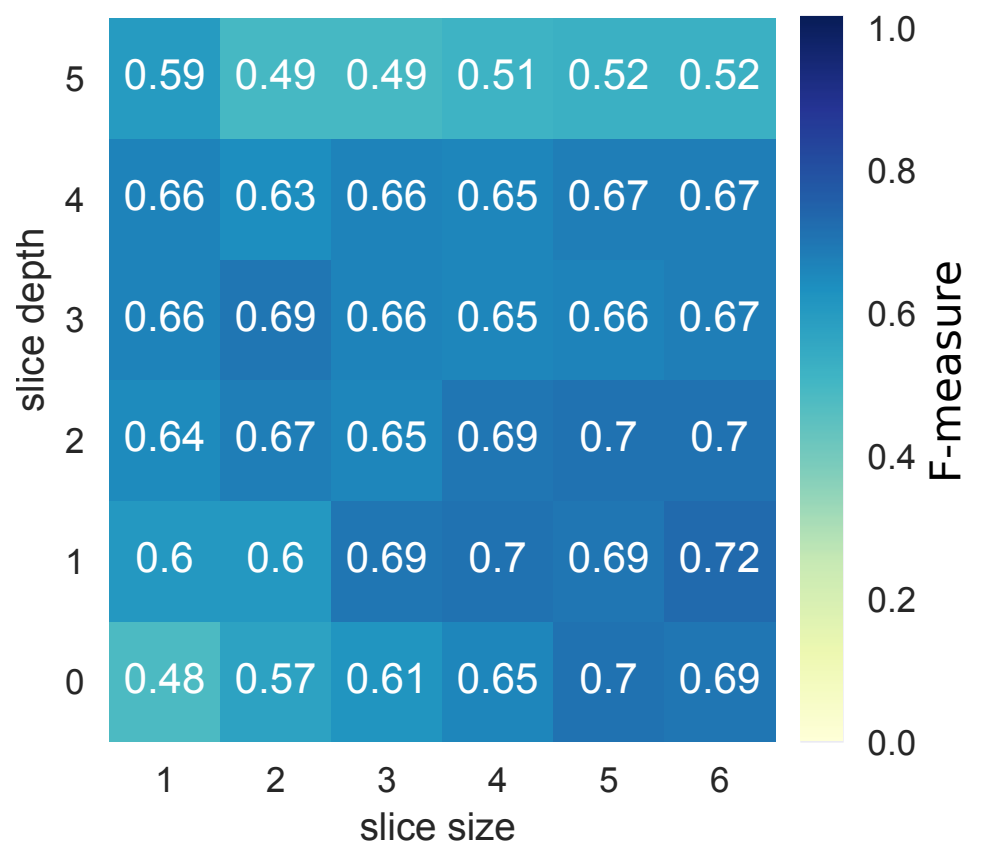




\section{Capítulo 5}

\section{Considerações finais}

\subsection{Conclusões}

A classificação de neurônios ainda é um problema desafiador, mas graças a certas iniciativas que fornecem cada vez mais informações, os trabalhos em neurociências que avançavam lentamente, estão sendo acelerados agora. Da mesma forma, pesquisas independentes usando suas próprias fontes e técnicas para extrair informações estão se beneficiando do compartilhamento de dados já previamente processados e padronizados. Finalmente, trabalhar com dados homogeneizados ajuda na replicação de testes e métodos. Na classificação supervisionada, uma rotulagem de classe padronizada e homogênea é essencial.

$\mathrm{Na}$ literatura, trabalhos como o nosso costumam considerar pequenas quantidades de dados, poucas classes, poucos neurônios e sempre utilizam o neurônio inteiro. Para a realização dos testes foi usado o banco de dados do Neuromorpho.Org, onde foram cuidadosamente selecionadas 10 das classes definidas nesse repositório, pertencentes a diferentes espécies, mais de 5.000 neurônios foram considerados nesse estudo.

Foi usada a ferramenta L-Measure para extrair medidas morfológicas dos neurônios as quais foram usadas para povoar os vetores de características. As características foram submetidas a um processo de eliminação iterativa, com a finalidade de escolher o número ótimo de características. O teste de controle da classificação morfológicas, foi realizado considerando 22 características morfológicas computadas sobre neurônios inteiros. 
No trabalho foi apresentado um método para caracterizar neurônios usando partes das árvores dendríticas em vez das respectivas células inteiras. Assim foram implementadas e analisadas quatro abordagens para decomposição do neurônio, baseadas em: ramos principais da árvore dendrítica, profundidade, altura e fatias da árvore dendrítica.

Os experimentos apresentados neste trabalho mostraram que é possível identificar partes relevantes, nas árvores dendríticas dos neurônios, para a classificação morfológica. Os resultados obtidos usando apenas ditas partes relevantes se mostraram equivalentes a aqueles obtidos usando os neurônios inteiros. Também foi possível determinar que os ramos mais próximos do soma fornecem informações mais discriminativa para a classificação do que os ramos mais afastados do soma.

Tanto os ramos principais como os ramos mais próximos do soma são os mais relevantes para a classificação. O mecanismo de aprendizado utilizado neste trabalho basicamente foca na identificação de padrões comuns intraclasse e padrões diferentes interclasse temos que resultados obtidos essencialmente mostram que os ramos pertencentes às hierarquias menores, e que são os primeiros a se desenvolver no neurônio, tendem a seguir um padrão comum dentro da mesma classe. Isto possivelmente acontece porque a morfologia inicial do neurônio está geneticamente predeterminada. Por outro lado, os ramos de hierarquias maiores se desenvolvem seguindo padrões menos específicos de cada classe de neurônio. Isto pode ser consequência da influência de factores externos ou ambientais. Portanto, estes últimos não contribuem melhorando a classificação.

Por outro, no experimentos envolvendo neurônios bastante semelhantes nos ramos de hierarquia baixa, o mecanismo de aprendizado foca nas fatias com tamanhos e profundidades que permitam distinguir mais claramente as classes de neurônios. Nestes casos específicos, embora os ramos principais e próximos do soma sejam relevantes, não fornecem informações relevantes para a classificação dado que eles tendem a ter uma diferença interclasse pequena. Este é o motivo pelo qual o resultado do experimento sete sugere que os ramos mais relevantes são os que pertencem a hierarquias superiores a três.

Finalmente, o desenvolvimento de dendritos obedece a mecanismos intrínsecos, extrínsecos, mecanismos dependentes de atividade e mecanismos dedicados que controlam 
a manutenção as árvores dendríticas [Dong et al., 2015, Lefebvre et al., 2015]. Neste trabalho, foram identificados claramente os padrões intraclasse. Estes padrões mostraram que nos ramos mais próximos do soma possuem algum tipo de padrão de crescimento específico de cada classe. Por outro lado os ramos mais distantes apresentam uma maior diversificação possivelmente causada por fatores extrínsecos dificultando a identificação de padrões neles.

\subsection{Trabalhos futuros}

A seguir apresentamos alguns possíveis caminhos para continuar esta pesquisa:

- Deverão ser considerados mais tipos neuronais ou ainda tipos neuronais mais específicos, incluindo diferentes espécies.

- Seria interessante investigar se existem partes relevantes das árvores dendríticas que sejam próprias de algumas classes.

- Utilização de outras ferramentas além da utilizada (L-measure) para cálculo de medidas morfológicas, para ampliar os vetores de características.

- Dado que os neurônios estão sendo armazenados como árvores, poderia ser incluída entre as características alguma medida de similaridade entre árvores.

- Neste trabalho, os neurônios estão sendo estudados como indivíduos isolados, ignorando o fato deles fazerem parte de circuitos neurais. Achamos que talvez poderia ser incluída alguma característica que permita definir a posição do neurônio no circuito.

- Utilização de novos classificadores e mais medidas morfológicas. 


\section{Apêndice A}

\section{Gráficos do PCA e do LDA do}

\section{experimento 3}

As imagens apresentadas a seguir são visualizações do Experimento 3. A seguir são apresentados os gráficos obtidos do PCA e LDA assim como uma imagem escolhida aleatoriamente de cada classe com sua árvore dendrítica segmentada até um determinado

nível de profundidade. É possível observar nos gráficos tanto do PCA quanto do LDA estabilizam depois da profundidade 6 e os níveis de profundidade maiores não causam grandes mudanças nos gráficos. Esses resultados podem ser observados também no seguinte link:

http://www.vision.ime.usp.br/ epcervantes/pca_lda/apical_basal/

Alguns resultados e testes adicionais podem ser observados no seguinte link:

http://www.vision.ime.usp.br/ epcervantes/pca_lda/_index.html 
Figura A.1: $P C A$ e LDA utilizando dendritos até a profundidade 0
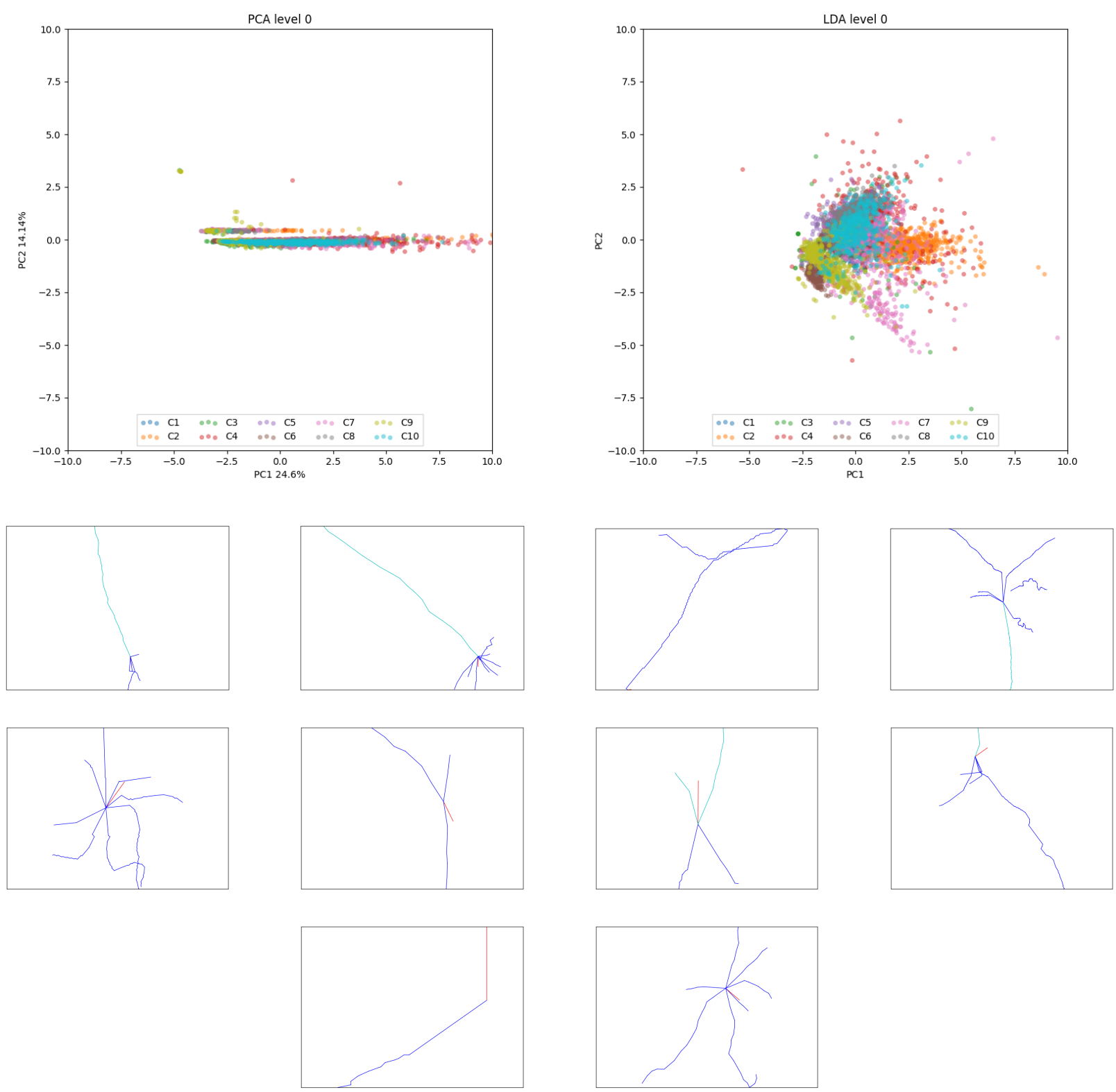
Figura A.2: $P C A$ e LDA utilizando dendritos até a profundidade 1
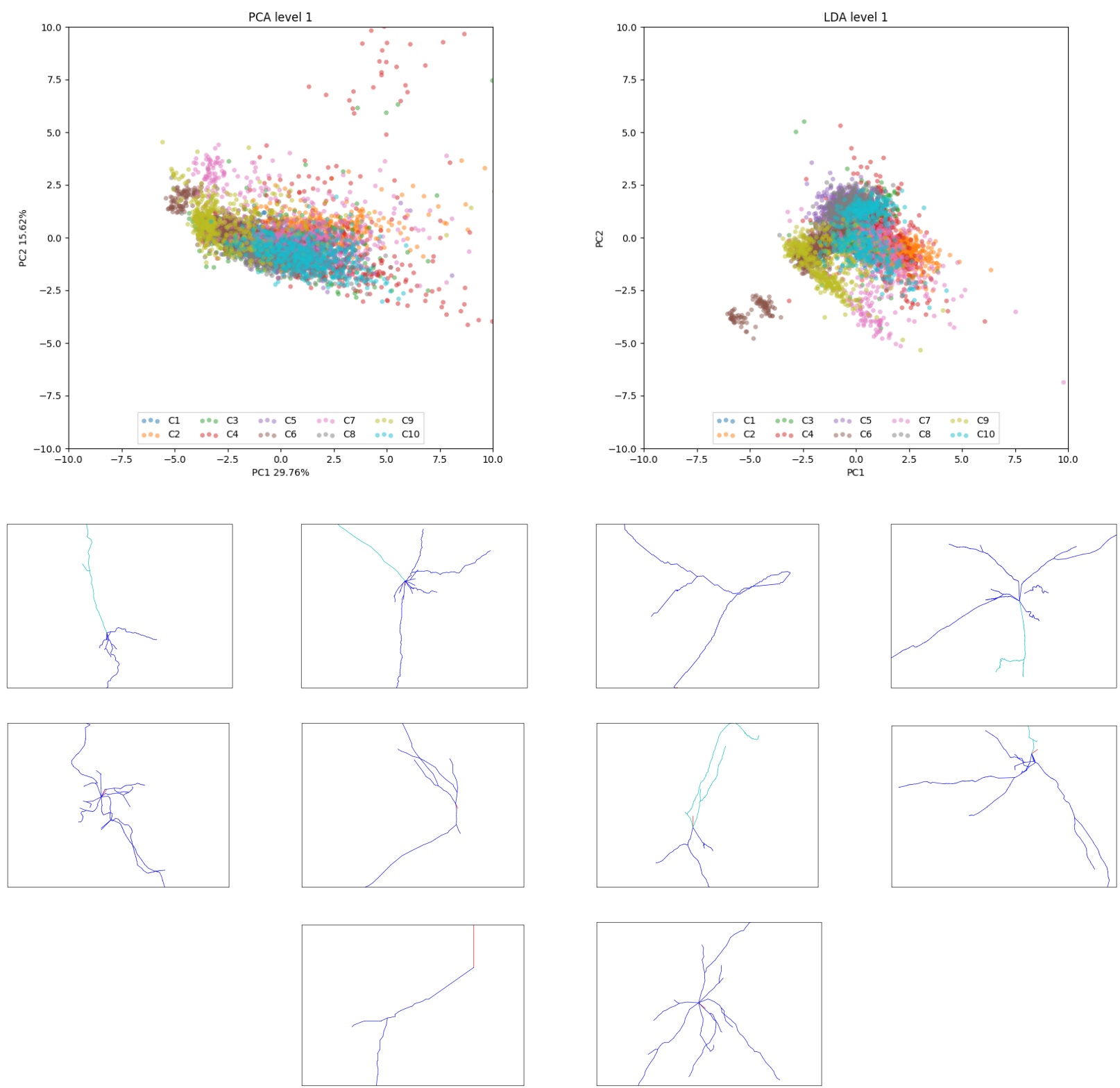
Figura A.3: PCA e LDA utilizando dendritos até a profundidade 2
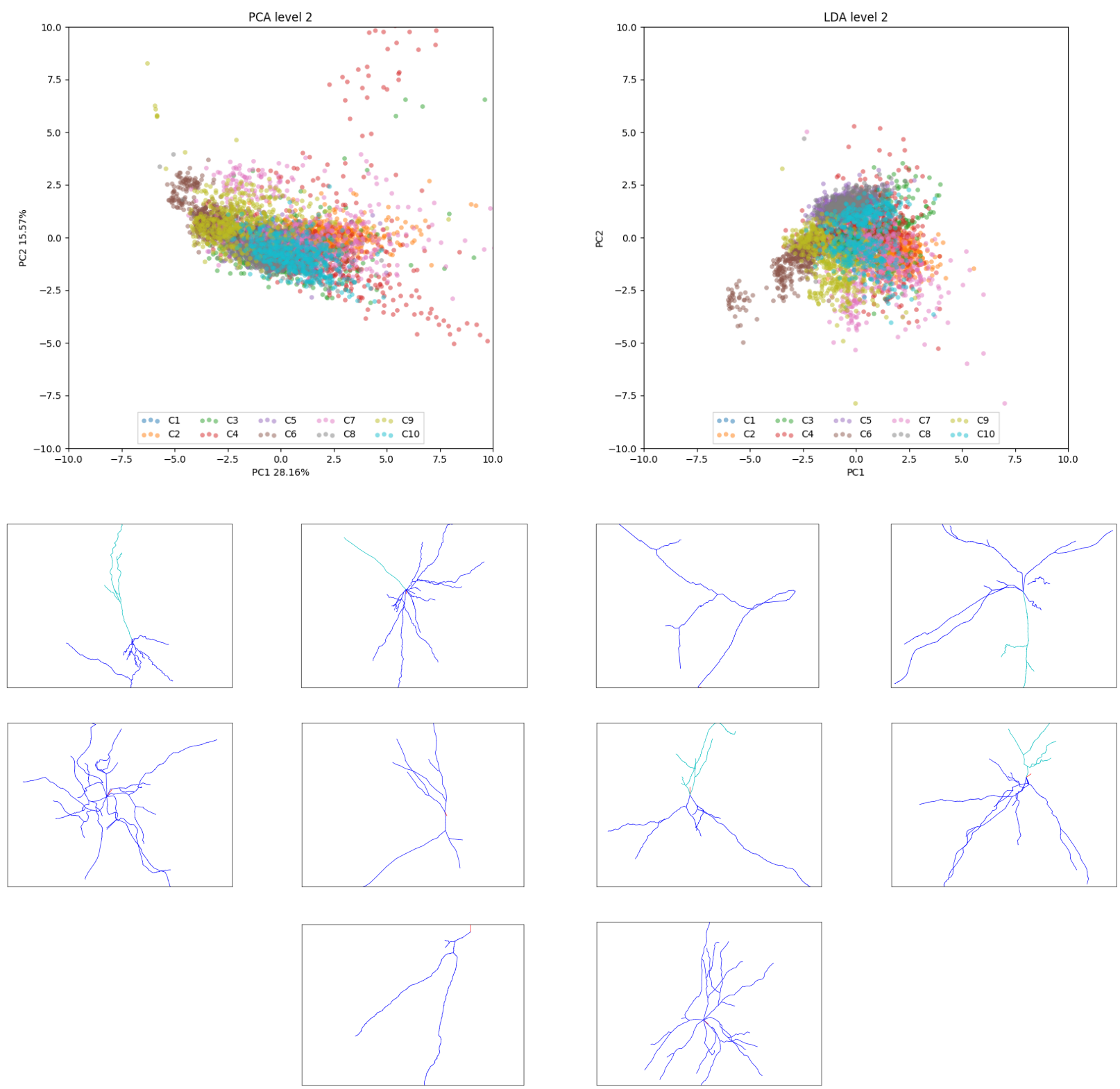
Figura A.4: $P C A$ e LDA utilizando dendritos até a profundidade 3
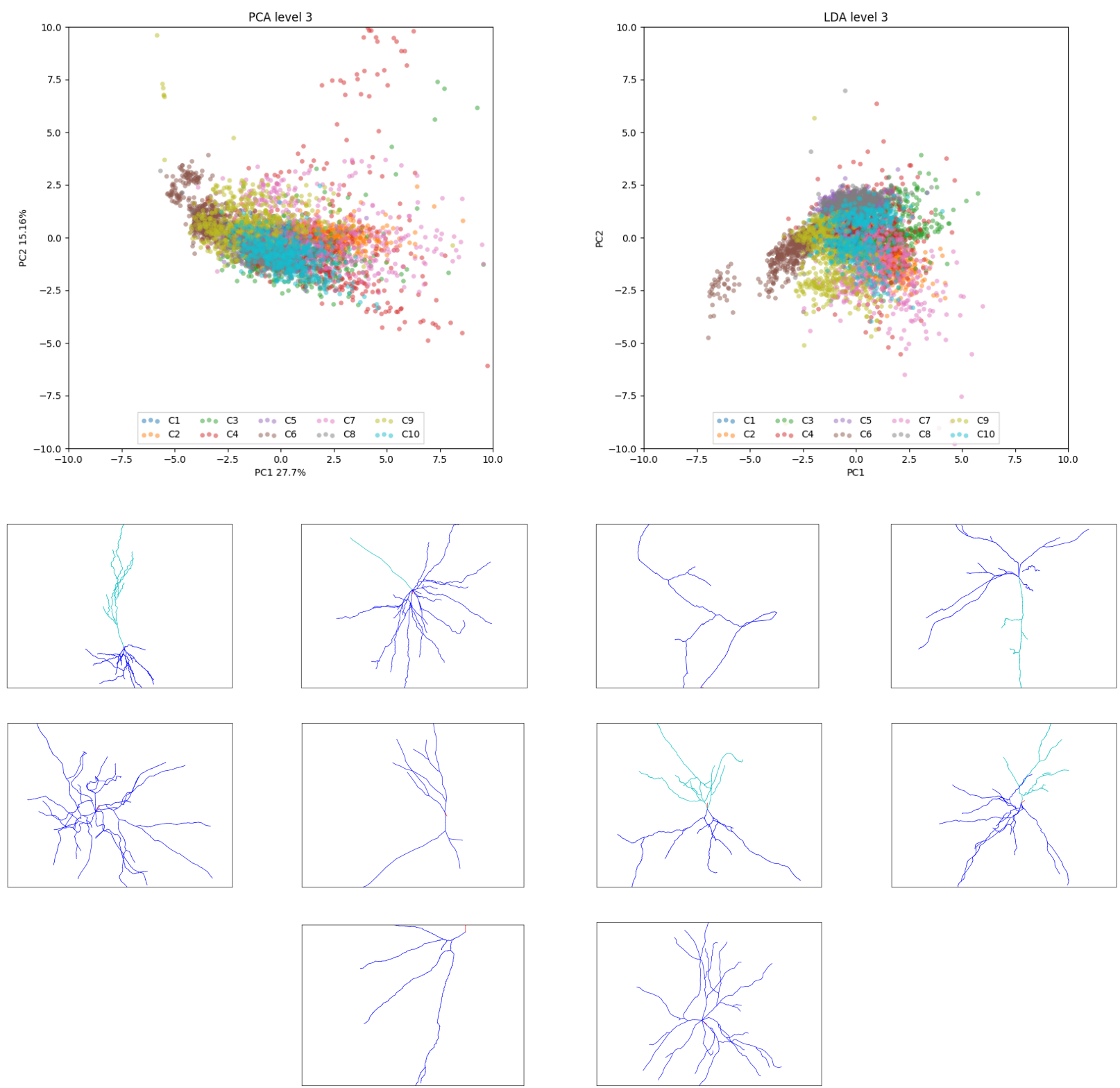
Figura A.5: $P C A$ e LDA utilizando dendritos até a profundidade 4
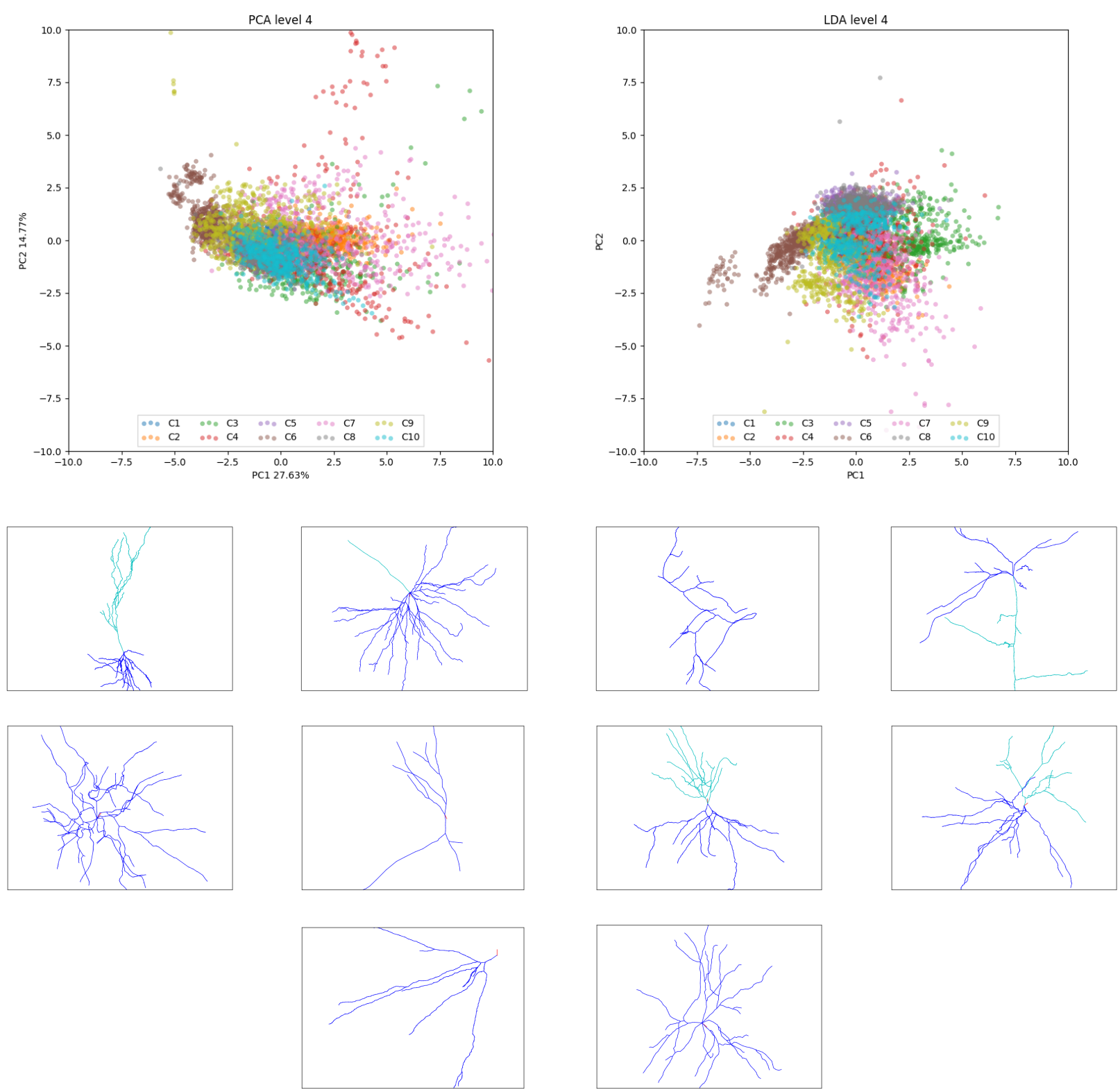
Figura A.6: $P C A$ e LDA utilizando dendritos até a profundidade 5
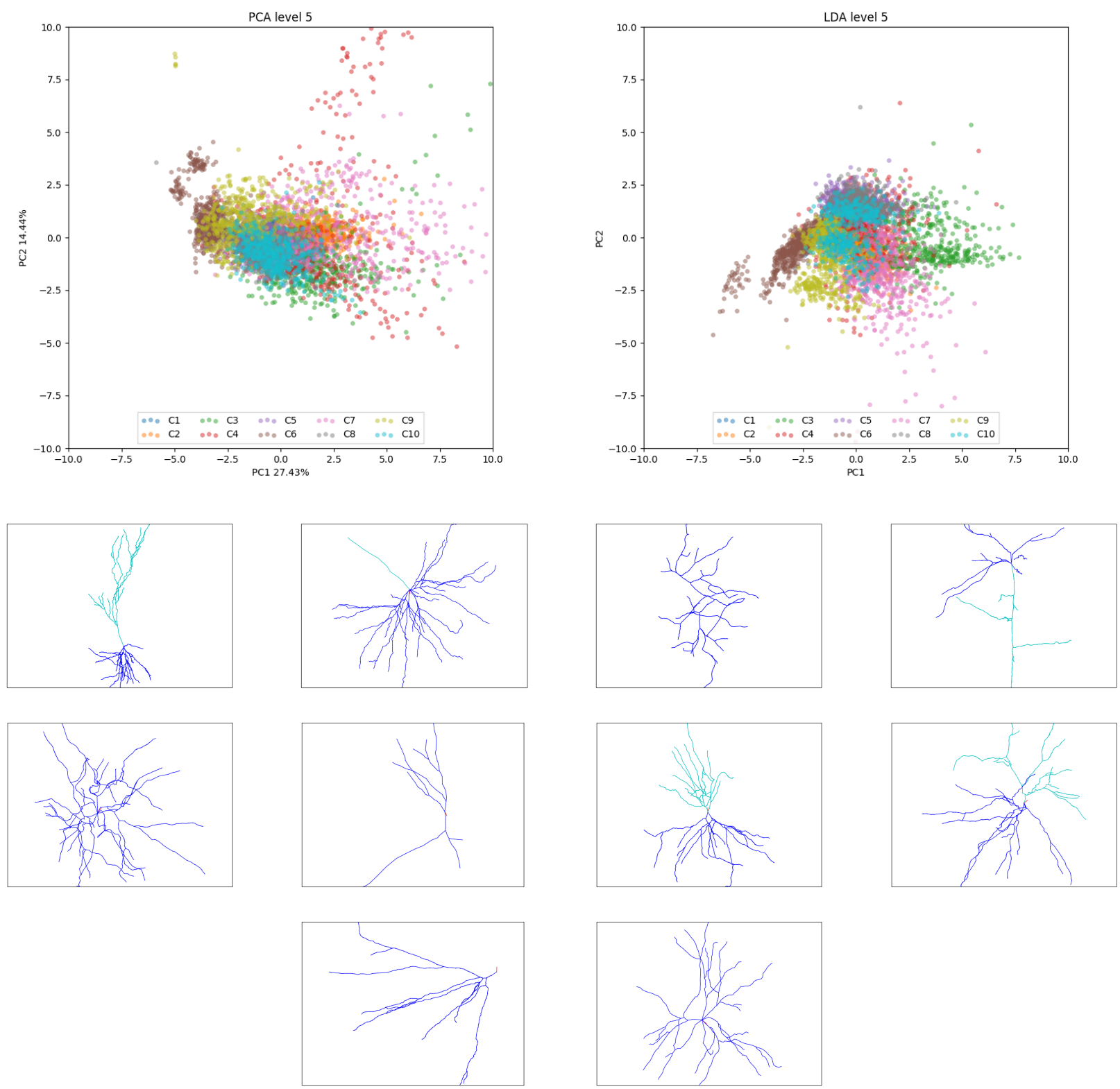
Figura A.7: PCA e LDA utilizando dendritos até a profundidade 6
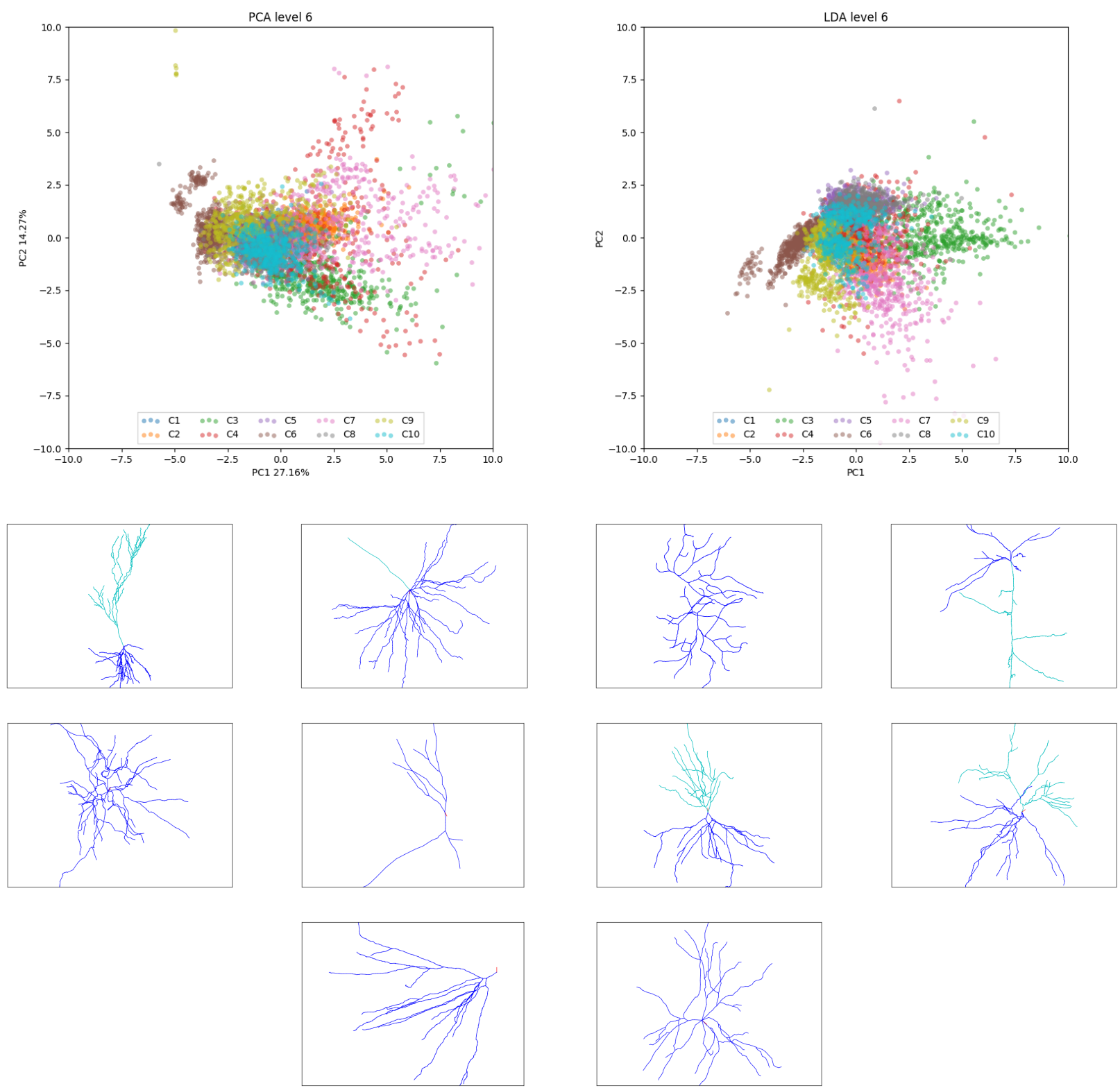
Figura A.8: $P C A$ e LDA utilizando dendritos até a profundidade 8
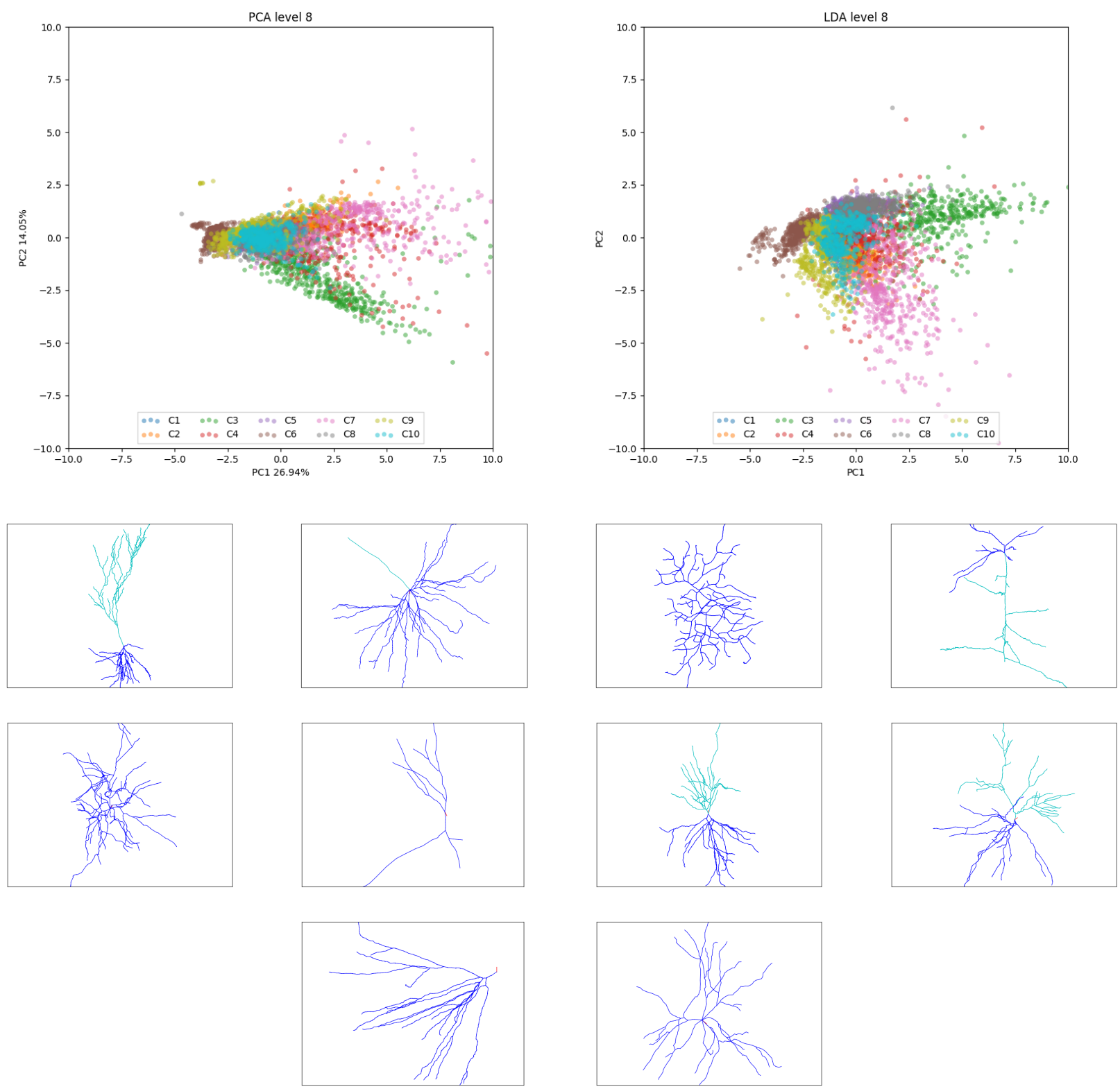
Figura A.9: PCA e LDA utilizando dendritos até a profundidade 10
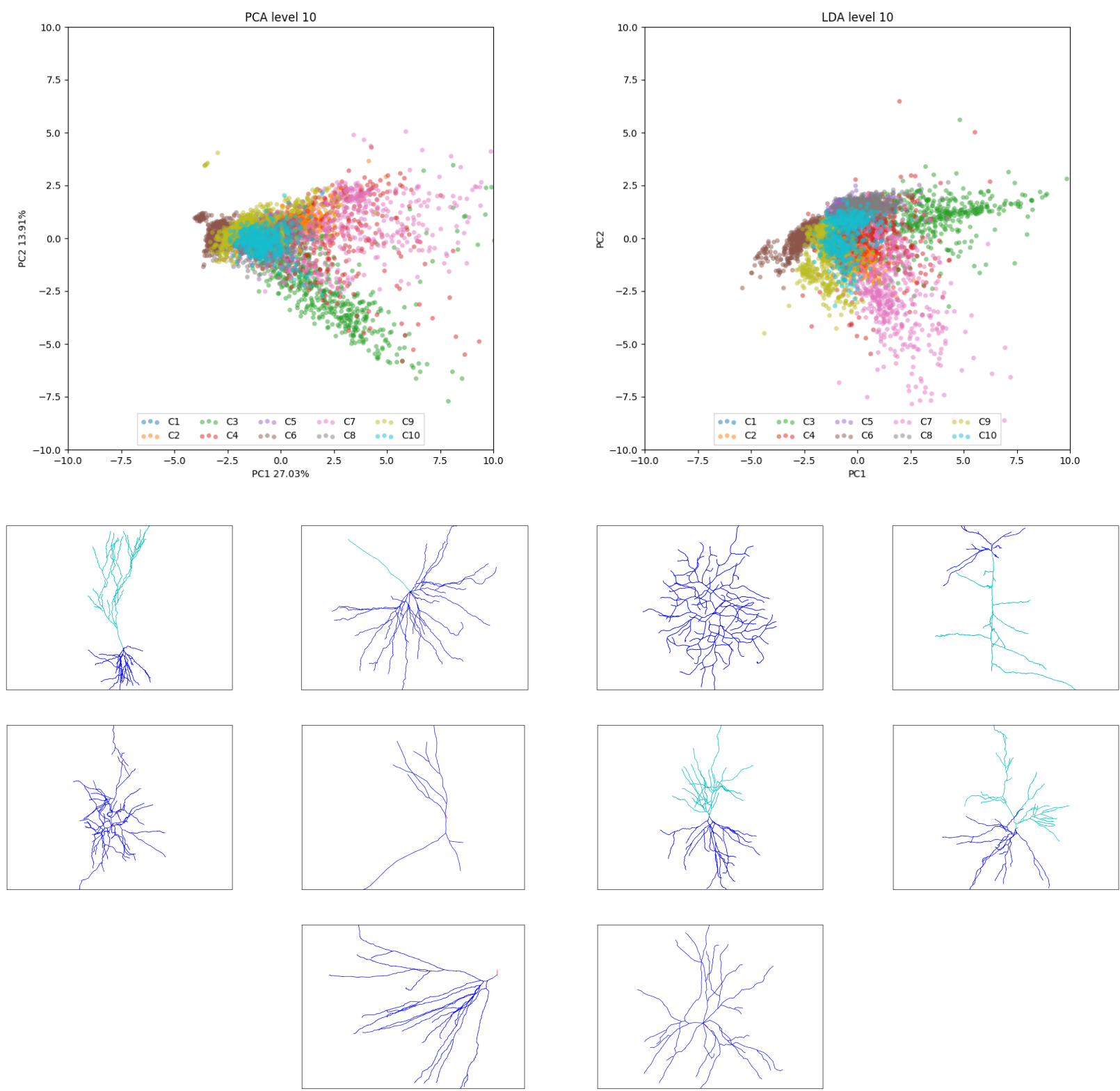
Figura A.10: $P C A$ e LDA utilizando dendritos até a profundidade 16
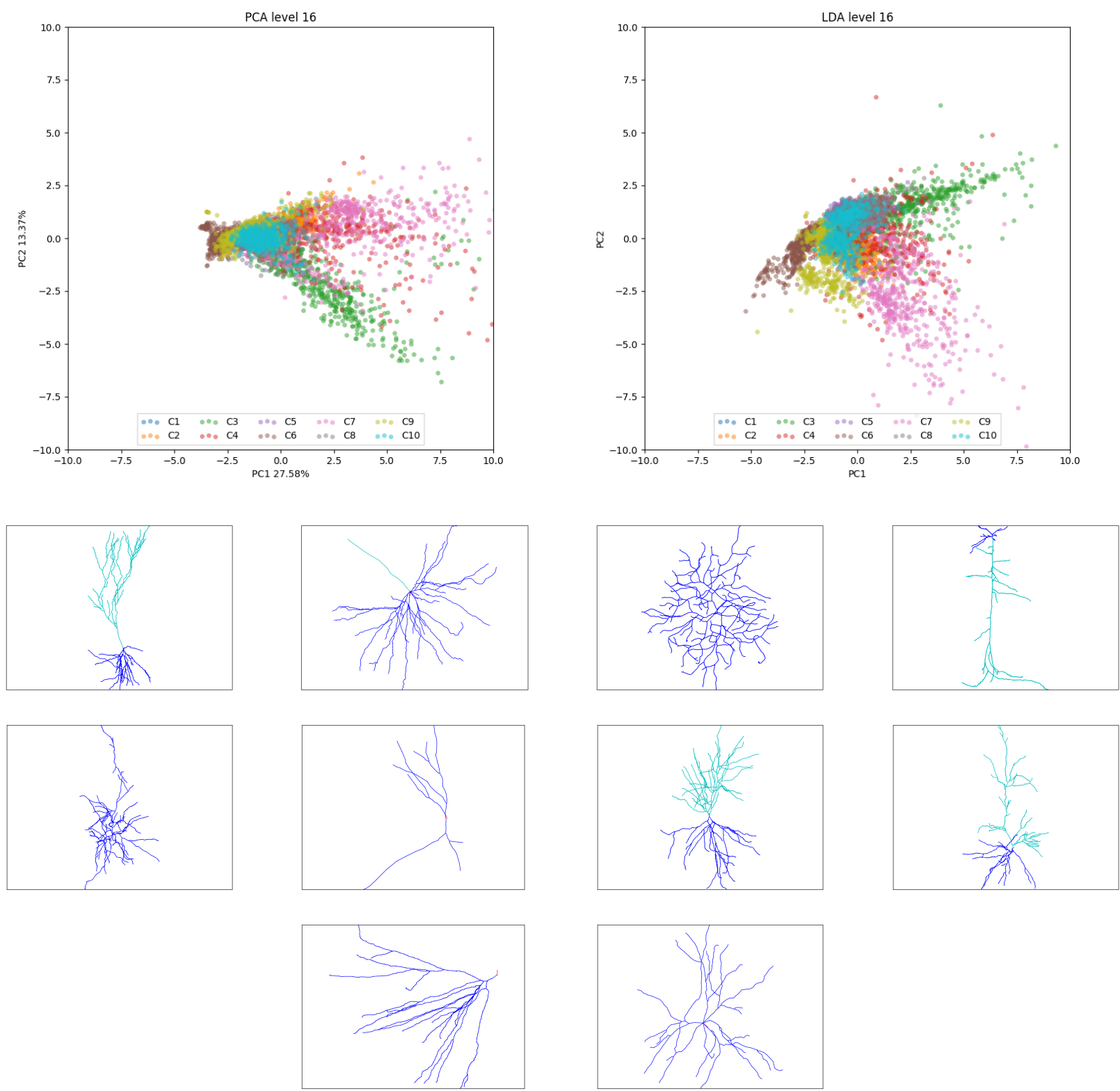
Figura A.11: $P C A$ e LDA utilizando dendritos até a profundidade 20
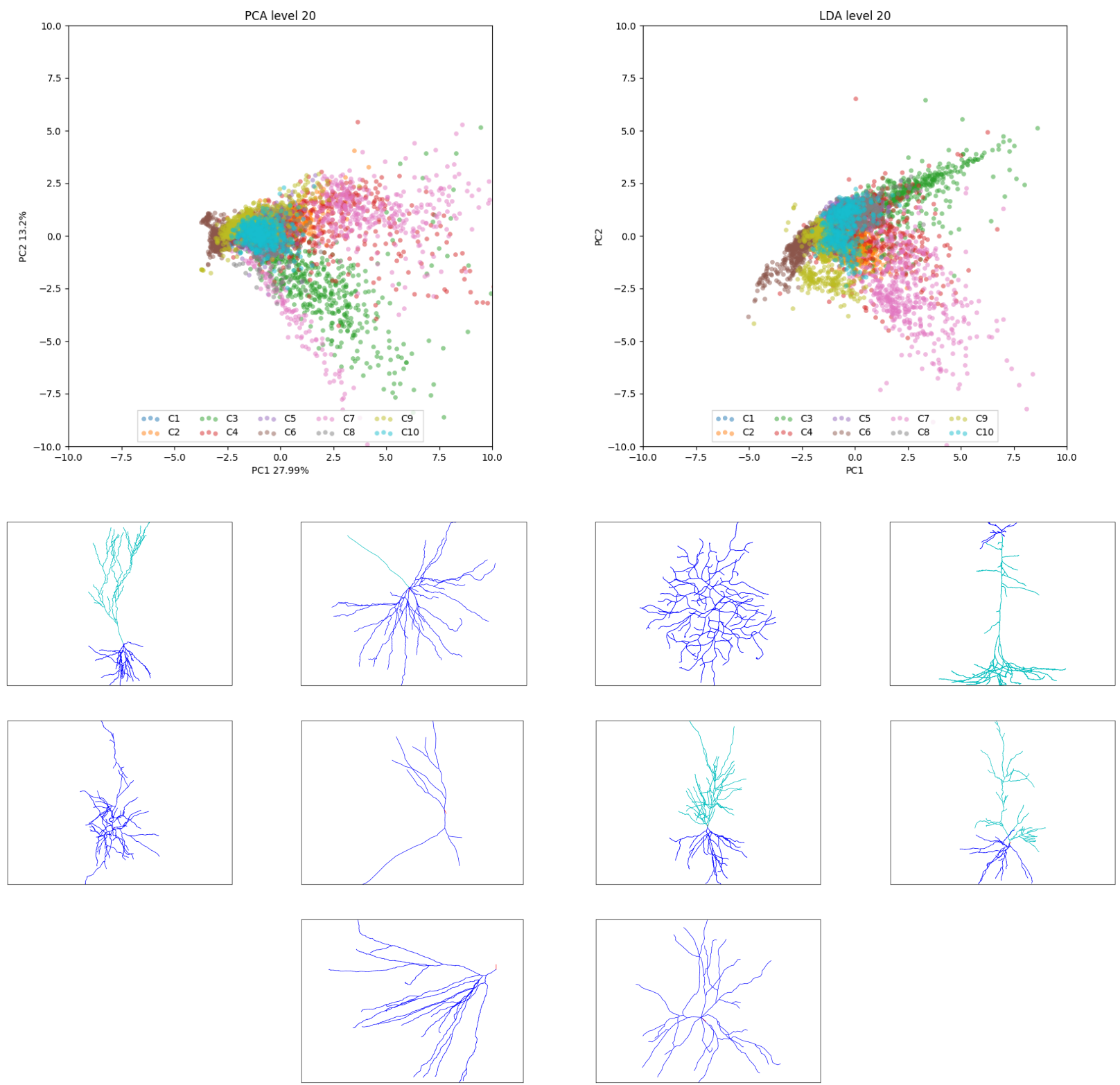


\section{Apêndice B}

\section{Gráficos do PCA e do LDA de dendritos apicais e basais}

Alguns outros testes foram realizados utilizando o conjuntos de dados de 10 classes. A seguir apresentamos as visualizações criadas aplicando o método de decomposição por profundidade. Neste o experimento foi feito em duas etapas, na primeira delas foram analisados somente dendritos apicais e na segunda etapa foram analisados somente dendritos basais. A seguir são apresentados os gráficos obtidos do PCA e LDA assim como uma imagem escolhida aleatoriamente de cada classe com sua árvore dendrítica segmentada até um determinado nível de profundidade.

Nas figuras B.1, B.2, B.3, B.4, B.5 é possível observar que tanto os gráficos do PCA quanto do LDA mudam somente nos três primeiros níveis de profundidade estabilizando depois disso. Mesmo assim os gráficos mostram grande sobreposição das classes. Todos os resultados deste experimento podem ser observados também no seguinte link: http://www.vision.ime.usp.br/ epcervantes/pca_lda/apical/

As Figuras B.6, B.7, B.8, B.9, B.10 correspondem aos experimentos realizados levando em conta somente dendrito basais. É possível observar que tanto os gráficos do PCA quanto do LDA mudam nos 8 primeiros níveis de profundidade estabilizando depois disso. Todas as visualizações deste experimento podem ser observados também no seguinte link: http://www.vision.ime.usp.br/ epcervantes/pca_lda/basal/ 
Figura B.1: PCA e LDA utilizando dendritos apicais até a profundidade 0
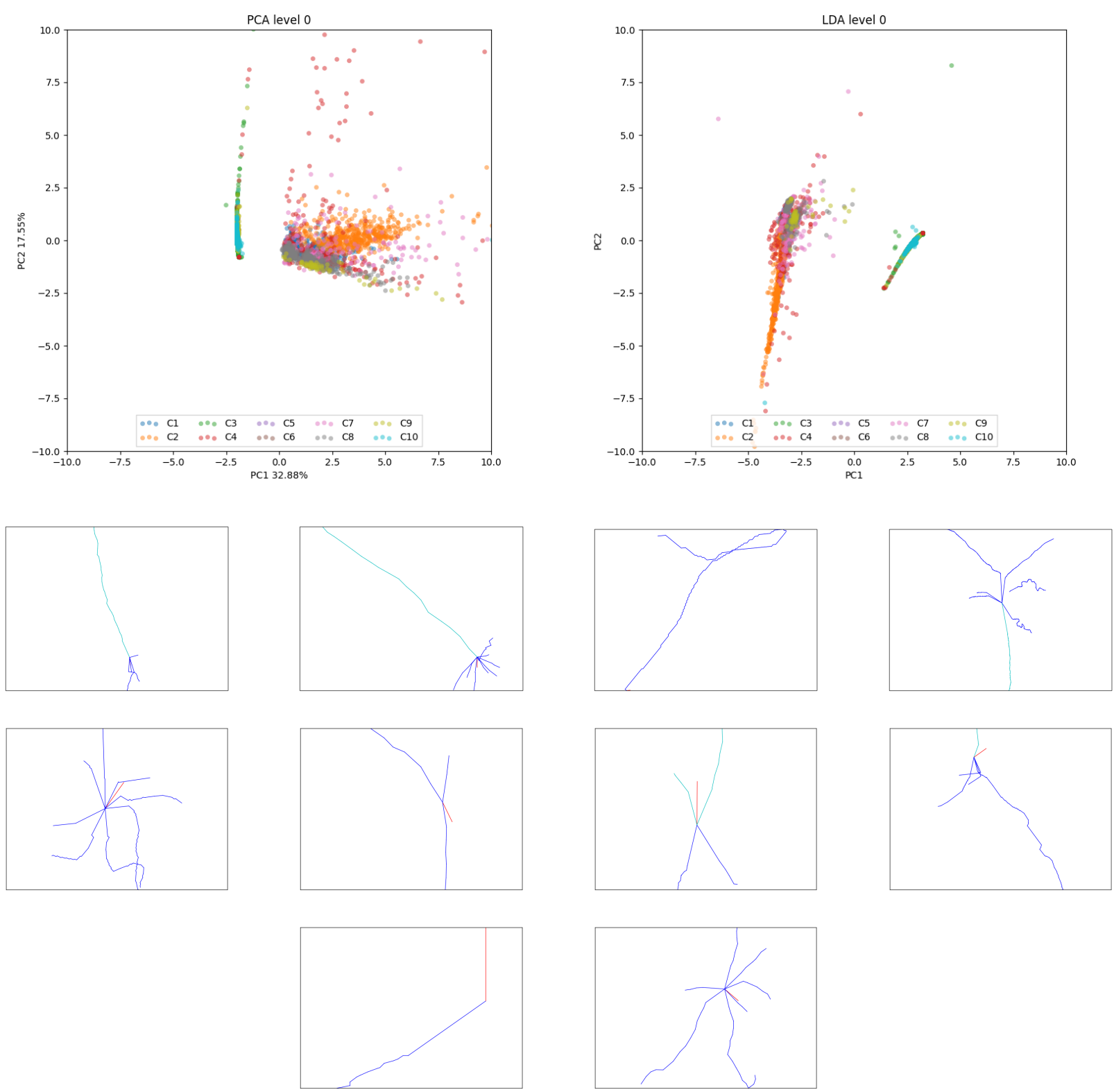
Figura B.2: PCA e LDA utilizando dendritos apicais até a profundidade 1
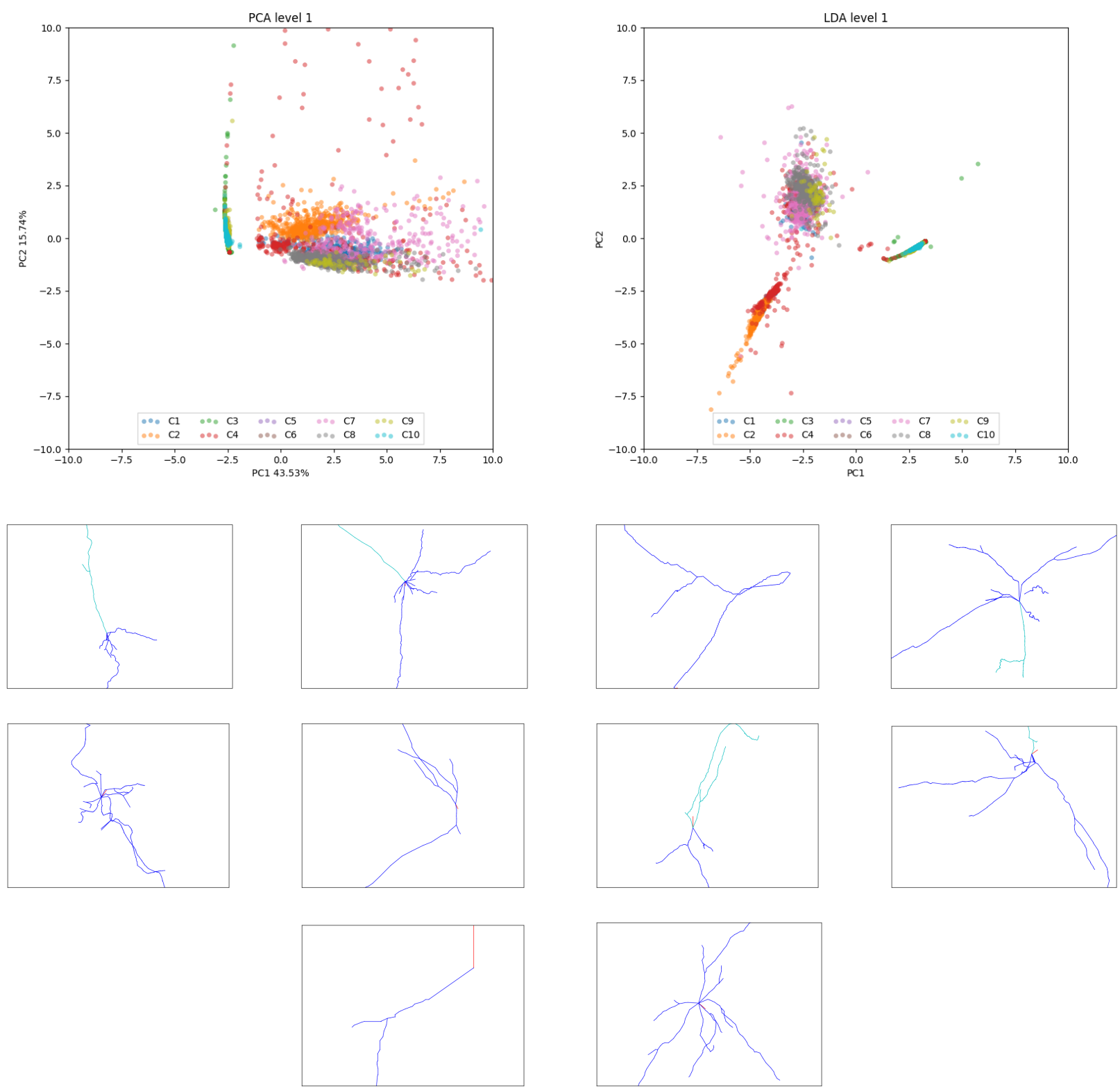
Figura B.3: PCA e LDA utilizando dendritos apicais até a profundidade 2
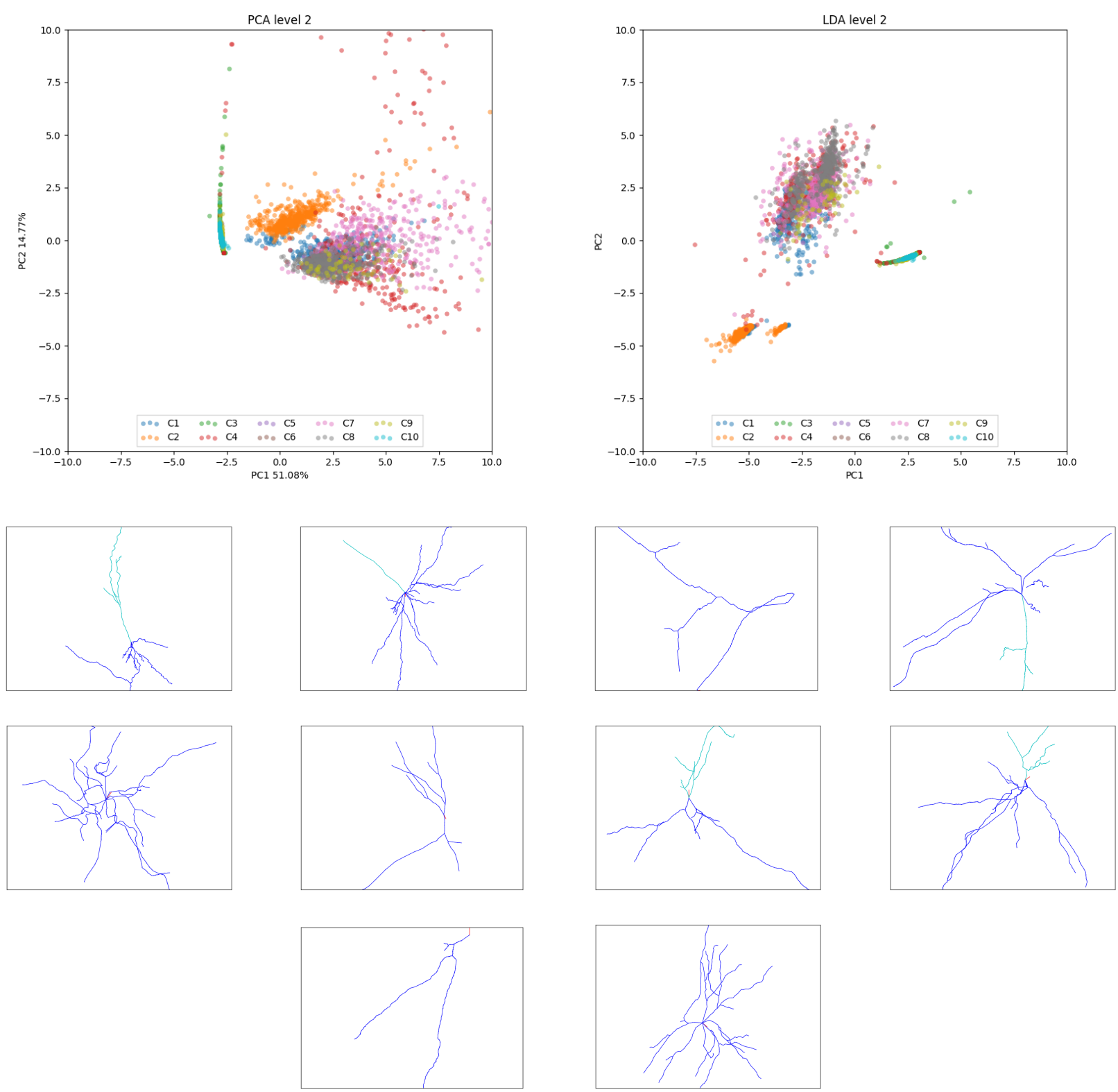
Figura B.4: PCA e LDA utilizando dendritos apicais até a profundidade 6
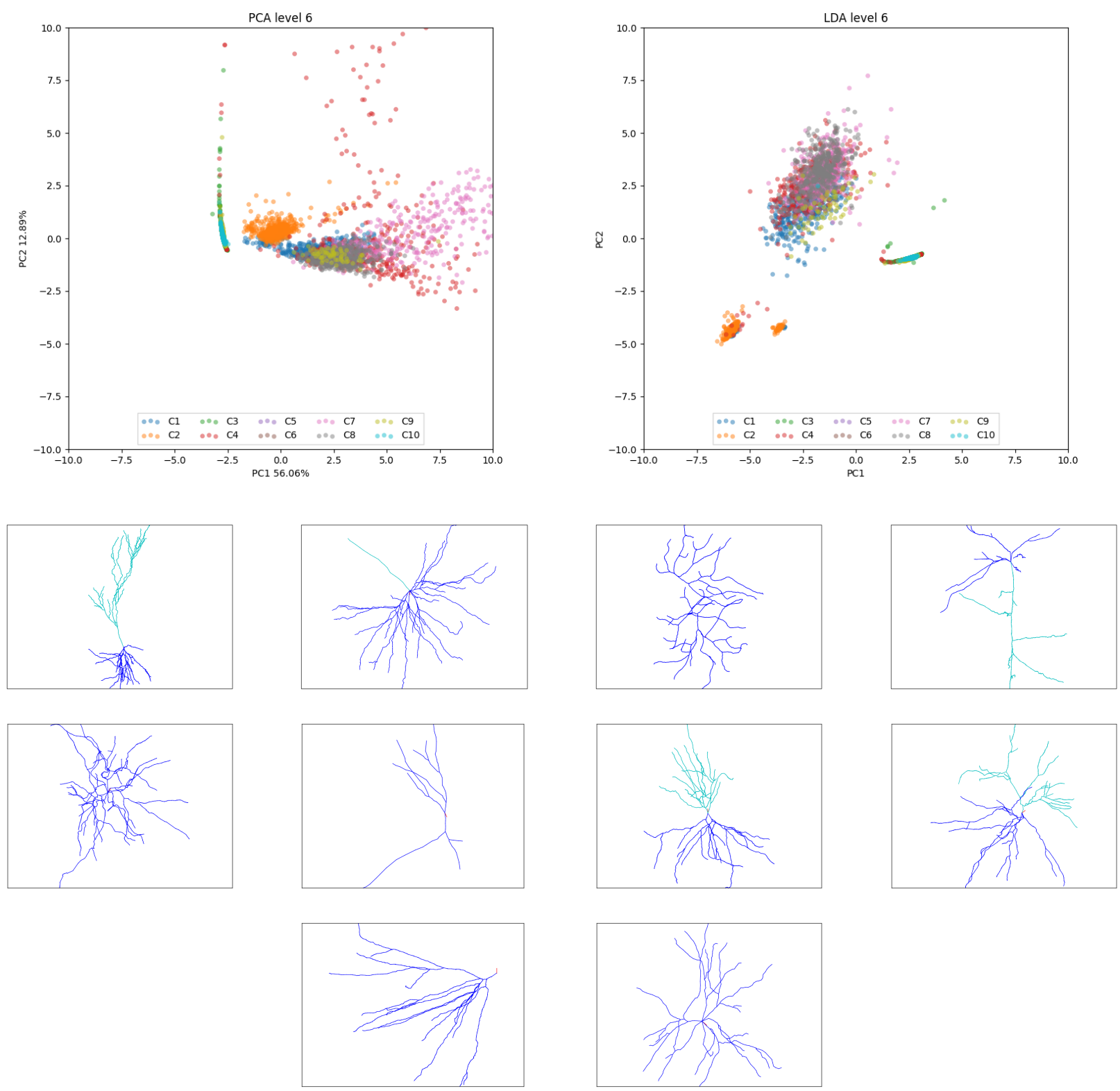
Figura B.5: PCA e LDA utilizando dendritos apicais até a profundidade 9
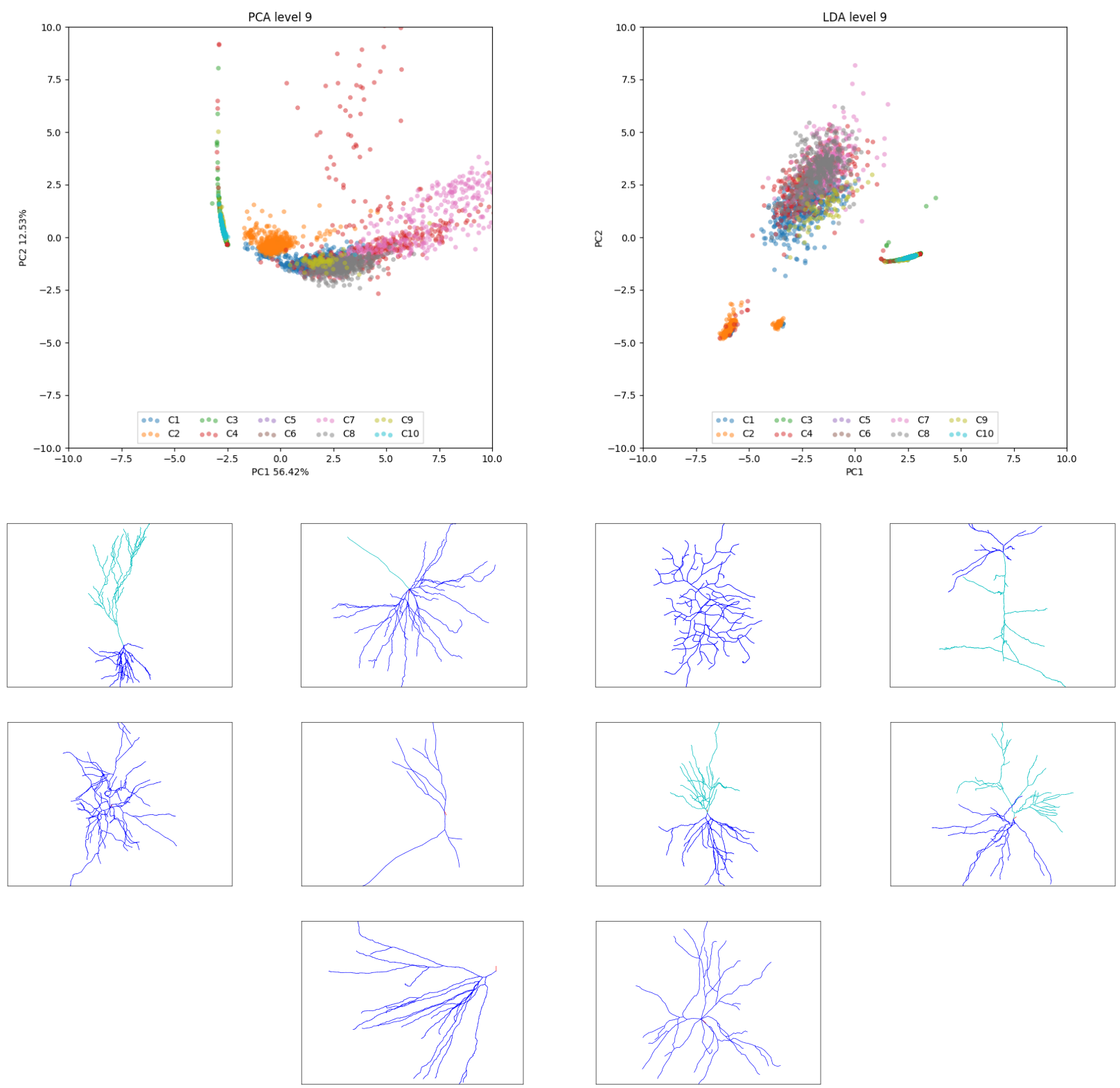
Figura B.6: $P C A$ e LDA utilizando dendritos basais até a profundidade 0
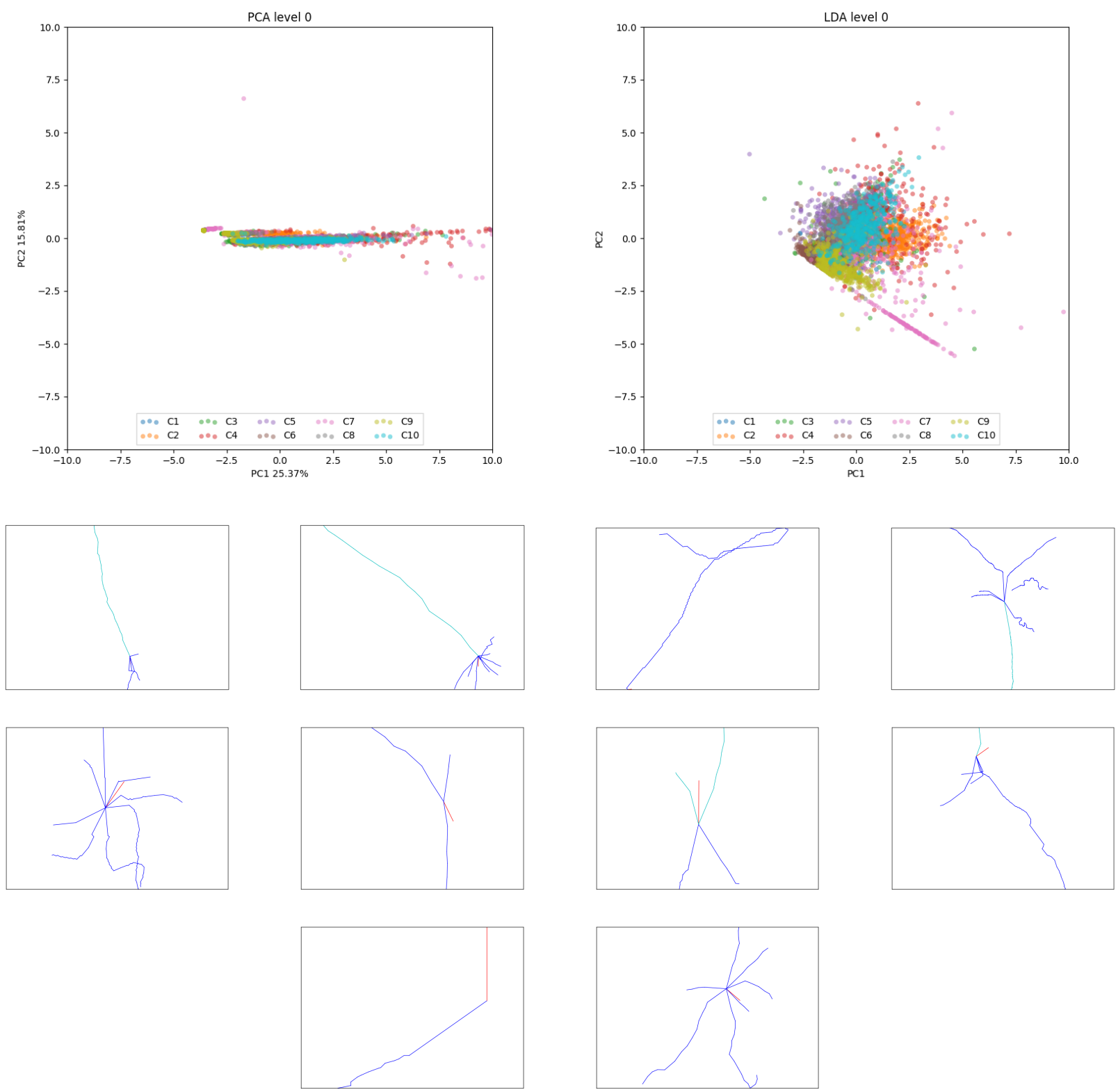
Figura B.7: PCA e LDA utilizando dendritos basais até a profundidade 1
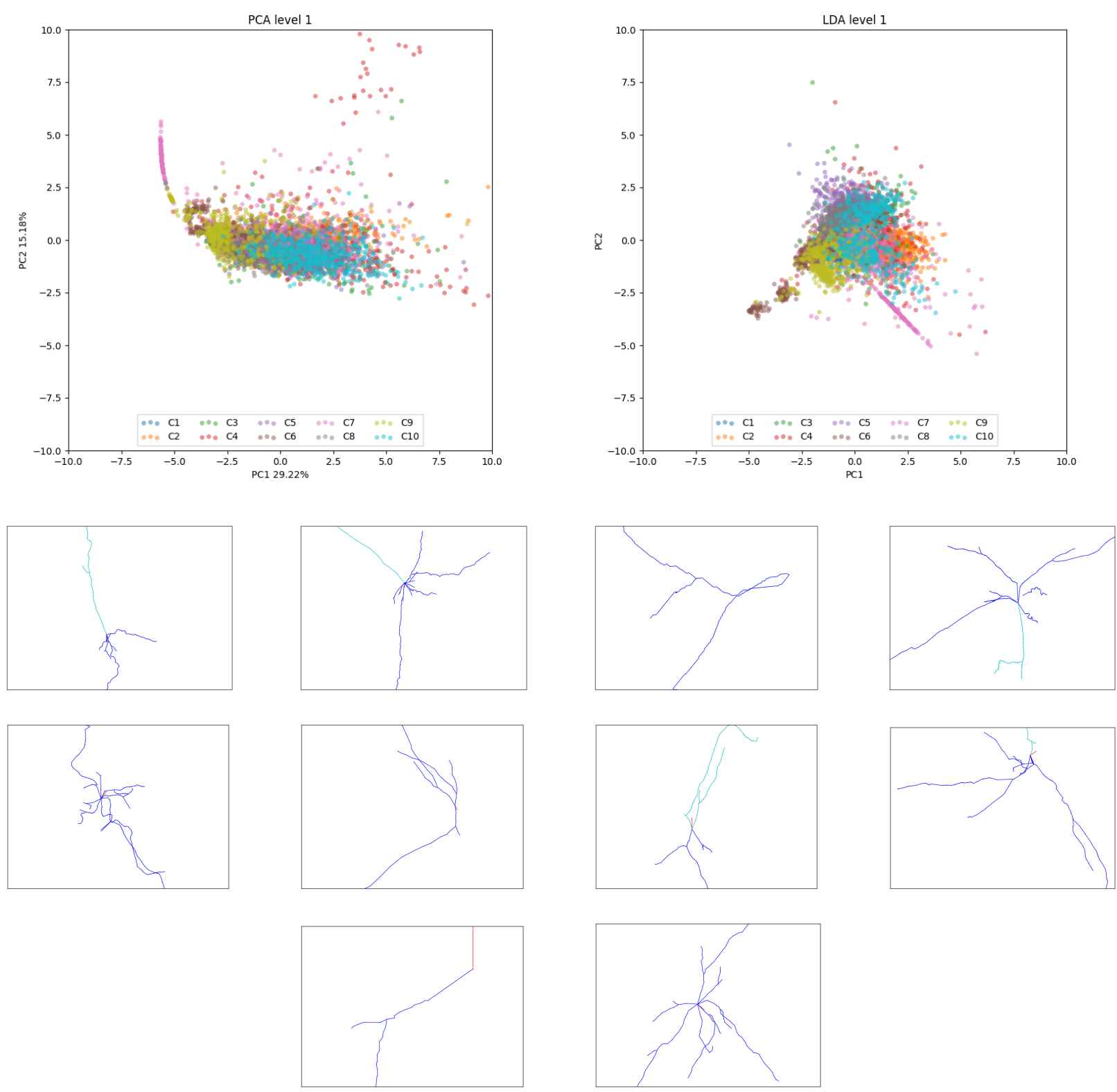
Figura B.8: PCA e LDA utilizando dendritos basais até a profundidade 2
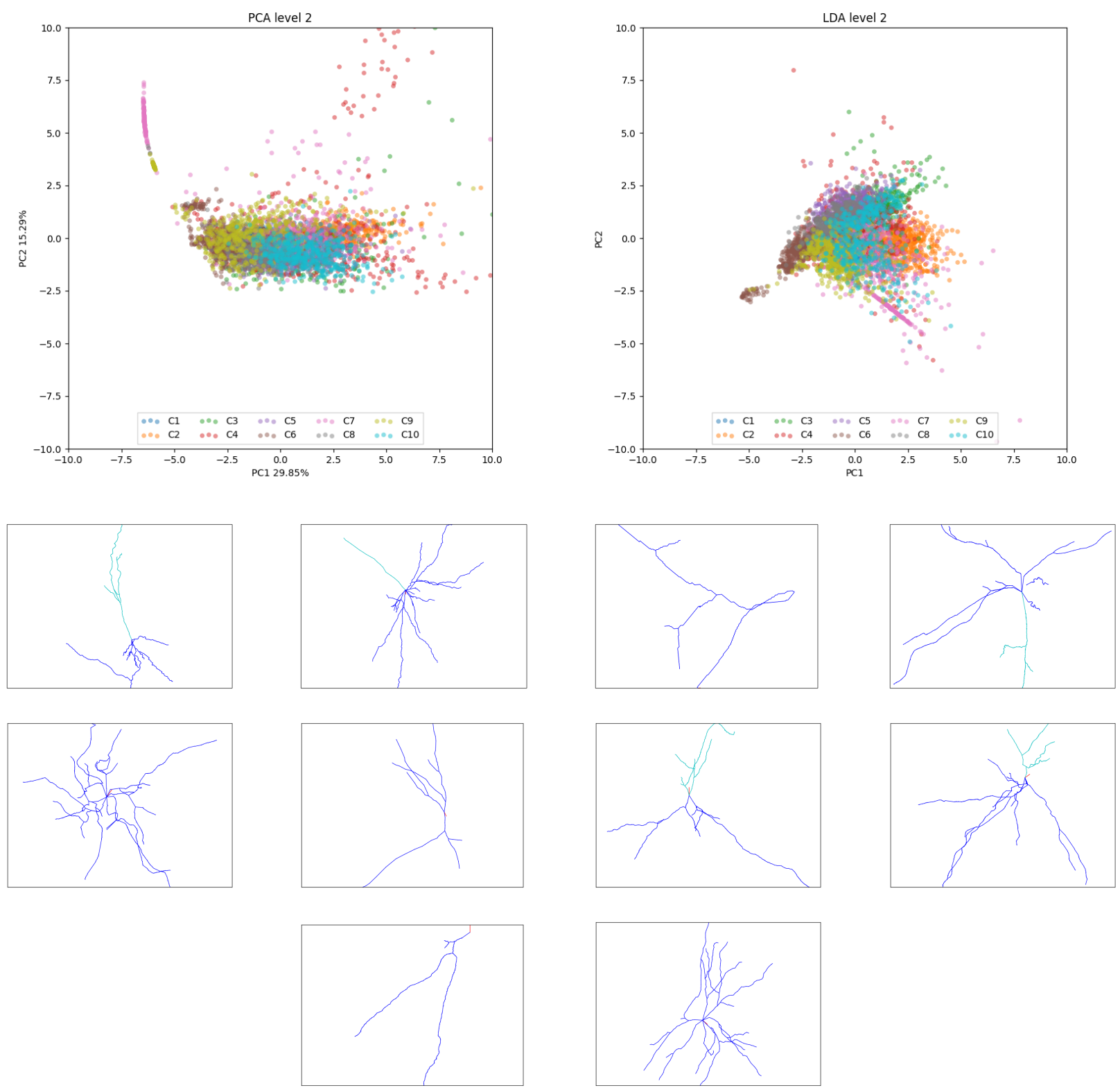
Figura B.9: $P C A$ e LDA utilizando dendritos basais até a profundidade 6
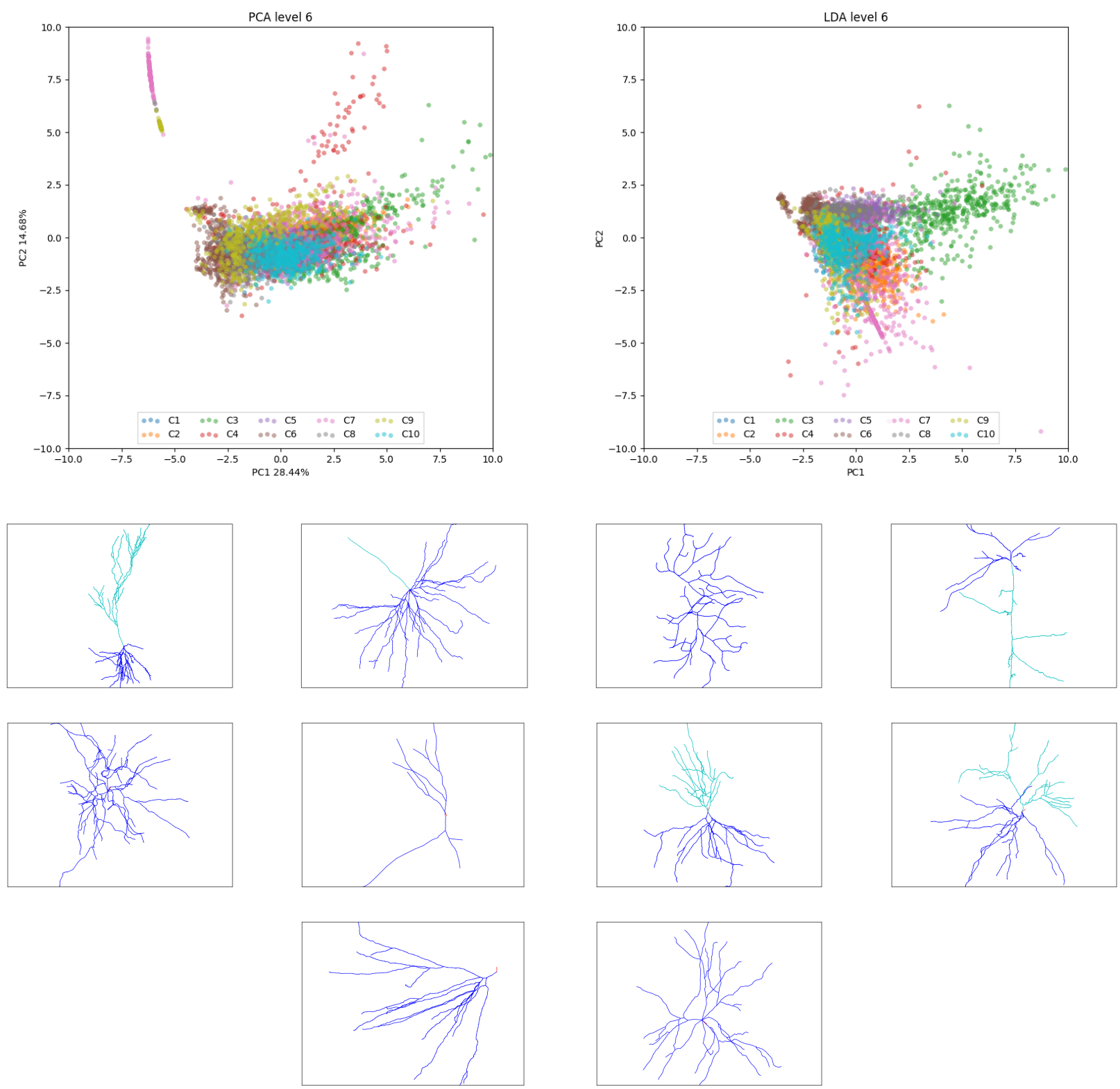
Figura B.10: PCA e LDA utilizando dendritos basais até a profundidade 9
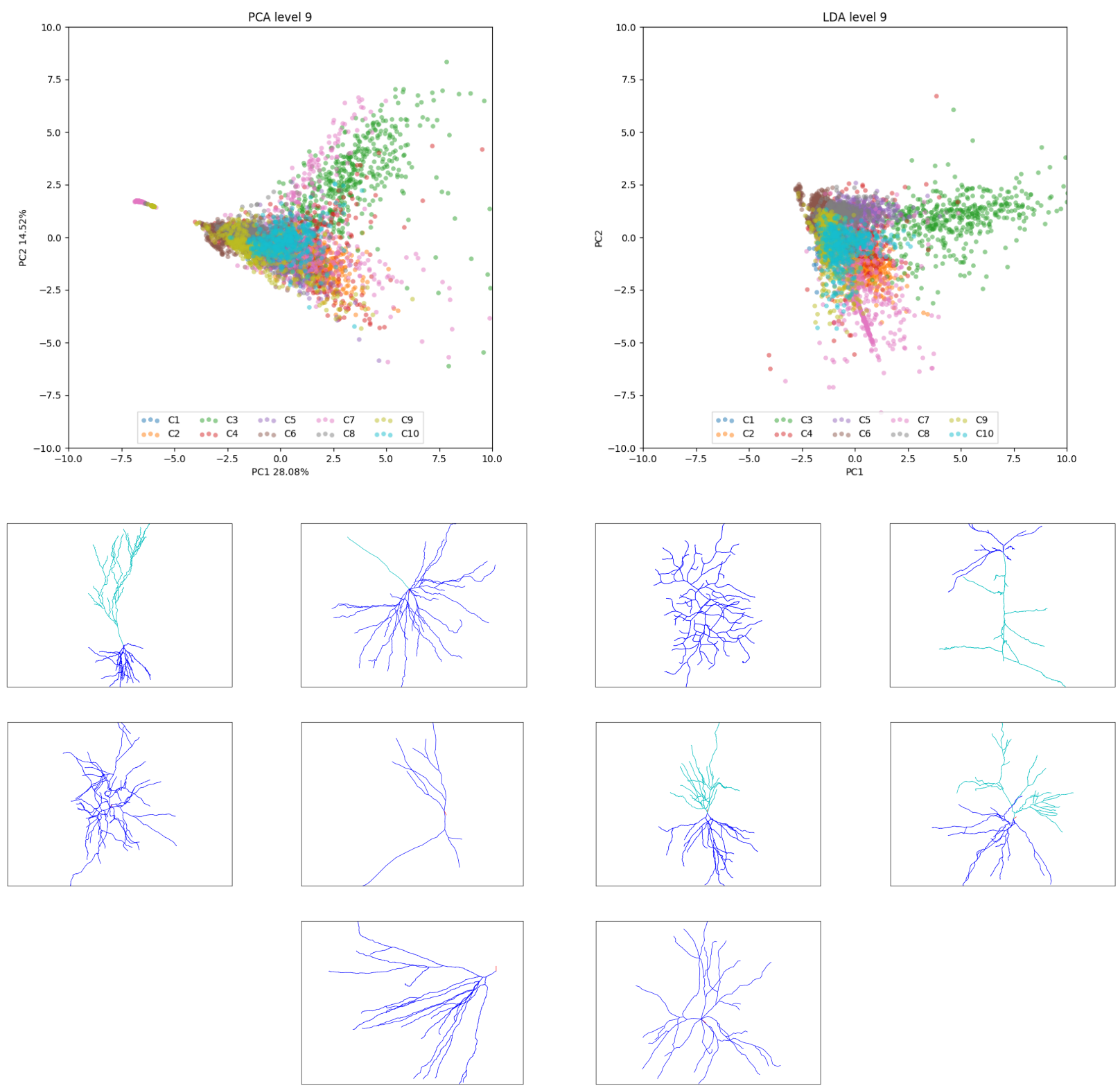


\section{Apêndice C}

\section{Publicações}

- PEREZ-CeRVANTES, EVELyN; COMIN, C. H.; CESAR-JR, ROBERTO M.; COSTA, L. F. Morphological Neuron Classification Based on Dendritic Tree Hierarchy, Neuroinformatics 17 (1), 147-161, 2018.

- PEREZ-CERVANTES, EVELyN; COMIN, C. H.; CESAR-JR, ROBERTO M.; COSTA, L. F. Data-oriented neuron classification from their parts. In: 2016 IEEE 12th International Conference on eScience, 2016, Baltimore. 2016 IEEE 12th International Conference on eScience. 2016. 


\title{
Morphological Neuron Classification Based on Dendritic Tree Hierarchy
}

\author{
Evelyn Perez Cervantes ${ }^{1}$ (1) . Cesar Henrique Comin ${ }^{2} \cdot$ Roberto Marcondes Cesar Junior $^{1}$. \\ Luciano da Fontoura Costa ${ }^{3}$
}

Published online: 14 July 2018

(C) Springer Science+Business Media, LLC, part of Springer Nature 2018

\begin{abstract}
The shape of a neuron can reveal interesting properties about its function. Therefore, morphological neuron characterization can contribute to a better understanding of how the brain works. However, one of the great challenges of neuroanatomy is the definition of morphological properties that can be used for categorizing neurons. This paper proposes a new methodology for neuron morphological analysis by considering different hierarchies of the dendritic tree for characterizing and categorizing neuronal cells. The methodology consists in using different strategies for decomposing the dendritic tree along its hierarchies, allowing the identification of relevant parts (possibly related to specific neuronal functions) for classification tasks. A set of more than 5000 neurons corresponding to 10 classes were examined with supervised classification algorithms based on this strategy. It was found that classification accuracies similar to those obtained by using whole neurons can be achieved by considering only parts of the neurons. Branches close to the soma were found to be particularly relevant for classification.
\end{abstract}

Keywords Neuron · Morphological reconstruction · Morphometry · Dendritic arborization · Dendritic tree - Digital neuronal reconstruction · Data sharing $\cdot$ Morphological classification $\cdot$ Supervised classification $\cdot$ Feature selection

\section{Introduction}

The problem of classifying neurons has been studied since the beginnings of neuroscience, even before the advent of electron microscopy. In particular, Cajal and Azoulay (1955) made a functional interpretation of the nervous system structures and demonstrated the morphological and functional independence of cells using the Golgi stain methodology invented in 1873 by Camillo Golgi. Based on

Evelyn Perez Cervantes

eperezc@ime.usp.br

Cesar Henrique Comin

chcomin@gmail.com

Roberto Marcondes Cesar Junior

cesar@ime.usp.br

Luciano da Fontoura Costa

ldfcosta@gmail.com

1 Institute of Mathematics and Statistics,

University of São Paulo, São Paulo, Brazil

2 Department of Computer Science,

Federal University of São Carlos, São Carlos, Brazil

3 São Carlos Institute of Physics, University of São Paulo, PO Box 369, 13560-970, São Carlos, SP, Brazil the knowledge provided by Cajal, many researches started developing more quantitative attempts to understand how the brain works. A key aspect is to provide a census of the different types or classes of nerve cells as well as their functionality. However, even now there is no agreement about the total number of neurons, even less about how they should be classified. Classifying neurons, in the strict sense, is the process of separating neurons into groups or classes based on some common characteristics (Armañanzas and Ascoli 2015). This process, which appears to be simple, is in fact far from being fully resolved. Even with the current technological advances, there are limitations from the data acquisition process, disagreements of how to define a neuron discretely as well as on the selection of the most pertinent features used to define the neuron class in the presence of only molecular information. As a consequence, the number of neuronal classes remains unknown (Bernard et al. 2009; Sümbül et al. 2014a). Neurons can be characterized by their morphology, physiology and biochemistry. These characteristics vary substantially for the same neuron type, depending, among other possibilities, on location or function (Barbosa et al. 2003; Ding and Glanzman 2011). Neuronal morphology is relatively easier to access, which makes it a key feature in the study of neurons, and is also directly related to neuronal functionality. In recent 


\section{Data-oriented neuron classification from their parts}

\author{
Evelyn Perez Cervantes \\ Institute of Mathematics and Statistics, \\ University of São Paulo, São Paulo, Brazil \\ Email: eperezc@ime.usp.br \\ Roberto Marcondes Cesar Junior \\ Institute of Mathematics and Statistics, \\ University of São Paulo, São Paulo, Brazil \\ Email: cesar@ime.usp.br
}

\begin{abstract}
The shape of a neuron can reveal many interesting properties about its function. Therefore, organizing neuronal cells into appropriate classes according to their respective shape is a fundamental endeavor in neuroscience. Available online datasets allow new data-oriented approaches to solve such neuroscience problems. Here we analyze the feasibility of classifying neurons according not to their respective wholes, but to its constituent parts. Such a study may reveal interesting insights, including whether parts of the neuronal dendritic arborization preserve proper information about the morphology of the whole neuron. Experimental results using open datasets are reported, thus corroborating our approach.
\end{abstract}

\section{INTRODUCTION}

The problem of classifying neurons has been addressed from the beginning of neuroscience, because a systematic census of neuronal cell types can provide subsidies for better understanding the brain [1], [2]. Neuronal classification, in a strict sense, is the process of dividing a set of neurons into groups or classes, which can be pre-determined (supervised classification) or inferred from the own data relationships (unsupervised classification, categorization or clustering) [3]. A standard neuron has three main structures: the cell body also called soma, the axon and the dendrites. The soma encloses the nucleus, which stores the cell's genes; the axon is a long branch that transports the electrical signals toward other neurons, and the dendrites are typically shorter branches that receive signals from other neurons. The axon communicates with the dendrites, axons and soma of other neurons through synapses and gap junctions [4].

Commonly, a neuron is characterized by its morphology, physiology and biochemistry [5], [6], [7]. It is known that the morphology of neurons provides information about their functionality [8], [3], [9], [10], [11]. A neuron can be classified by using any subset of its properties. Several attempts at neuronal classification have been formulated taking into account their axonal and dendritic structures [3], [12], [13], [14], [15], [16]. Amañazas and Ascoli in [3] present a review of automatic neuronal classification methods based on quantitative measures and machine learning.

\author{
Cesar Henrique Comin \\ So Carlos Institute of Physics, \\ University of São Paulo, São Carlos, SP, Brazil \\ Email: chcomin@gmail.com \\ Luciano da Fontoura Costa \\ So Carlos Institute of Physics, \\ University of São Paulo, \\ PO Box 369, 13560-970, São Carlos, SP, Brazil \\ Email: ldfcosta@gmail.com
}

Recent attempts have been made to categorize neurons according to their morphological properties [6], [7]. Some approaches consider the neural arbor branch density [17] as the main morphological feature. For instance, Sümbül et al. [13] proposed a method based on the relative position of the dendritic arbor to define neuronal types, and compared the identified types with molecularly defined ones. In addition to arbor density, layer-specific distribution and length have also been described as key parameters to define clusters [18]. Zhao and Plaza [19] proposed a location-based method, considering that neuron similarity is directly related to density overlaps between dendritic arbors. Lu et al. [20] considered neurons obtained from the NeuroMorpho.org [21] dataset and measurements calculated with the L-measure [22] software and applied a harmonic co-clustering algorithm based on diffusion properties. Harris et al. [23] investigated how the clustering algorithm called affinity propagation, applied to a collection of morphological and physiological variables, can identify neuronal types not revealed by morphological properties alone. Bayesian networks and clustering algorithms over axonal and dendritic arborizations were also applied to categorize interneurons [24]. Gillette et al. [25], [26] considered an encoding of axonal and dendritic arbors into sequences of characters representing bifurcations. This allowed the application of similarity measurements, commonly defined to compare gene sequences, to perform clustering analysis and define respective arbor types.

The advent and steady growth of public databases containing neuronal morphology data [27], [28], [29], such as NeuroMorpho.Org [21], have paved the way for more systematic approaches to neuronal classification [30], [31], [32], [33]. Because these databases contain data from different types of neurons, electrophysiology, laboratories, species, among other properties, it becomes possible to tackle questions, linking these various aspects with the neuronal morphology. Thus, it can give valuable insights about the diversity of neuronal shape as well as its relationship with function and evolution. However, the consideration of the neuronal morphology 


\section{Referências Bibliográficas}

Abu-Mostafa et al.(2012) Yaser S Abu-Mostafa, Malik Magdon-Ismail e Hsuan-Tien Lin. Learning from data, volume 4. AMLBook New York, NY, USA:. Citado na pág. 26

Armañanzas e Ascoli(2015) Rubén Armañanzas e Giorgio A Ascoli. Towards the automatic classification of neurons. Trends in neurosciences, 38(5):307-318. Citado na pág. $1,2,13,26,41$

Ascoli(2002) Giorgio A Ascoli. Computational neuroanatomy: Principles and methods. Springer Science \& Business Media. Citado na pág. 16, 21, 43

Ascoli et al.(2007) Giorgio A Ascoli, Duncan E Donohue e Maryam Halavi. Neuromorpho. org: a central resource for neuronal morphologies. Journal of Neuroscience, 27 (35):9247-9251. Citado na pág. 2, 11, 14, 47

Barbosa et al.(2003) Marconi Soares Barbosa, Luciano da Fontoura Costa e Esmerindo de Sousa Bernardes. Neuromorphometric characterization with shape functionals. Physical Review E, 67(6):061910. Citado na pág. 2

Bazán e Lolley(2013) Nicolás G Bazán e Richard N Lolley. Neurochemistry of the Retina: Proceedings of the International Symposium on the Neurochemistry of the Retina Held in Athens, Greece, August 28-September 1, 1979. Elsevier. Citado na pág. 2

Bear et al.(2007) Mark F Bear, Barry W Connors e Michael A Paradiso. Neuroscience, volume 2. Lippincott Williams \& Wilkins. Citado na pág. 9, 10, 16, 17, 19

Bernard et al.(2009) Amy Bernard, Staci A Sorensen e Ed S Lein. Shifting the paradigm: new approaches for characterizing and classifying neurons. Current opinion in neurobiology, 19(5):530-536. Citado na pág. 2 
Bota e Swanson(2007) Mihail Bota e Larry W Swanson. The neuron classification problem. Brain res rev, 56(1):79-88. Citado na pág. 1, 2

Cajal(1911) S Ramon Cajal. Histologie du syste me nerveux de i'homme et des verte be s. Maloine (Paris), 2:891-942. Citado na pág. 1

Capowski(2012) Joseph J Capowski. Computer techniques in neuroanatomy. Springer Science \& Business Media. Citado na pág. 16, 21

Cervantes et al.(2016) Evelyn Perez Cervantes, Cesar Henrique Comin, Roberto Marcondes Cesar e Luciano da Fontoura Costa. Data-oriented neuron classification from their parts. Em e-Science (e-Science), 2016 IEEE 12th International Conference on, páginas 243-250. IEEE. Citado na pág. 4, 6, 34

Cervantes et al.(2019) Evelyn Perez Cervantes, Cesar Henrique Comin, Roberto Marcondes Cesar Junior e Luciano da Fontoura Costa. Morphological neuron classification based on dendritic tree hierarchy. Neuroinformatics, 17(1):147-161. Citado na pág. 6

Cesar Jr e da Fontoura Costa(1998) Roberto Marcondes Cesar Jr e Luciano da Fontoura Costa. Neural cell classification by wavelets and multiscale curvature. Biological Cybernetics, 79(4):347-360. Citado na pág. 13

Comin e da Fontoura Costa(2013) Cesar Henrique Comin e Luciano da Fontoura Costa. Shape, connectedness and dynamics in neuronal networks. Journal of neuroscience methods, 220(2):100-115. Citado na pág. 2

Cortes e Vapnik(1995) Corinna Cortes e Vladimir Vapnik. Support-vector networks. Machine learning, 20(3):273-297. Citado na pág. 27

Costa e Cesar Jr(2009) Luciano da Fona Costa e Roberto Marcond Cesar Jr. Shape classification and analysis: theory and practice. Crc Press. Citado na pág. 43

Cuntz et al.(2014) Hermann Cuntz, MW Remme e Benjamin Torben-Nielsen. The computing dendrite. $A M C, 10: 12$. Citado na pág. 16, 17, 18 
da F Costa e Velte(1999) Luciano da F Costa e Toby J Velte. Automatic characterization and classification of ganglion cells from the salamander retina. Journal of Comparative Neurology, 404(1):33-51. Citado na pág. 13

DeFelipe(2001) Javier DeFelipe. Cortical interneurons: from cajal to 2001. Progress in brain research, 136:215-238. Citado na pág. 2

Ding e Glanzman(2011) Mingzhou Ding e Dennis Glanzman. The dynamic brain: an exploration of neuronal variability and its functional significance. Oxford University Press, USA. Citado na pág. 2

Dong et al.(2015) Xintong Dong, Kang Shen e Hannes E Bülow. Intrinsic and extrinsic mechanisms of dendritic morphogenesis. Annual review of physiology, 77:271-300. Citado na pág. 77

Galenus() Claudius Galenus. De usu partium corporis humani, libri XVII. apud Gulielmum Rouillium. Citado na pág. 9

Gillette e Ascoli(2015) TA Gillette e GA Ascoli. Topological characterization of neuronal arbor morphology via sequence representation. i. Motif analysis. Citado na pág. 15

Gillette e Grefenstette(2009) Todd A Gillette e John J Grefenstette. On comparing neuronal morphologies with the constrained tree-edit-distance. Neuroinformatics, $7(3)$ : 191-194. Citado na pág. 15

Götz e Huttner(2005) Magdalena Götz e Wieland B Huttner. Developmental cell biology: The cell biology of neurogenesis. Nature reviews Molecular cell biology, 6(10): 777. Citado na pág. 20

Guerra et al.(2011) Luis Guerra, Laura M McGarry, Víctor Robles, Concha Bielza, Pedro Larrañaga e Rafael Yuste. Comparison between supervised and unsupervised classifications of neuronal cell types: a case study. Developmental neurobiology, 71(1): 71-82. Citado na pág. 13, 41 
Halavi et al.(2012) Maryam Halavi, Kelly A Hamilton, Ruchi Parekh e Giorgio A Ascoli. Digital reconstructions of neuronal morphology: three decades of research trends. Front Neurosci, 6(49):1-11. Citado na pág. 2

Heumann e Wittum(2009) Holger Heumann e Gabriel Wittum. The tree-edit-distance, a measure for quantifying neuronal morphology. Neuroinformatics, 7(3):179-190. Citado na pág. 15

Jan e Jan(2010) Yuh-Nung Jan e Lily Yeh Jan. Branching out: mechanisms of dendritic arborization. Nature Reviews Neuroscience, 11(5):316-328. Citado na pág. 42

Jolliffe(2002) Ian Jolliffe. Principal component analysis. Wiley Online Library. Citado na pág. 49

Kandel et al.(2000) Eric R Kandel, James H Schwartz, Thomas M Jessell et al. Principles of neural science, volume 4. McGraw-hill New York. Citado na pág. 2, 9, 10, 16, 17

Karagiannis et al.(2009) Anastassios Karagiannis, Thierry Gallopin, Csaba Dávid, Demian Battaglia, Hélène Geoffroy, Jean Rossier, Elizabeth MC Hillman, Jochen F Staiger e Bruno Cauli. Classification of npy-expressing neocortical interneurons. Journal of Neuroscience, 29(11):3642-3659. Citado na pág. 13

Koch(2004) Christof Koch. Biophysics of computation: information processing in single neurons. Oxford university press. Citado na pág. 42

Laturnus et al.(2019) Sophie Laturnus, Dmitry Kobak e Philipp Berens. A systematic evaluation of neural morphology representations for cell type discrimination. BioRxiv, página 591370. Citado na pág. 14

Lefebvre et al.(2015) Julie L Lefebvre, Joshua R Sanes e Jeremy N Kay. Development of dendritic form and function. Annual review of cell and developmental biology, 31: 741-777. Citado na pág. 20, 77 
Lin e Zheng(2019) Xianghong Lin e Jianyang Zheng. A neuronal morphology classification approach based on locally cumulative connected deep neural networks. Applied Sciences, 9(18):3876. Citado na pág. 14

Liu(2011) Yuan Liu. The diadem and beyond, 2011. Citado na pág. 11

López-Cruz et al.(2014) Pedro L López-Cruz, Pedro Larrañaga, Javier DeFelipe e Concha Bielza. Bayesian network modeling of the consensus between experts: An application to neuron classification. International Journal of Approximate Reasoning, 55(1):3-22. Citado na pág. 2, 13

Lu et al.(2015) Yanbin Lu, Lawrence Carin, Ronald Coifman, William Shain e Badrinath Roysam. Quantitative arbor analytics: Unsupervised harmonic co-clustering of populations of brain cell arbors based on l-measure. Neuroinf, 13(1):47-63. Citado na pág. 14

Maaten e Hinton(2008) Laurens van der Maaten e Geoffrey Hinton. Visualizing data using t-sne. Journal of machine learning research, 9(Nov):2579-2605. Citado na pág. 49

Marks e Burke(2007) William B Marks e Robert E Burke. Simulation of motoneuron morphology in three dimensions. i. building individual dendritic trees. Journal of Comparative Neurology, 503(5):685-700. Citado na pág. 43

Masland(2004) Richard H Masland. Neuronal cell types. Current Biology, 14(13): R497-R500. Citado na pág. 1, 2

McGarry et al.(2010) Laura M McGarry, Adam M Packer, Elodie Fino, Volodymyr Nikolenko, Tanya Sippy e Rafael Yuste. Quantitative classification of somatostatinpositive neocortical interneurons identifies three interneuron subtypes. Front. in neural circuits, 4:12. Citado na pág. 2

Meijering(2010) Erik Meijering. Neuron tracing in perspective. Cytometry Part A, 77 (7):693-704. Citado na pág. 23

Mohri et al.(2018) Mehryar Mohri, Afshin Rostamizadeh e Ameet Talwalkar. Foundations of machine learning. MIT press. Citado na pág. 26 
Mottini et al.(2014) Alejandro Mottini, Xavier Descombes e Florence Besse. Axonal tree classification using an elastic shape analysis based distance. Em Biomedical Imaging (ISBI), 2014 IEEE 11th International Symposium on, páginas 850-853. IEEE. Citado na pág. 2

Nanda et al.(2015) Sumit Nanda, M Mowafak Allaham, Maurizio Bergamino, Sridevi Polavaram, Rubén Armañanzas, Giorgio A Ascoli e Ruchi Parekh. Doubling up on the fly: Neuromorpho. org meets big data. Neuroinformatics, 13(1):127. Citado na pág. 11

Olson e Delen(2008) David L Olson e Dursun Delen. Advanced data mining techniques. Springer Science \& Business Media. Citado na pág. 28

Parekh e Ascoli(2013) Ruchi Parekh e Giorgio A Ascoli. Neuronal morphology goes digital: a research hub for cellular and system neuroscience. Neuron, 77(6):1017-1038. Citado na pág. 11

Parekh e Ascoli(2015) Ruchi Parekh e Giorgio A Ascoli. Quantitative investigations of axonal and dendritic arbors: development, structure, function, and pathology. The Neuroscientist, 21(3):241-254. Citado na pág. 13, 19

Parekh et al.(2015) Ruchi Parekh, Rubén Armañanzas e Giorgio A Ascoli. The importance of metadata to assess information content in digital reconstructions of neuronal morphology. Cell and tissue research, 360(1):121-127. Citado na pág. 11

Poirazi e Mel(2001) Panayiota Poirazi e Bartlett W Mel. Impact of active dendrites and structural plasticity on the memory capacity of neural tissue. Neuron, 29(3):779-796. Citado na pág. 42

Polavaram et al.(2014) Sridevi Polavaram, Todd A Gillette, Ruchi Parekh e Giorgio A Ascoli. Statistical analysis and data mining of digital reconstructions of dendritic morphologies. Frontiers in neuroanatomy, 8. Citado na pág. 13

Rall(1962) Wilfrid Rall. Electrophysiology of a dendritic neuron model. Biophysical journal, 2(2 Pt 2):145. Citado na pág. 42 
Rall(2011) Wilfrid Rall. Core conductor theory and cable properties of neurons. Comprehensive physiology. Citado na pág. 42

Ruz e Schultz(2014) Isabel Delgado Ruz e Simon R Schultz. Localising and classifying neurons from high density mea recordings. Journal of neuroscience methods, 233:115128. Citado na pág. 2

Santana et al.(2013) Roberto Santana, Laura McGarry, Concha Bielza, Pedro Larrañaga e Rafael Yuste. Classification of neocortical interneurons using affinity propagation. Front neur circ, 7:185. Citado na pág. 13, 14

Scorcioni et al.(2008) Ruggero Scorcioni, Sridevi Polavaram e Giorgio A Ascoli. Lmeasure: a web-accessible tool for the analysis, comparison and search of digital reconstructions of neuronal morphologies. Nature protocols, 3(5):866-876. Citado na pág. 14, $33,42,51$

Scott e Luo(2001) Ethan K Scott e Liqun Luo. How do dendrites take their shape? Nat neurosci, 4(4):359-365. Citado na pág. 42

Seung e Sümbül(2014) H Sebastian Seung e Uygar Sümbül. Neuronal cell types and connectivity: lessons from the retina. Neuron, 83(6):1262-1272. Citado na pág. 2

Sharpee(2014) Tatyana O Sharpee. Toward functional classification of neuronal types. Neuron, 83(6):1329-1334. Citado na pág. 2

Sholl(1953) Dd A Sholl. Dendritic organization in the neurons of the visual and motor cortices of the cat. Journal of anatomy, 87(Pt 4):387. Citado na pág. 13

Singer(1956) Charles Joseph Singer. Galen on anatomical procedures: de Anatomicis administrationibus. Oxford University Press for the Wellcome Historical Medical Museum. Citado na pág. 9

Skiena(1998) Steven S Skiena. The algorithm design manual: Text, volume 1. Springer Science \& Business Media. Citado na pág. 22 
Sümbül et al.(2014a) Uygar Sümbül, Sen Song, Kyle McCulloch, Michael Becker, Bin Lin, Joshua R Sanes, Richard H Masland e H Sebastian Seung. A genetic and computational approach to structurally classify neuronal types. Nature communications, 5 . Citado na pág. 2, 14

Sümbül et al.(2014b) Uygar Sümbül, Aleksandar Zlateski, Ashwin Vishwanathan, Richard H Masland e H Sebastian Seung. Automated computation of arbor densities: a step toward identifying neuronal cell types. Frontiers in neuroanatomy, 8:139. Citado na pág. 2

Teeter e Stevens(2011) Corinne M Teeter e Charles F Stevens. A general principle of neural arbor branch density. Current Biology, 21(24):2105-2108. Citado na pág. 14

Torben-Nielsen(2014) Benjamin Torben-Nielsen. An efficient and extendable python library to analyze neuronal morphologies. Neuroinformatics, 12(4):619. Citado na pág. 31, 32,33

Uji et al.(1995) Yukitaka Uji, Hideki Yamamura et al. Morphological classification of retinal ganglion cells in mice. Journal of Comparative Neurology, 356(3):368-386. Citado na pág. 2

Uylings e van Pelt(2002) Harry BM Uylings e Jaap van Pelt. Measures for quantifying dendritic arborizations. Network: Computation in Neural Systems, 13(3):397-414. Citado na pág. 2

Uylings et al.(1989) Harry BM Uylings, Jaap Van Pelt, Ronald WH Verwer e Patricia McConnell. Statistical analysis of neuronal populations. Em Computer techniques in neuroanatomy, páginas 241-264. Springer. Citado na pág. 2

Vapnik(2013) Vladimir Vapnik. The nature of statistical learning theory. Springer science \& business media. Citado na pág. 44

Vasques et al.(2016) Xavier Vasques, Laurent Vanel, Guillaume Villette e Laura Cif. Morphological neuron classification using machine learning. Frontiers in Neuroanatomy, 10. Citado na pág. 14 
West et al.(1996) Douglas Brent West et al. Introduction to graph theory, volume 2. Prentice hall Upper Saddle River, NJ. Citado na pág. 21

Zhao e Plaza(2014) Ting Zhao e Stephen M Plaza. Automatic neuron type identification by neurite localization in the drosophila medulla. arXiv preprint arXiv:1409.1892. Citado na pág. 14

Zippo e Biella(2015) Antonio G Zippo e Gabriele EM Biella. Quantifying the number of discriminable coincident dendritic input patterns through dendritic tree morphology. Scientific reports, 5:11543. Citado na pág. 13 